\title{
Role of lysosomes in physiological activities, diseases, and therapy
}

\author{
Ziqi Zhang ${ }^{\dagger}$, Pengfei Yue ${ }^{\dagger}$, Tianqi $\mathrm{Lu}^{\dagger}$, Yang Wang ${ }^{\dagger}$, Yuquan Wei and Xiawei Wei (i)
}

\begin{abstract}
Long known as digestive organelles, lysosomes have now emerged as multifaceted centers responsible for degradation, nutrient sensing, and immunity. Growing evidence also implicates role of lysosome-related mechanisms in pathologic process. In this review, we discuss physiological function of lysosomes and, more importantly, how the homeostasis of lysosomes is disrupted in several diseases, including atherosclerosis, neurodegenerative diseases, autoimmune disorders, pancreatitis, lysosomal storage disorders, and malignant tumors. In atherosclerosis and Gaucher disease, dysfunction of lysosomes changes cytokine secretion from macrophages, partially through inflammasome activation. In neurodegenerative diseases, defect autophagy facilitates accumulation of toxic protein and dysfunctional organelles leading to neuron death. Lysosomal dysfunction has been demonstrated in pathology of pancreatitis. Abnormal autophagy activation or inhibition has been revealed in autoimmune disorders. In tumor microenvironment, malignant phenotypes, including tumorigenesis, growth regulation, invasion, drug resistance, and radiotherapy resistance, of tumor cells and behaviors of tumor-associated macrophages, fibroblasts, dendritic cells, and T cells are also mediated by lysosomes. Based on these findings, a series of therapeutic methods targeting lysosomal proteins and processes have been developed from bench to bedside. In a word, present researches corroborate lysosomes to be pivotal organelles for understanding pathology of atherosclerosis, neurodegenerative diseases, autoimmune disorders, pancreatitis, and lysosomal storage disorders, and malignant tumors and developing novel therapeutic strategies.
\end{abstract}

Keywords: Lysosome, Atherosclerosis, Neurodegenerative disease, Pancreatitis, Autoimmune disorder, Lysosomal storage disorder, Tumor microenvironment, Tumor-associated macrophage

\section{Background}

\section{Overview of lysosomes}

Lysosomes are composed of acid lumen and a layer of lysosomal membrane formed by phospholipid bilayer. The acid lumen contains a host of hydrolytic enzymes, including nucleases, proteases, phosphatases, lipases,

\footnotetext{
*Correspondence: xiaweiwei@scu.edu.cn ${ }^{\dagger}$ Ziqi Zhang, Pengfei Yue, Tianqi Lu, and Yang Wang have contributed equally to this work
}

Laboratory of Aging Research and Cancer Drug Target, State Key Laboratory of Biotherapy, National Clinical Research Center for Geriatrics, West China Hospital, Sichuan University, No. 17, Block 3, Southern Renmin Road, Chengdu 610041, Sichuan, People's Republic of China Ziqi Zhang, Pengfei Yue, Tianqi Lu, and Yang Wang have contributed equally to this work sulfatases, and others. These enzymes are synthesized in endoplasmic reticulum, and modified in Golgi, where the proteins are added mannose- 6 -phosphate residue, a tag targeting lysosomes [1]. On lysosomal membranes, the overarching protein maintaining acid luminal $\mathrm{pH}$ is vacuolar $\mathrm{H}+$-ATPase (v-ATPase) that hydrolyses adenosine triphosphate (ATP) to transport protons into lysosomes [2]. Other key lysosomal membrane proteins include several ion channels, through which ions move inward/outward [3]; lysosome-associated membrane proteins (LAMPs), including LAMP1-5, among which LAMP1 and LAMP2 are well documented to be involved in phagocytosis, chaperone-mediated autophagy (CMA), macroautophagy, lipid transport, and aging [4]; original author(s) and the source, provide a link to the Creative Commons licence, and indicate if changes were made. The images or other third party material in this article are included in the article's Creative Commons licence, unless indicated otherwise in a credit line to the material. If material is not included in the article's Creative Commons licence and your intended use is not permitted by statutory regulation or exceeds the permitted use, you will need to obtain permission directly from the copyright holder. To view a copy of this licence, visit http://creativecommons.org/licenses/by/4.0/. The Creative Commons Public Domain Dedication waiver (http://creativeco mmons.org/publicdomain/zero/1.0/) applies to the data made available in this article, unless otherwise stated in a credit line to the data. 
soluble N-ethylmaleimide-sensitive factor activating protein receptors (SNAREs) and RAB GTPases that are involved in trafficking and fusion [5]; toll-like receptors (TLRs) that sense pathogen-associated molecular patterns (PAMPs) and initiate inflammatory response [6]; and mammalian target of rapamycin (mTOR) that coordinates several homeostatic signaling pathways [7]. Notably, a series of terms have been proposed to classify lysosomes, such as terminal lysosomes, endolysosomes, protolysosomes, phagolysosomes, and autolysosomes indicating heterogeneity of lysosomes. In a word, the complex lysosomal luminal and membrane proteins indicate lysosomes to be pleiotropic organelles.

Lysosomes are formed through fusion of endosomes and vesicles budded from trans-Golgi network. The main regulator of lysosomal biogenesis is microphthalmia/ transcription factor $\mathrm{E}$ (MiT/TFE) protein family including transcription factor EB (TFEB), transcription factor EC (TFEC), transcription factor binding to IGHM enhancer 3 (TFE3), and melanocyte inducing transcription factor (MITF) [8], among which TFEB is the best studied. TFEB can be phosphorylated on several sites by a number of kinases and phosphatases, such as mechanistic target of rapamycin complex 1 (mTORC1) on Ser211 [9], Ser142 [10], and Ser122 [11], glycogen synthase kinase $3 \beta$ (GSK3 $\beta$ ) on Ser134 and Ser138 [12], extracellular signal-regulated kinase (ERK) on Ser142 [13], mitogen-activated protein kinase kinase kinase kinase 3 (MAP4K3) on Ser3 [14], and protein kinase B $(\mathrm{PKB})$ on Ser467 [15] repressing nuclear translocation of TFEB. Dephosphorylation of TFEB by calcineurin [16] and protein phosphatase 2 (PP2A) [17] lets TFEB enter nuclear to regulate transcription. For example, if nutrient is in abundance, TFEB is phosphorylated by mTORC1, which facilitates 14-3-3-dependent retention of TFEB in cytoplasm and prevents transcription function of TFEB [9]. On the contrary, in the context of starvation or mTOR inhibitor treatment, inactivated mTOR leads to accumulation of dephosphorylated TFEB resulting in nuclear translocation of TFEB [10]. Alternatively, in some cases, lysosomes release $\mathrm{Ca}^{2+}$ through transient receptor potential mucolipin 1 (TRPML1) to activate calcineurin that dephosphorylates TFEB [16]. In nucleus, TFEB transcribes coordinated lysosomal expression and regulation (CLEAR) network genes that code proteins highly related to structure and function of lysosomes [18] including receptors and enzymes participating in lysosomal sorting. Both soluble and membrane lysosomal proteins should be recognized by sorting receptors. The best-known sorting receptor is the mannose-6-phosphate receptors (M6PRs) that recognize M6P-tagged proteins in the Golgi complex [19]. Newly synthesized lysosomal proteins are successively modified by oligosaccharyltransferase [20], GlcNAc1-phosphotransferase, and uncovering enzyme [21] to be tagged with M6P residues. In Golgi complex with $\mathrm{pH}$ 6.7, tagged proteins bind with M6PRs, while in acidic endosomes with $\mathrm{pH} 6$, the proteins are released [19]. Additionally, a subgroup of M6PRs, cation-independent MPR, is able to localize at plasma membrane, which underpins retrieving of escaped extracellular lysosomal proteins [19]. Besides M6PRs, two sorting receptors are also found, sortilin and lysosomal integral membrane protein 2 (LIMP-2). Sortilin is involved in the sorting of prosaposin [22], acid sphingomyelinase [23], cathepsin $\mathrm{D}$, and cathepsin H [24]. LIMP-2 mediates the transport of $\beta$-glucocerebrosidase [25], whose dysfunction is associated with Gaucher disease (GD). For lysosomal membrane proteins, tyrosine-based or dileucine-based signals are essential for their lysosomal targeting through adaptor proteins or Golgi-localising, Gamma-adaptin ear domain homology, ARF-binding proteins (GGAs) [26, 27]. Early endosomes budding from post-Golgi complex engage multiple rounds of membrane fusion and fission, resulting in formation of late endosomes and lysosomes $[28,29]$. In a word, the lysosomal biogenesis pathway is accurately controlled to keep the homeostasis of cell.

\section{Function of lysosomes}

Recent discoveries have changed the former consideration of lysosomes as organelles that degrade and recycle cellular waste. It is now clear that lysosomes are key organelles in degradation, innate and adaptive immunity, and nutrient sensing [28]. Tempting researches have highlighted many signal pathways interacting with lysosomal activities manifesting the central role of lysosomes in many physiological processes [29]. In addition, progressions of several diseases are also regulated by lysosomes [30].

\section{Autophagy}

Lysosomal degradation is classified as endocytosis and autophagy that is composed of macroautophagy, microautophagy, and CMA. Cytoplasmic materials, like mitochondria, are recycled through macroautophagy triggered by Unc-51-like kinase (ULK) complex and phosphatidylinositol 3-kinase (PI3K) complex, during which double-membrane phagophores are formed and then mature into autophagosomes [31]. To undergo degradation, autophagosomes then fuse with lysosomes with help of microtubule-associated protein 1A/B light chain 3B (LC3B)-I/II [32]. Microautophagy is described as a concise process that lysosome directly engulfs cytosolic material via invagination of lysosomal membrane under the mediation of vacuolar protein sorting 4 (VPS4) and ALG-2 interacting protein X (ALIX) [33]. In 
CMA, cytosolic soluble proteins are recognized through KFERQ-like motif by complex containing members of heat shock proteins (HSPs), HSPA8/HSC70. Then the proteins are translocated into the lysosomal lumen with help of lysosome-associated membrane protein type $2 \mathrm{~A}$ (LAMP2A) for degradation [34]. At present, the mechanisms of autophagy have been intensively studied, thus demonstrating autophagy dysfunction to be a crucial step in the pathology of many diseases and a target for interventions.

\section{Innate and adaptive immunity}

Immunity is directly impacted by lysosomal activities in cells like DCs and macrophages. For innate immunity, pathogens like bacteria are internalized through phagocytosis and targeted to lysosomes for degradation. In cases of bacteria that are able to escape from phagosomes into cytosol, autophagy presents an additional mechanism that captures and delivers bacteria for lysosomal degradation [35, 36]. Additionally, several TLRs on lysosomal membrane are able to recognize various microbial and host-derived ligands and elicit pro-inflammatory signals [6]. For adaptive immunity, antigenic peptides are generated for presentation by major histocompatibility complex class II (MHC-II) molecules to $\mathrm{CD} 4^{+} \mathrm{T}$ cells. During this process, tubulation of phagosomes and lysosomes elicited by TLR4 signaling is important for antigen presentation [37, 38]. Interestingly, autophagy displays the opposite role in MHC-II and MHC-I antigen presentation. Transfer of cytosolic proteins into lysosomes and MHC-II presentation is promoted by autophagy [39], while inhibition of autophagy downregulates MHC-II presentation [40]. On the contrary, autophagy augments major histocompatibility complex class I (MHC-I) internalization resulting in dampened MHC-I presentation [41], which is mainly based on transporter associated with antigen processing complex. A better understanding of the innate and adaptive immunity pathway would be quite important for developing immunotherapy for cancer.

\section{Amino acid sensing}

Another function of lysosomes is amino acid sensing dependent on the localization of mTORC1 complex to lysosomal membrane. Activation of Ragulator and Rag GTPases mediated by amino acid is the key for lysosomal membrane localization of mTORC1 complex [42]. Solute carrier family 38 member 9 (SLC38A9), an amino acid transporter and sensor, putatively senses arginine [43], glutamine, and leucine [44] to activate mTORC1 through Ragulator and Rag GTPases. Additional sensing components that are involved in mTORC1 activation are Sestrin2 for leucine [45] and cellular arginine sensor for mTORC1 (CASTOR) for arginine [46], respectively. When activated, mTOR functions as the master regulator of various cellular behaviors such as growth, autophagy, and lysosomal biogenesis. It's still unknown whether other nutrient sensing mechanisms on lysosomal membranes exist.

In brief, lysosomes are the hub of several crucial cellular activities and signals in physiological conditions. In addition, extra lysosome-related mechanisms have been reported in diseases including atherosclerosis, neurodegenerative diseases, pancreatitis, autoimmune disorders, lysosomal storage disorders, and cancer. There are some interesting similarities among these mechanisms. Detailed understanding of these mechanisms inspires the development of therapies targeting lysosomes.

\section{Role of lysosomes in non-malignant diseases Lysosomes in atherosclerosis}

The development of atherosclerosis may result in coronary syndromes [47], ischaemic strokes [48], intermittent claudication [49], and aneurysms [50], owing to plaque growth and thrombus formation. Low-density lipoprotein cholesterol (LDL-C) and oxidized LDL (oxLDL) [51] engulfed by macrophage-derived foam cells accumulation in the intima of arteries is the key during atherosclerosis, which causes chronic inflammation [52]. Afterward, these cells may engage programmed cell death resulting in a necrotic core covered by a fibrous cap, whose rupturing exposes tissue factor and provokes thrombosis [53]. As the main source of foam cells, macrophages have been rigorously studied, in which lysosomes are demonstrated to be involved in almost the whole process of atherosclerosis.

During the initiation of atherosclerosis, membrane scavenger receptors such as CD36 [54, 55], scavenger receptor A (SR-A) [55], and lipoprotein receptor-1 (LOX1) [56] are responsible for the internalization of lipids, especially oxLDL, into lysosomes. The internalized LDL is hydrolyzed by enzymes like lysosomal acid lipase to produce free cholesterol that is exported to endoplasmic reticulum for re-esterification and storage. Substantial decrease in lysosomal acid lipase activity leads to development of premature atherosclerosis in human [57]. The lipid processing course can be in trouble when macrophages are exposed to oxLDL [54]. Treatment with oxLDL or cholesterol crystal caused lysosomal dysfunction featured with elevated lysosomal $\mathrm{pH}$, increased lysosomal membrane permeability, diminished degradation capacity, and morphological changes [58]. Together, dysfunction of lysosomes owing to oxLDL or decreased lipase may lead to pathological changes that cause atherosclerosis through regulating autophagy, inflammasomes, apoptosis, and lysosomal biogenesis. 
Autophagy has shown its protective role in atherosclerosis development through promoting lipid droplet hydrolysis and eventual efflux of free cholesterol from foam cells [59]. Inhibition of autophagy by autophagyrelated 5 (Atg5) deletion accelerated atherosclerotic plaque development [60]. Unfortunately, atherosclerotic plaque development did impair autophagy conversely in macrophages [61, 62] accounting for cholesterol crystal accumulation and dysfunctional mitochondria, which are responsible for inflammasome hyperactivation, M1-like polarization, and apoptosis [63]. The cholesterol crystal accumulation activated NOD-like receptor family, pyrin domain containing 3 (NLRP3) inflammasome that releases interleukin-1 beta (IL-1ß) [62] through lysosomal leakage containing cathepsins [54]. Impaired autophagy also caused dysfunctional mitochondria that triggered apoptosis through reactive oxygen species (ROS) and cytochrome $C$ [63]. In addition, it has been proved in other disease models that cathepsins from lysosomes are also the inducer of apoptosis in cytoplasm [64, 65]. Apoptosis of macrophages, or foam cells, is the key step in the formation of lipid-rich necrotic core [53]. In a word, both activated inflammasome and apoptosis in macrophages are crucial for atherosclerotic plaque development.

The aforementioned deteriorations initiate several signal changes, which are largely based on activated mTOR indirectly by cholesterol via a lysosomal transmembrane protein SLC38A9 [66]. Activated mTOR may start several detrimental mechanisms. First, mTOR activation inhibits autophagy, whose suppression causes damages described in the foregoing paragraph. Second, cholesterol trafficking from lysosomes to endoplasmic reticulum is obstructed by activated mTOR [67]. Third, activated mTOR inhibits nuclear translocation of TFEB $[9,10]$ that reverses lysosomal dysfunction [58]. Therapeutic benefits of mTOR disruption by Cre/loxP recombination [68] or small molecular inhibitors [69] are in accordance with these mechanisms. What's more, although detailed mechanisms are still fuzzy, the association between mTOR and macrophage polarization are proposed [70, 71]. Inhibiting mTOR elevated M2-like polarization that stabilizes plaques and hampered M1-like polarization that promotes plaque rupture [70, 72-74]. It's noteworthy that a more complex grouping of macrophages in plaques has been put forward based on single-cell RNA sequencing [75]. A better understanding of mTOR-related pathways is tempting for mediation of atherosclerotic plaque development.

In summary, lysosomes in macrophages are involved in initiation, development, and progression of atherosclerotic plaque, which have been exhibited in Fig. 1 and Table 1 . They are the crucial nodes linking lipid degradation, autophagy, apoptosis, inflammasome, lysosomal biogenesis, and macrophage polarization. Researches on lysosomes and mTOR signal are promising for prevention and therapy of atherosclerosis, several of which have inspired lysosome-targeting clinical trials listed in Table 4.

\section{Lysosomes in neurodegenerative diseases}

Aggregation of abnormal proteins and organelles is common in neurodegenerative diseases. The autophagylysosome pathway (ALP) is essential for the survival of non-dividing neurons by contributing to the removal of abnormal large protein aggregates and organelles [76, 77]. Defective clearance by ALP and/or increased abnormal protein aggregation is common in the pathogenesis of several neurodegenerative diseases, including Alzheimer's disease (AD), Parkinson's Disease (PD), and Huntington disease (HD) [78]. It is difficult to determine whether the defect of ALP is the cause or result of neurodegeneration. Indeed, aggregation of toxic proteins, impaired organelles, oxidative stress, and insufficient ATP can interact with defective ALP leading to a worse situation and eventual cell death [79, 80]. Several genetic defects and lysosome-targeting clinical trials have been summarized in Tables 1 and 4, respectively. Here we summarily review the role of lysosomal dysfunction in progressive neurodegenerative disorders.

\section{Alzheimer's disease}

The pathology of $\mathrm{AD}$ is defined by the deposition of amyloid-beta $(A \beta)$ peptides in extracellular amyloid plaques and the accumulation of neurofibrillary tangles in cells formed by phosphorylated microtubule-associated protein tau [81]. The dysfunction of ALP has been proposed to play an important role in $\mathrm{AD}$ [82].

Amyloid precursor protein (APP) can be cleaved through the non-amyloidogenic pathway or the amyloidogenic pathway. The non-amyloidogenic pathway excludes the formation of $A \beta[83,84]$, while the amyloidogenic pathway produces $A \beta 40$ and $A \beta 42$, which tend to misfold to form aggregates [85]. If lysosomal function is impaired or $A \beta$ production increases, $A \beta$ will accumulate in neurons leading to cell death and the pathological manifestations of AD [86]. Tau, a microtubule-associated phosphoprotein, is normally localized in the neuronal axon, where it promotes microtubule assembly and stabilizes microtubules. In AD, ALP dysfunction promotes tau aggregation and causes hyperphosphorylated tau that accumulate and form neurofibrillary tangles in neurons $[87,88]$ promoting neurodegenerative development in AD patients [89]. Additionally, the hyperphosphorylation of tau may in turn cause autophagy dysfunction owing to the instability of neuronal microtubules, which affects the position and function of lysosomes [90]. 


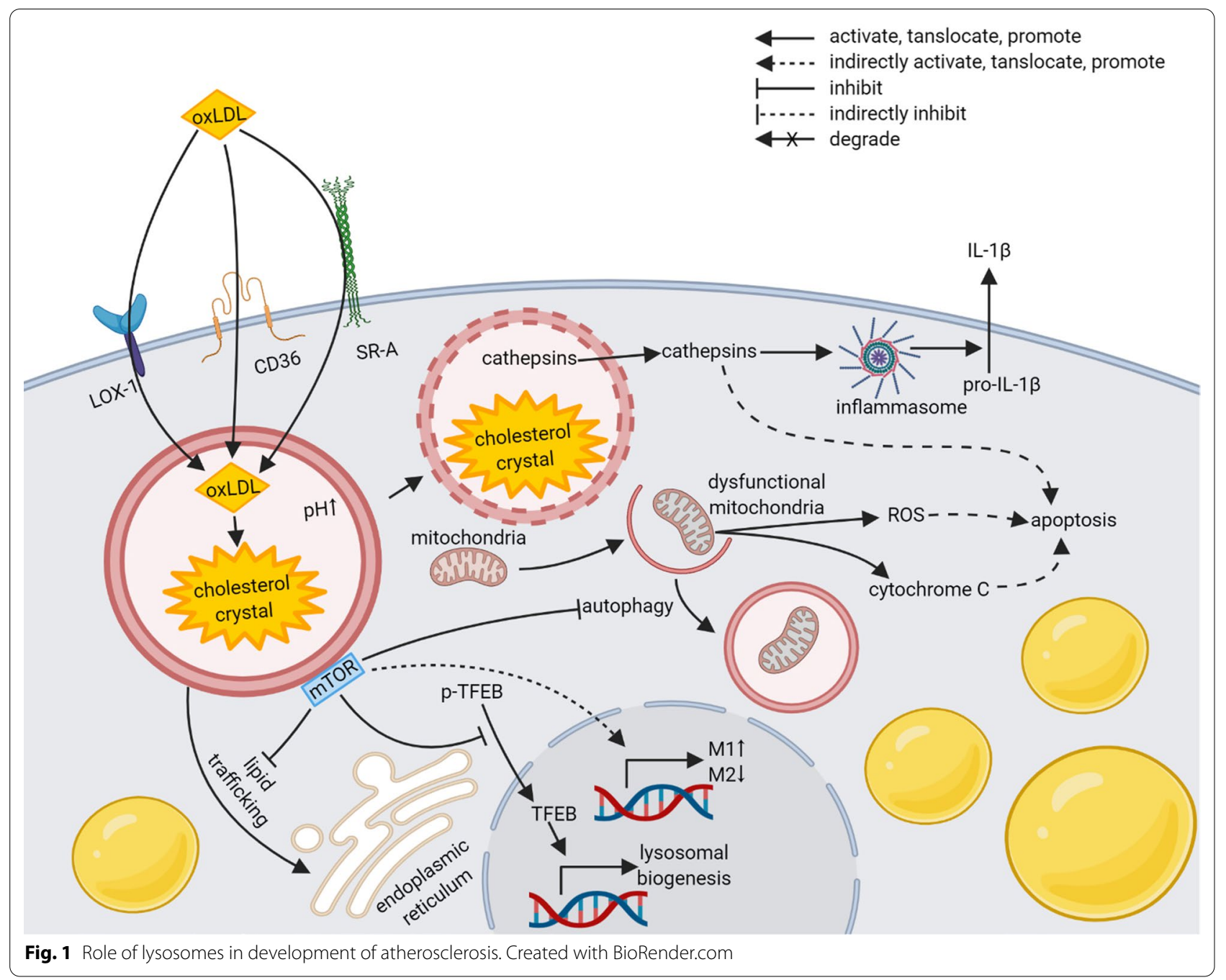

Genetic variations causing dysfunction in ALP pathway are important in the pathogenesis of $\mathrm{AD}$. In mice, genetic inactivation of cathepsin $B$ that cleaves $A \beta 42$ increased A $\beta 42$ and potentiated plaque deposition, while cathepsin $\mathrm{B}$ over-expression reduced the deposition of pre-existing amyloid protein [91]. Consistent with this, in a population-based cohort study, the $\mathrm{T}$ allele of cathepsin $\mathrm{D}$ rs17571 was associated with an increased risk of AD [92]. Presenilin 1 (PS1) mutation is one of the main causes of early-onset familial AD $[93,94]$. The PS1 mutant impedes $\mathrm{v}$-ATPase V0a1 subunit resulting in impaired proton pump function, increased lysosomal $\mathrm{pH}$, affected lysosomal proteolysis, and destroyed autophagy [95]. The expression of Beclin 1, an initiator of autophagy pathway, in AD brain is reduced [96]. The deficient Beclin 1 in vitro and vivo reduced neuronal autophagy resulting in the deposition of $A \beta$, while its overexpression mitigated the accumulation of $A \beta$ [97]. Other attempts to restore
ALP [98], such as TFEB transfection [99], have yield promising therapeutic effects.

In summary, these genetic variations deter the clearance of abnormal proteins in neurons by lysosomes, indicating restoring LAP in neurons to be a potential therapeutic strategy.

\section{Parkinson's disease}

The accumulation of misfolded proteins plays a central role in the pathogenesis in PD and impairs lysosomal function [100]. Accumulation of aggregated proteins in Lewy bodies, which are mainly composed of alphasynuclein ( $\alpha$-syn), is the major pathogenic event in PD [101]. Both CMA pathway and macroautophagy pathway are important for mediating $\alpha$-syn degradation in neurons [102], while lysosomal dysfunction leads to $\alpha$-syn aggregation [103-105]. Inhibition of either system leads to increased levels of $\alpha$-syn [106]. 
Table 1 Diseases related with lysosomal dysfunction

\begin{tabular}{|c|c|c|c|}
\hline Diseases & Lysosomal dysfunction & Outcomes & Reference \\
\hline \multirow[t]{2}{*}{ Atherosclerosis } & Lysosomal acid lipase deficient & $\begin{array}{l}\text { Substantial decrease in lysosomal acid lipase } \\
\text { activity leads to premature atherosclerosis } \\
\text { in human }\end{array}$ & [57] \\
\hline & OxLDL or cholesterol crystal accumulation & $\begin{array}{l}\text { OxLDL or cholesterol crystal causes lysosomal } \\
\text { membrane permeability, autophagy defi- } \\
\text { cient, mitochondrial dysfunction, inflamma- } \\
\text { some activation, and apoptosis }\end{array}$ & {$[54,58,61-63]$} \\
\hline \multicolumn{4}{|l|}{ Neurodegeneration diseases } \\
\hline \multirow[t]{4}{*}{ Alzheimer's disease } & Presenilin 1 mutation & $\begin{array}{l}\text { Defective Presenilin 1-dependent lysosomal } \\
\text { acidification is one of the main causes of } \\
\text { early-onset familial AD }\end{array}$ & {$[93-95,340,341]$} \\
\hline & Becn1 ablation & $\begin{array}{l}\text { Heterozygous deletion of beclin } 1 \text { (Becn } 1 \text { ) } \\
\text { results in autophagy disruption, A } \beta \text { deposi- } \\
\text { tion, and neurodegeneration }\end{array}$ & [97] \\
\hline & Cathepsin D mutation & $\begin{array}{l}\text { The T-allele of cathepsin D rs17571 increases } \\
\text { risk of AD }\end{array}$ & [92] \\
\hline & Cathepsin B ablation & $\begin{array}{l}\text { Ablation of cathepsin B increases the abun- } \\
\text { dance of A } 42 \text { and potentiates plaque } \\
\text { deposition }\end{array}$ & [91] \\
\hline \multirow[t]{3}{*}{ Parkinson's disease } & Snca mutation & $\begin{array}{l}\text { A53T point mutation in the Snca gene causes } \\
\text { familial PD }\end{array}$ & {$[107,108]$} \\
\hline & Atp13a2 ablation & $\begin{array}{l}\text { Atp13a2 depletion leads to lysosomal mem- } \\
\text { brane instability, impaired acidification, } \\
\text { blocked clearance of autophagosomes, } \\
\text { a-syn accumulation, and cell death }\end{array}$ & {$[109,110]$} \\
\hline & Gbal mutation & $\begin{array}{l}\text { Mutations in the Gbal gene are important risk } \\
\text { factors for PD }\end{array}$ & [113] \\
\hline \multirow[t]{3}{*}{ Huntington disease } & Htt mutation & $\begin{array}{l}\text { Mutated HTT protein has abnormally long } \\
\text { polyglutamine (polyQ) repeats near the } \\
\text { N-terminus, which promotes formation } \\
\text { of toxic oligomers and neuronal inclusion } \\
\text { bodies }\end{array}$ & {$[119,120]$} \\
\hline & Wdfy3 ablation & $\begin{array}{l}\text { Depletion of Wdfy3 accelerates the accumula- } \\
\text { tion of polyQ aggregates }\end{array}$ & [127] \\
\hline & Sqstm 1 knockdown & $\begin{array}{l}\text { Sastm } 1 \text { knockdown increases mHTT-induced } \\
\text { cell death }\end{array}$ & [128] \\
\hline \multirow[t]{2}{*}{ Pancreatitis } & Impaired autophagy flux & $\begin{array}{l}\text { Increased autophagosome formation and } \\
\text { decreased autophagosome clearance are } \\
\text { observed }\end{array}$ & {$[140,342]$} \\
\hline & Imbalanced cathepsin B and cathepsin L & $\begin{array}{l}\text { Imbalance between cathepsin } B \text { and cath- } \\
\text { epain } L \text { contributes to accumulation of } \\
\text { activated intracellular trypsin }\end{array}$ & [140] \\
\hline \multicolumn{4}{|l|}{ Autoimmune disorders } \\
\hline \multirow[t]{3}{*}{ Systemic lupus erythematosus } & Enhanced autophagy in T cells & $\begin{array}{l}\text { Enhanced autophagy causes imbalanced T } \\
\text { cell subsets }\end{array}$ & [146-148] \\
\hline & Defect LC3-associated phagocytosis & $\begin{array}{l}\text { Defect LC3-associated phagocytosis leads } \\
\text { to blunted clearance of dying cells and } \\
\text { elevated inflammation }\end{array}$ & [149] \\
\hline & Defect lysosomal acidification & $\begin{array}{l}\text { Macrophages in lupus shows elevated lyso- } \\
\text { somal pH }\end{array}$ & [343] \\
\hline \multirow[t]{2}{*}{ Crohn's disease } & Defect autophagy & $\begin{array}{l}\text { Human or mice deficient in ATG16L1 are more } \\
\text { susceptible to Crohn's disease }\end{array}$ & {$[150,151]$} \\
\hline & Defect lysosomal acidification & $\begin{array}{l}\text { Elevated luminal pH links lysosomal dysfunc- } \\
\text { tion with Crohn's disease risk }\end{array}$ & [344] \\
\hline Rheumatoid arthritis & Impaired autophagy & $\begin{array}{l}\text { Reduced autophagy links altered metabolism } \\
\text { and T cell exhaustion }\end{array}$ & [152] \\
\hline Multiple sclerosis & Enhanced autophagy & $\begin{array}{l}\text { Enhanced ATG5 expression in T cells is cor- } \\
\text { related with more sever disability }\end{array}$ & [153] \\
\hline
\end{tabular}


Table 1 (continued)

\begin{tabular}{|c|c|c|c|}
\hline Diseases & Lysosomal dysfunction & Outcomes & Reference \\
\hline \multicolumn{4}{|l|}{ Lysosomal storage disorder } \\
\hline Niemann-Pick type C (NPC) disease & Npc1 or Npc2 mutation & $\begin{array}{l}\text { Defective NPC1 or NPC2 causes lysosomal } \\
\text { accumulation of cholesterol and glycosphin- } \\
\text { golipids leading to hepatic, pulmonary, and } \\
\text { neuropsychiatric disorder }\end{array}$ & {$[345]$} \\
\hline Fabry disease & Galactosidase a mutation & $\begin{array}{l}\text { Galactosidase a mutation causes globotria- } \\
\text { osylceramide accumulation in lysosomes } \\
\text { leading to vascular diseases }\end{array}$ & {$[346]$} \\
\hline Tay-Sachs disease & $\beta$-hexosaminidase a mutation & $\begin{array}{l}\text { Deficient } \beta \text {-hexosaminidase a causes GM2 } \\
\text { ganglioside accumulation in lysosomes of } \\
\text { nerve cells leading to neuro disorder }\end{array}$ & {$[347]$} \\
\hline Mucopolysaccharidoses diseases & $\begin{array}{l}\text { Mutation in mucopolysaccharide catabolic } \\
\text { enzymes }\end{array}$ & $\begin{array}{l}\text { Lysosomal accumulation of mucopolysac- } \\
\text { charides leads to disorders in bone, cartilage, } \\
\text { connective tissues, and nervous }\end{array}$ & {$[348]$} \\
\hline Pompe disease & a glucosidase mutation & $\begin{array}{l}\text { Mutated a glucosidase causes glycogen accu- } \\
\text { mulation in lysosomes leading to cardiac } \\
\text { and respiratory failure }\end{array}$ & {$[349]$} \\
\hline Gaucher disease & glucosylceramidase $\beta$ mutation & $\begin{array}{l}\text { Glucosylceramide accumulates in mac- } \\
\text { rophage lysosomes leading to disorder in } \\
\text { visceral organs and nervous system }\end{array}$ & {$[162]$} \\
\hline
\end{tabular}

The A53T point mutation in the Snca gene that encodes $\alpha$-syn causes familial PD via accelerated oligomerization or fibrillization of the protein [107, 108]. Other alterations in lysosome-related genes impair the degradation of misfolded proteins. ATPase cation transporting 13A2 (ATP13A2) depletion leads to $\alpha$-syn accumulation through lysosomal dysfunction [109, 110]. Mutations in lysosomal hydrolases are also critical risk factors for the disease [111, 112]. For instance, mutated glucocerebrosidase, commonly found in Gaucher disease, is important risk factor for PD [113]. Activating autophagy by Latrepirdine [114] or TFEB overexpression $[13,115]$ showed promising therapeutic effects in preclinical researches.

In a word, genetic alterations promote PD through both accelerating $\alpha$-syn accumulation and decelerating $\alpha$-syn clearance, and enhancing autophagy is a possible strategy.

\section{Huntington disease}

$\mathrm{HD}$ is a rare autosomaldominant neurodegenerative disease caused by detrimental aggregationprone HTT mutants (mHTT) with an aberrant expansion of cysteine, adenine, and guanine (CAG) trinucleotide repeats within exon 1 of the HTT gene [116-118]. The mHTT has abnormally long polyglutamine (polyQ) repeats near the $\mathrm{N}$-terminus, which promotes the formation of toxic oligomers and aggregates to form nuclear and cytoplasmic neuronal inclusion bodies [119, 120]. Because wild-type huntingtin serves as a scaffold for the recruitment of several autophagy proteins [121], accumulation of mHTT induces lysosomal and autophagy dysfunctions.

Interestingly, HD neurons show an increased number of autophagosomes and maintain appropriate (or even higher) levels of autophagy flux [122, 123]. Although the initiation of autophagy and the formation of autophagic vesicles increased through inactivating mTOR [124], the aggregated mHTT and damaged organelles will be seldom transferred to autophagosomes resulting in their accumulation in the cytoplasm and toxicity [123]. Macroautophagy plays a key role in the clearance of mutant HTT aggregates [125, 126], during which adaptor protein, autophagy-linked FYVE protein (ALFY), is necessary for clearing mHTT aggregation [127]. Depletion of ALFY accelerated the accumulation of aggregates, while increasing ALFY expression reduced protein aggregates and mitigated polyQ toxicity [127]. In addition, dysfunction of p62, an autophagy receptor protein, significantly increased neuron death induced by mHTT [128]. Notably, when macroautophagy is impaired by mHTT, compensatory CMA activity may be up-regulated suggesting the existence of crosstalk among autophagy pathways [129]. However, the compensation mechanism may decrease with age, leading to neuronal loss and the pathological manifestations of HD [130]. Rapamycin and rapamycin analog CCI-779 (temsirolimus) can effectively attenuate the accumulation of huntingtin protein and improve the motor performance in the mice [124].

Thus, developing therapies that upregulate autophagy is likely to relieve mHTT aggregation in patients. 


\section{Lysosomes in pancreatitis}

Present researches shed light on the involvement of lysosomes in pathophysiology of pancreatitis [131]. Normally, pancreatic acinar cells secrete digestive enzymes, many of which are inactive zymogens packed in zymogen granules until they reach the intestines [132]. A canonical hypothesis for pancreatitis is intra-acinar trypsinogen activation [131]. Excessive secretagogue-receptor or bile salt receptor activation causes abnormal peak-plateau calcium signal, which disrupts zymogen granule exocytosis, blocks secretion, and initiates the formation of endocytic vacuoles $[133,134]$. The vacuoles containing trypsin and trypsinogen fuse with lysosomes containing cathep$\sin B$ that transforms trypsinogen into trypsin $[131,135]$. Alternatively, macrophages phagocytose extracellular zymogen-containing vesicles and generate active trypsin [136]. The unstable endocytic vacuoles would rupture and release trypsin and cathepsin B into cytoplasm, thus provoking apoptosis or necrosis [137]. Additionally, calcium or tumor necrosis factor- $\alpha$ (TNF- $\alpha$ ) from recruited leukocytes are able to initiate necroptosis in acinar cells $[138,139]$.

However, debates about the intra-acinar trypsinogen activation exist, because cathepsins co-localize with digestive enzymes in physiological autophagy without manifestation of pancreatitis [140]. Lysosomal dysfunction in pancreatitis is indicated by the findings that the maturation of cathepsin B and cathepsin $\mathrm{L}$ are reduced and that autophagosome formation is increased while lysosomal degradation is decreased [140]. Since cathepsin B converts trypsinogen to trypsin [141] while cathepsin L digests both trypsinogen and trypsin [142], the imbalance between cathepsin B and cathepsin L, especially insufficient cathepsin L maturation, may contribute to trypsin accumulation and development of pancreatitis [140]. Besides abnormal cathepsins, disruption of autophagy-related genes, ATG5 [143], ATG7 [144], or $L A M P 2$ [145], induces spontaneous or chronic pancreatitis implying the importance of autophagy in pancreatitis pathology.

In summary, the detailed involvement of lysosomal dysfunction and cathepsin activities in pancreatitis is still controversial. Quantification or semi-quantification of autophagy activities and cathepsin activities in patients or animal models may help clarify the mechanisms. The lysosomal dysfunction in pancreatitis has been summarized in Table 1.

\section{Lysosomes in autoimmune disorders}

Multi-facetted role of lysosomes in autoimmune disorders has been demonstrated by the finding that autophagy, cathepsin expression, and luminal $\mathrm{pH}$ are altered in different immune cells in patients or mouse models [30]. In lupus, activated autophagy supports survival, development, and differentiation in $\mathrm{B}$ cells and $\mathrm{T}$ cells $[146,147]$. Imbalance between pro-inflammatory Th17 and immunosuppressive regulatory $\mathrm{T}$ cells (Tregs) is attributed to autophagy activation in these $\mathrm{T}$ cell subsets [148]. However, mice deficient in LC3-associated phagocytosis, a non-canonical autophagy, showed blunted clearance of dying cells and elevated inflammatory cytokines, immune complex deposition, and autoantibodies as well as more sever lupus symptom [149]. Autophagy deficiency is also indicated in Crohn's disease $[150,151]$ and $\mathrm{T}$ cells from rheumatoid arthritis [152], while intensified autophagy in $\mathrm{T}$ cells is highlighted in multiple sclerosis [153]. The regulation of glucocorticoid receptors by lysosomal degradation is a contentious topic that lysosome inhibitors, chloroquine or bafilomycin A1, enhance therapeutic effects of glucocorticoid in rheumatoid arthritis [154], while autophagy activator, rapamycin, declines prednisone requirement in lupus patients [155]. The above findings imply various autophagy alterations in different cell subsets from different autoimmune disorders. Thus, interventions targeting autophagy pathway should be carefully designed and tested. The lysosomal dysfunction and lysosome-targeting clinical trials for autoimmune disorders have been summarized in Tables 1 and 4 , respectively.

\section{Lysosomes in lysosomal storage disorders (LSDs)}

LSDs are a group of heterogeneous inherited metabolic disorders, most of which are attributed to mutations of particular lysosomal hydrolases. The pathology of LSDs can be explained by the accumulation of the substrates of the hydrolases or the secondary products formation instigated by the substrates [30]. An exception is mucolipidosis type IV, where mutated $M C O L N 1$, a nonselective cation channel gene, impairs the fusion of lysosomes with both autophagosomes and late endosomes [156]. Common detrimental autophagy alterations and following changes have been revealed in LSDs. Deregulated mitophagy leads to increased damaged mitochondria engendering reactive oxygen species, ATP production, and imbalanced $\mathrm{Ca}^{2+}$ [157]. Microautophagy is impaired in Pompe disease [158]. Defective CMA caused by mutated LAMP2 has been claimed in Danon disease [159]. Detailed descriptions of the deficient proteins in LSDs have been listed in Table 1. The enzyme replacement therapies for LSDs are underpinned by the mechanisms that some cation-independent MPRs are localized at plasma membrane to retrieve escaped extracellular lysosomal proteins [19]. Thus, supplying the appropriate enzymes is able to reverse the pathology of LADs. Alternatively, gene therapies are newly developed to restore deficient genes in patients. Clinical trials 
testing enzyme replacement therapies and gene therapies of LADs have been listed in Table 4. It will be an interesting topic to compare enzyme replacement therapies with gene therapies.

A special feature for GD is its relationship with increased risk for malignancies, particularly hematological malignancies $[160,161]$. The biallelic glucosylceramidase $\beta$ gene mutation causes glucocerebroside accumulation in lysosomes in macrophages, the Gaucher cells (GCs) [162] that conglomerate to form Gaucheromas in liver, spleen, bone marrow, and even nervous system $[160,161]$. Patients with GD are more frequent to develop multiple myeloma and several hematological malignancies [161, 163]. Additionally, elevated frequencies of malignancies in kidney, liver, prostate, testis, brain, bone, colon, and melanoma are also related with GD $[161,164]$. The predisposition of malignant tumor could be explained, at least partially, by an altered microenvironment related to phenotypes of GCs [160]. Impaired autophagy in GCs led to p65-nuclear factor-kappaB (NF$\kappa B)$ activation following with IL- $1 \beta$ secretion by inflammasome pathway [165]. However, anti-inflammatory interleukin-13 (IL-13) was also increased [166]. Several works demonstrated that the phenotype of GCs resembled alternatively activated macrophages [167, 168]. In fact, M2-like GCs were surrounded by spleen cells with strong and frequent M1-like markers such as IL-1 $\beta$ and monocyte chemotactic protein-1 (MCP-1) [167]. We propose that the existence of both M1-like and M2-like macrophages in GD tissues resembles a sterile chronic inflammation environment facilitating malignancies development in various mechanisms [169-172]. In a word, abnormal lysosomal storage disorder in macrophages is closely related to macrophage activation that may create an inflammatory microenvironment suitable for tumorigenesis.

\section{Role of lysosomes in tumor microenvironment}

Malignant tumor is an increasingly severe health problem making up the growing rate of death nowadays. In most cases, conventional therapies display only limited effects. The difficulties in therapy exist not only in complex tumor cells but also in complicated tumor microenvironment (TME) composed of macrophages, T cells, dendritic cells, fibroblasts, and other cells. It has been clear that the progression and regression of tumors are highly dependent on the dynamic interactions between various cells within TME [173]. In the microenvironment characterized by innutrition, acidity, hypoxia, and ischemia, tumor cells reprogram phenotypes and behaviors of stromal cells to promote tumor progression through inducing proliferation, drug resistance, invasion, metastasis, and immunosuppression [173]. These interactions are achieved through membrane proteins, cytokines, metabolites, exosomes, and others. Compelling results have substantiated lysosomes are exceedingly evolved in the phenotype and behavior changes. In the following paragraphs, lysosome-related mechanisms in several cell subgroups are introduced and these mechanisms are summarized in Table 3.

\section{Lysosomes in tumor cells}

Massive knowledge about tumor cells has been collected over the past decades. Tumor cells are now considered as a group of cells that contain unstable genome with numerous mutations and are able to proliferate continuously, evade cell death, induce angiogenesis, invade, metastasize, avoid immune supervision, resistant to chemotherapy, and resistant to radiotherapy [174]. Paradigms such as epithelial-mesenchymal transition and cancer stem cells have been proposed to explain and link these malignant behaviors. Additionally, activities of lysosomes are implicated in the phenotypes of malignant cells. The overarching lysosomal activity, autophagy, has been shown to inhibit tumorigenesis, yet promote tumor progression. Autophagy prevents tumorigenesis by inhibiting the transformation of pre-malignant cells $[175,176]$. Genotoxic ROS and dysfunctional mitochondria are eliminated by autophagy [177, 178]. Moreover, autophagy could process genomic instability, such as extruded cytoplasmic chromatin fragments [179], micronuclei [180], and endogenous retrotransposons [181]. However, elevation of autophagy has been shown in primary tumor cells and cell lines [182, 183]. Comparing the differences of autophagy between pre-malignant cells and cancer cells will be an interesting topic. Autophagy, as well as other lysosome-related mechanisms facilitate tumor progression by promoting malignant phenotypes mentioned above. Here we focus on the mechanisms through which lysosomes regulate proliferation, invasion, radiotherapy resistance, and chemotherapy resistance.

\section{Regulation of tumor cell proliferation by lysosomes}

Lysosomes regulate tumor cell proliferation through manipulating growth factor signals and providing nutrients. Growth factor signals are initiated at plasma membrane by receptor tyrosine kinases (RTK), which can be limited by endocytic degradation in lysosomes [184]. Epidermal growth factor receptor (EGFR), a member of RTK, can be internalized from plasma membrane to macropinocytic structures with help of adaptor molecule, growth factor receptor bound protein 2 (Grb2), when cells are stimulated with epidermal growth factor (EGF), the ligand of EGFR [185]. This feedback mechanism can be controlled by a tumor suppressor protein, receptor-associated late transducer (RALT) [186]. On the 
other hand, in order to sustain tumor growth, tumor cells need more nutrients than normal cells to provide energy and biosynthetic material [187]. Lysosomes degrade recycled intracellular materials and internalized extracellular proteins by autophagy and macropinocytosis, respectively, to supply amino acids $[183,187,188]$. The utilization of extracellular proteins for nutrient supplements is achieved when mTORC1 is inactivated [189]. As expected, inhibited autophagy and macropinocytosis impeded tumor growth [182, 187]. Moreover, Davidson et al. put the hypothesis forward in their review that autophagy may also be an adaptive strategy to salvage nucleotides by recycling endogenous and exogenous nucleic acids [174]. Collectively, lysosomes are the key regulator of both proliferation signal and proliferation materials. A good question is whether lysosomes are able to regulate other growth factor signals and provide other kinds of nutrients for tumor cells.

\section{Regulation of tumor cell invasion by lysosomes}

Invasion is one of the most crucial malignant behaviors, which jeopardizes adjacent normal tissues and is tightly related to metastasis. A key step of invasion is degradation of the extracellular matrix. Cathepsins, a family of peptidase in lysosome, have been extensively researched, because of their significant relationship with invasion, metastasis, and prognosis [190]. They are categorized into cysteine peptidases (cathepsins B, C, F, H, K, L, O, S, $\mathrm{V}, \mathrm{W}$, and $\mathrm{X}$ ), serine peptidases (cathepsins $\mathrm{A}$ and $\mathrm{G}$ ), and aspartic peptidases (cathepsins D and E) [65]. Expression alterations of cathepsins are ubiquitous in tumors, as summarized in Table 2. Both tumor cells and stromal cells are able to release cathepsins into TME; however, cathepsins from distinct cells may have different functions [191, 192]. In most cases, up-regulated cathepsins are associated with migration, invasion, and metastasis indicating tumor progression and poor prognosis. Thus, many of the cathepsins have been identified as prognostic markers or therapeutic targets. Cathepsin B, for example, is able to degrade laminin, collagen IV, and fibronectin, three major components of the basement membrane, at both acid and neutral pH [193]. To make matters worse, cystatins, endogenous cathepsin inhibitors, are down-regulated in some cancers [194]. Besides degradation of extracellular matrix, cathepsin B and $\mathrm{X}$ in several tumor cell lines are able to stimulate epithelialmesenchymal transition (EMT), a process that has been wildly recognized to promote invasion [195]. Moreover, cathepsin $\mathrm{B}$ also promotes migration in glioma-initiating cells through mediating c-Jun amino terminal kinase (JNK) [196]. Consistent with these findings, administration of cathepsin inhibitors diminished tumor invasion [197]. Interestingly, although potentiated invasion and metastasis caused by elevated expression of cathepsins are wildly recognized, several reverse relationships between cathepsins and tumor progression have been reported (Table 3). Augmented cathepsin X was involved in early tumorigenesis of colon carcinoma, nonetheless, gradual loss of cathepsin $\mathrm{X}$ was detected during advanced local invasion and metastasis leading to poor prognostic outcome [198]. A similar pattern was found in cathepsin E whose expression was significantly higher in Barrett's esophagus than normal tissue, but esophageal adenocarcinoma expressed a relatively lower cathepsin E level than Barrett's esophagus [199]. Another favorable role of cathepsins in patients was seen in cathepsin $\mathrm{V}$ from thymic carcinoma [200] and cathepsin E from bladder cancer [201] and breast cancer [202]. The diverse effects of cathepsins on different tumors imply various unknown mechanisms. In fact, the roles of cathepsins in tumor are considerably beyond promoting invasion [197]. More details about the involved mechanisms would be helpful for understanding their different effects on tumor progression.

\section{Regulation of tumor cell radioresistance by lysosomes}

Radiotherapy is now wildly used in the therapy of malignant tumors, whose therapeutic effect is based on direct DNA damage through radiation itself and indirect DNA damage through ROS and reactive nitrogen (RNS) species. Following DNA damage, cell death is induced in tumor cells. However, tumor cells sometimes develop radioresistance resulting in recrudesce and therapy failure. Several factors related to radioresistance have been revealed at present, including autophagy, cathepsins, and tumor stem cells. The autophagy response may vary depending on different dosages and kinds of radiation, as well as different tumor cells. More frequently, ionizing radiation induces autophagy [203] through mTOR inhibition [204] or autophagy-related 4B cysteine peptidase (ATG4B) [205] activation. Although detailed mechanisms are still ambiguous, the protective role of autophagy in tumor cells treated with radiation has been verified in various tumor cells, possibly depending on liver kinase B1 (LKB1) [206] and p53 [207]. In accordance with the reported protective role of autophagy, a series of attempts blocking autophagy resulted in increased radiosensitivity, including pharmacological inhibition, gene silencing, and gene knockout [203]. Therapy strategies combining radiotherapy and autophagy inhibition have been tested, which showed promising outcomes [208, 209]. Knockdown of TFEB, the downstream transcription factor of mTOR, diminished radioresistance in cancer cells, indicating the involvement of lysosomal biogenesis in autophagy-dependent radioresistance 

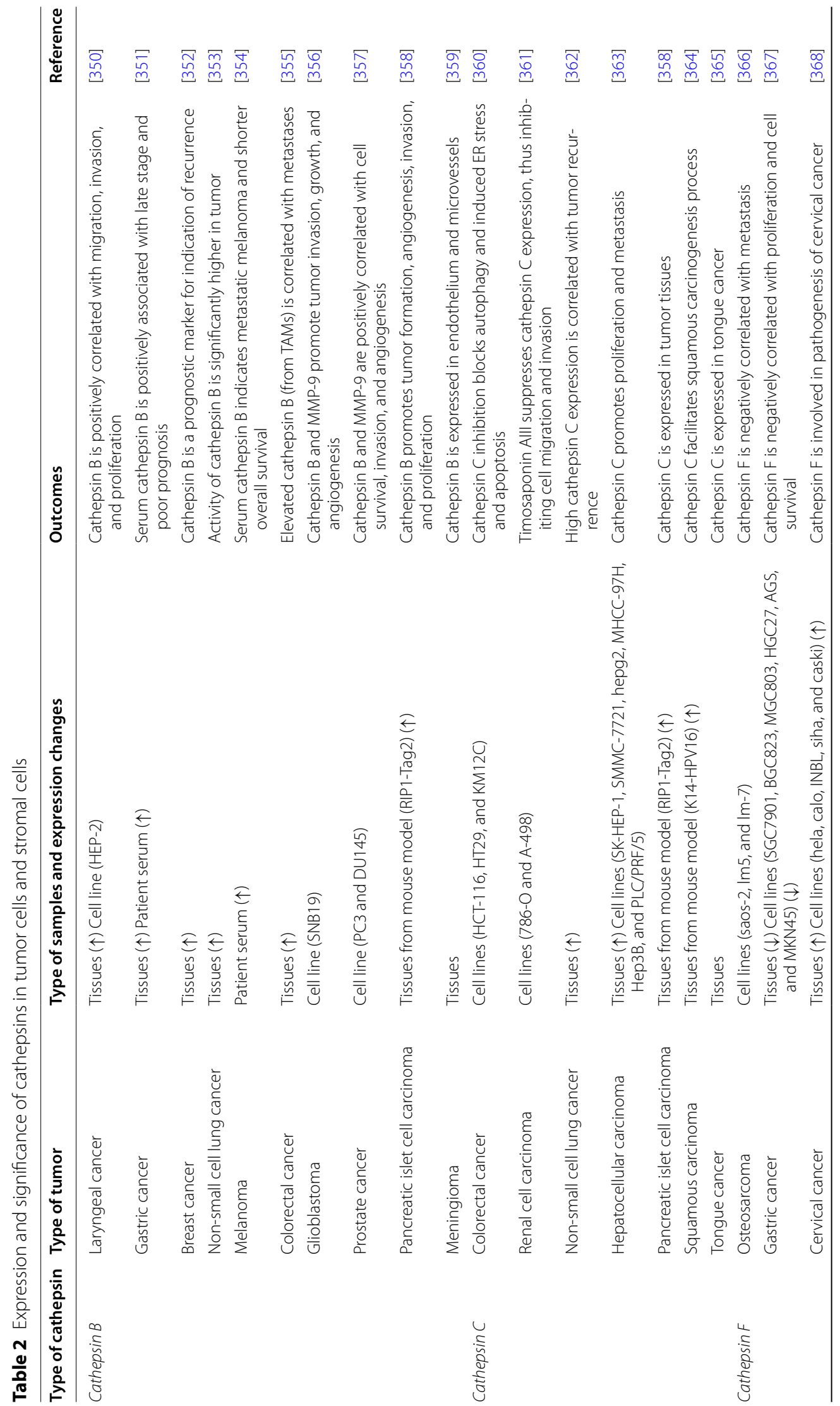


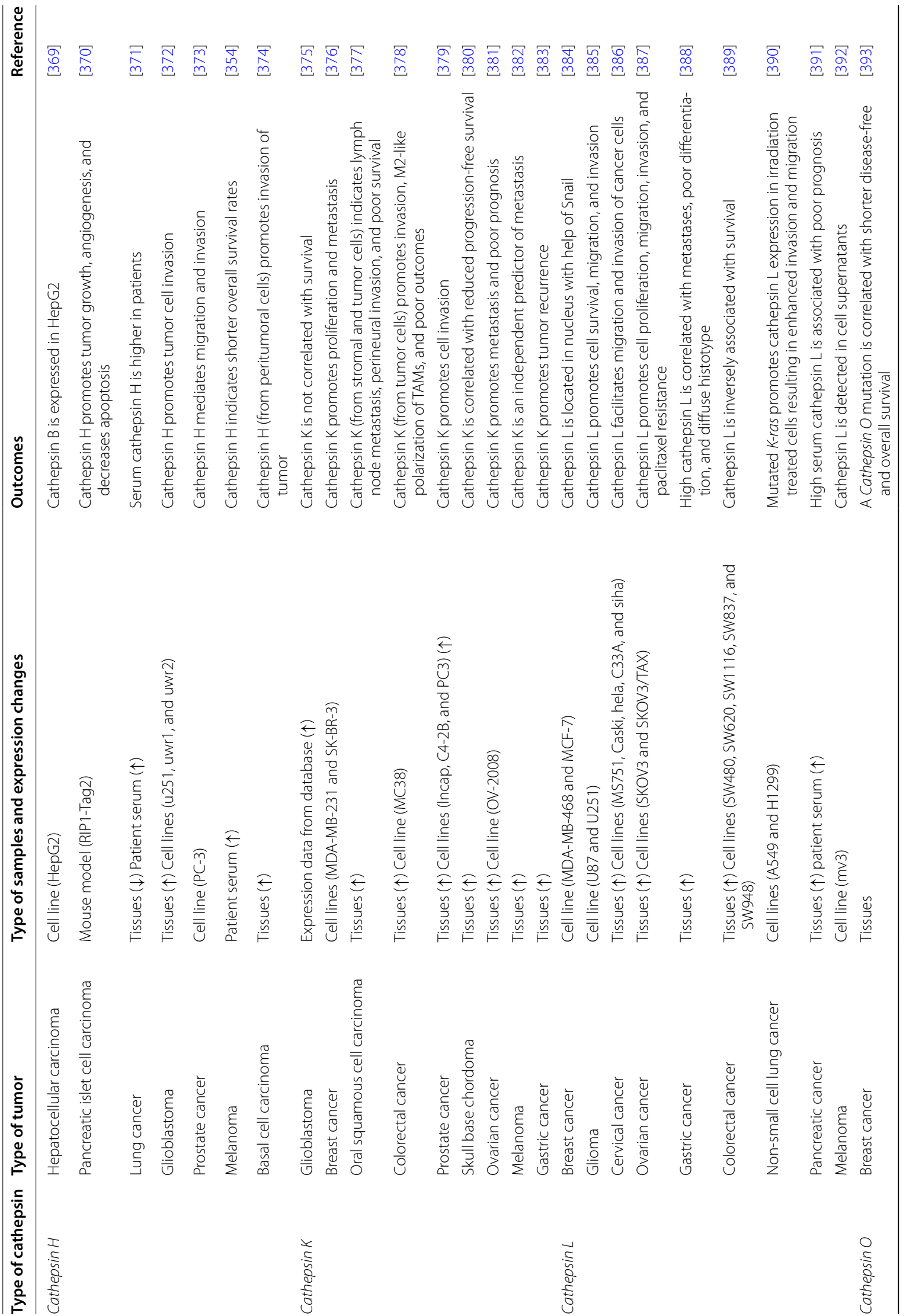




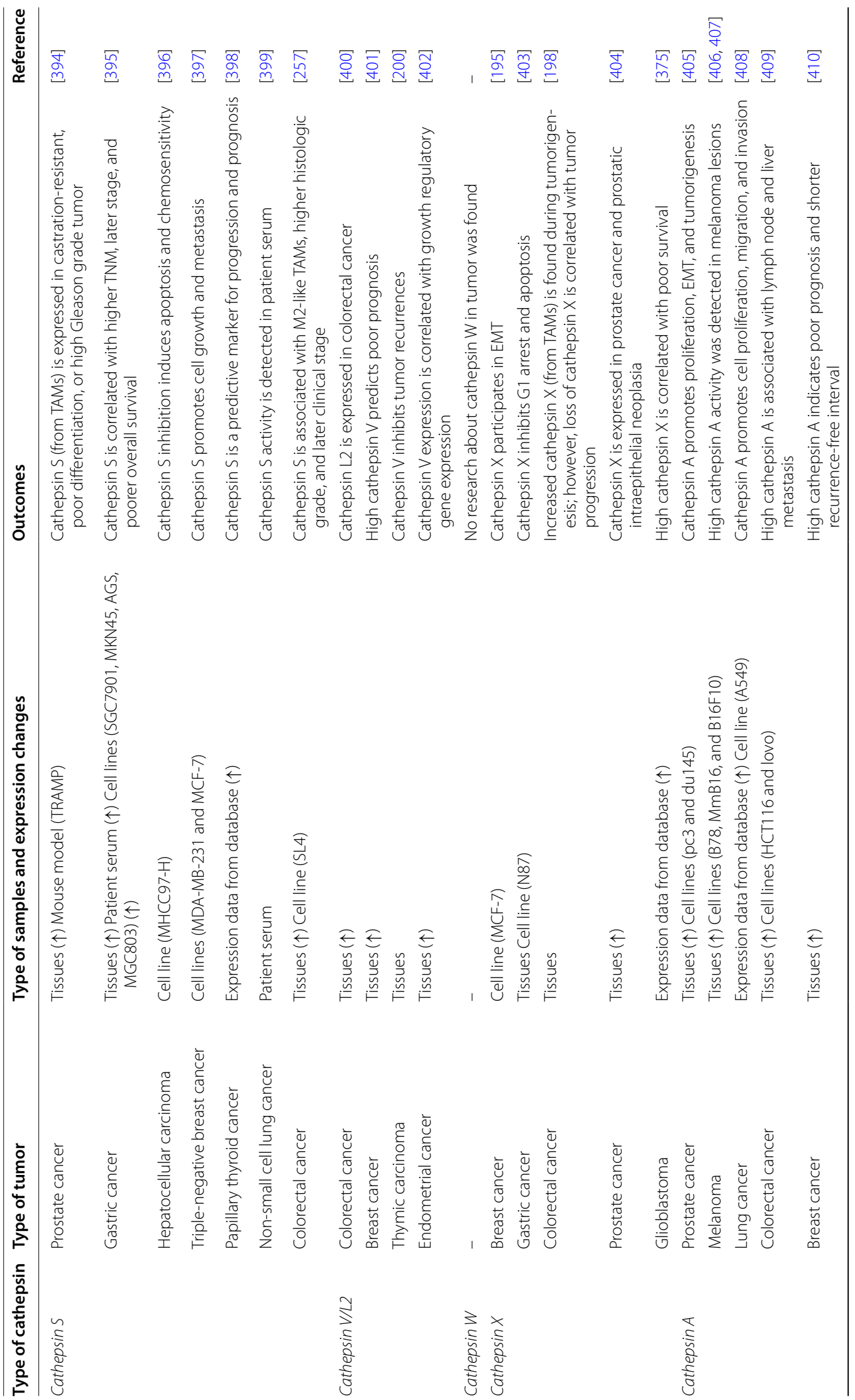




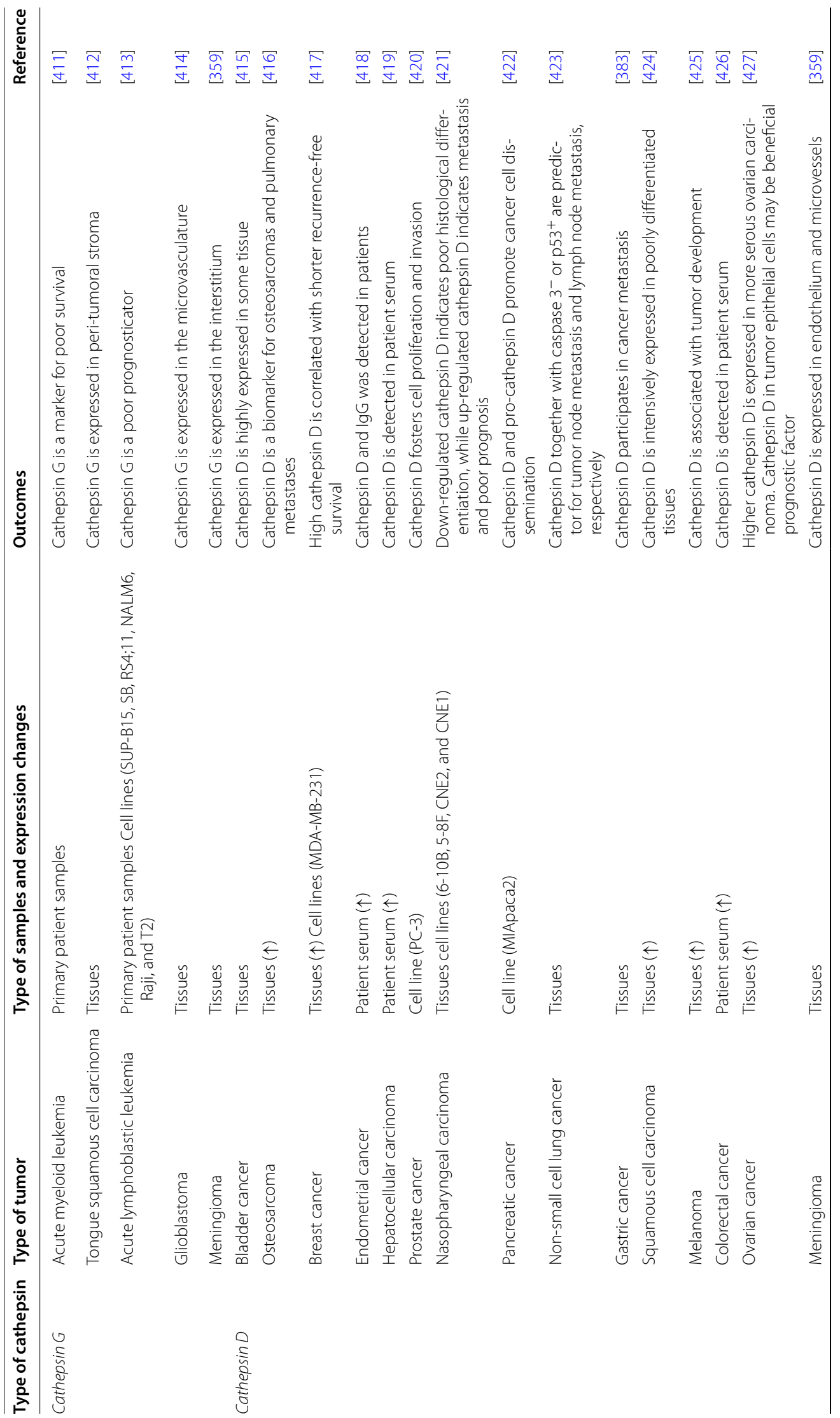




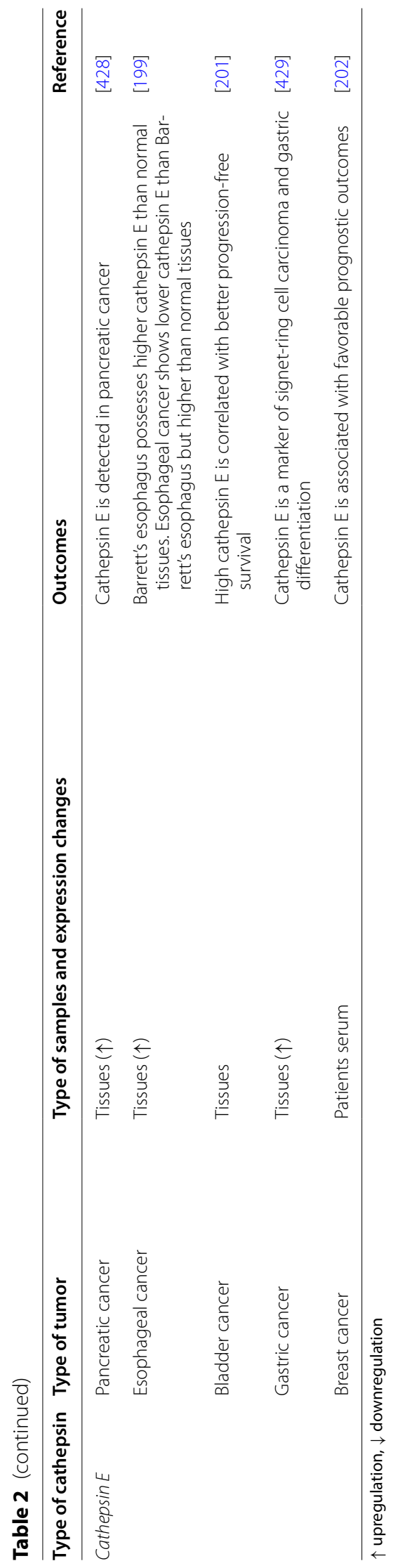


Table 3 Function of lysosomes in subset of cells in TME

\begin{tabular}{|c|c|c|c|}
\hline Cell subset & Function of lysosomes & Outcomes & Reference \\
\hline \multirow[t]{6}{*}{ Tumorcell } & Proliferation & EGFR can be internalized from plasma membrane and degrade in lysosomes & {$[184,185]$} \\
\hline & & Autophagy and macropinocytosis provide extra nutrients & {$[183,187,188]$} \\
\hline & Invasion & Cathepsins degrade extracellular component and promote EMT & {$[193,195]$} \\
\hline & Radioresistance & $\begin{array}{l}\text { Radioresistance can be achieved through autophagy, cathepsins, and tumor stem } \\
\text { cells }\end{array}$ & {$[205,206,212,214,215]$} \\
\hline & Chemoresistance & $\begin{array}{l}\text { Drugs are sequestrated in lysosomes by actively transportation or passive diffu- } \\
\text { sion }\end{array}$ & [220] \\
\hline & & Autophagy promotes or inhibits cancer cell death in different situation & [232-237] \\
\hline \multirow[t]{6}{*}{ TAMs } & M2-like polarization & Autophagy, LAP, and CMA regulate M2-like polarization at most cases & {$[257,259,260]$} \\
\hline & M1-like polarization & TLRs on lysosomal membrane regulate M1-like polarization & {$[262,264,266]$} \\
\hline & & Elevated luminal pH is correlated with M1-like polarization & {$[275,276]$} \\
\hline & Invasion promotion & TAM-derived cathepsins promote tumor invasion & {$[280,283,284]$} \\
\hline & Chemoresistance induction & TAM-derived cathepsins protect tumor cells from drug-induced apoptosis & {$[279]$} \\
\hline & Infiltration promotion & TAM-derived cathepsins promote macrophage infiltration into TME & {$[290,291]$} \\
\hline DCs & Antigen presentation & $\begin{array}{l}\mathrm{LAMP}^{+} \text {DCs are able to elicit CD8 }{ }^{+} \mathrm{T} \text { cell immunity. Autophagy may promote or } \\
\text { inhibit antigen presentation }\end{array}$ & [293-296] \\
\hline \multirow[t]{4}{*}{ CAFs } & Chemoresistance regulation & Autophagy in CAFs promotes or inhibits chemoresistance in different tumor & {$[303,304]$} \\
\hline & Proliferation promotion & Autophagy in CAFs provides nutrients for tumor cells & {$[299,300]$} \\
\hline & Invasion promotion & Autophagy in CAFs promotes EMT in tumor cells & [305] \\
\hline & Stemness promotion & CAFs with active autophagy release HMGB1 to enhance stemness in tumor cells & {$[306]$} \\
\hline \multirow[t]{3}{*}{ Tcells } & $\mathrm{CD}^{+} \mathrm{T}$ cell immunity & $\begin{array}{l}\text { Autophagy in } \mathrm{CD}^{+} \mathrm{T} \text { cells promotes or inhibits } \mathrm{CD} 8^{+} \mathrm{T} \text { cell immunity in different } \\
\text { tumor }\end{array}$ & {$[309,310]$} \\
\hline & $\mathrm{CD}^{+}{ }^{+} \mathrm{T}$ cell immunity & Autophagy in $C D 4^{+} T$ cells inhibits anti-tumor effects by $T_{H} 9$ cell & {$[311,312]$} \\
\hline & Treg inhibition & Autophagy in Treg promotes survival and stability of Treg cells & [313] \\
\hline
\end{tabular}

[210]. However, Kim et al. showed that radiation-activated mTOR and elicited de novo protein synthesis instead of autophagy [211] implying a context-dependent regulation of $\mathrm{mTOR}$ and autophagy. Besides autophagy, cathepsins also mediate radioresistance in tumor cells. Elevation of cathepsin B [212], S [213], and $L$ [214] was observed in tumor cells after radiation treatment. Potential mechanism of cathepsin-induced radioresistance is related to cell cycle mediation and DNA repairment, because knockdown of cathepsin $\mathrm{L}$ led to $\mathrm{G}_{2} / \mathrm{M}$ phase cell cycle arrest [214] and decreased phosphorylation of DNA repair checkpoint protein, ataxia-telangiectasia-mutated kinase (ATM) and DNAdependent protein kinase (DNA-PKcs) [215]. Nuclear translocation of NF- $\mathrm{kB}$ and following activation of cyclin D1 and ATM were highlighted as downstream signal of cathepsin L [216]. A link between cathepsins and tumor stem cells is another mechanism of radioresistance. Cathepsin B [212, 217] and L [218] have been shown to relate significantly with tumor stem cells, a subgroup of cells that are resistant to radiotherapy [219]. Cathepsin L knockdown dramatically reduced CD133, a stem cell marker [215]. In a word, knockdown or inhibition of cathepsins and autophagy are potential strategies to increase the radiosensitivity of tumor cells.

\section{Regulation of tumor cell chemoresistance by lysosomes}

An intriguing mechanism of lysosome-mediated chemoresistance in tumor cells has been well elaborated. Briefly, drugs can be sequestrated in lysosomes through passive diffusion or active transportation, which prevents drugs from reaching their intracellular targets [220]. For passive diffusion, lysosomes are distinguished by their luminal $\mathrm{pH}$ of about 4.5-5, hence lysosomes are able to sequester lipophilic, weakly basic drugs without the help of transporters [221, 222]. Once accumulate in lysosomes, these drugs can hardly pass the lysosomal membrane because of protonation [220]. Alternatively, chemotherapy drugs can also enter lysosomes through trafficking by P-glycoprotein (P-gP), an ATP-dependent efflux pump [221]. Normally, P-gp is embedded in the plasma membrane, but it can be incorporated into lysosomal membranes through intracellular trafficking [223]. Of note, acid lysosomal pH and P-gp may cooperate to achieve drug sequestration [224]. Several effectors are involved in the mediation of drug sequestration, including P-gp expression, luminal $\mathrm{pH}$, and lysosomal biogenesis. Expression of P-gp can be up-regulated by hypoxia-inducible factor- $1 \alpha$ (HIF- $1 \alpha)$ elicited by stressors in the microenvironment [223]. In breast cancer cell line, drug-resistant MCF-7 cells appeared more acid luminal 
$\mathrm{pH}$ than normal MCF-7 cells [225]. As expected, increase in lysosomal $\mathrm{pH}$ and drug-sensitization were observed through knockdown of v-ATPase that maintains luminal acid pH [226]. Exposed to hydrophobic weak bases drugs, cancer cells showed an increased number of lysosomes per cell [227], indicating lysosomal biogenesis. The lysosomal biogenesis could be regulated by inhibition of mTOR and nucleus translocation of TFEB when weak base drugs accumulate in lysosomes [228]. Development of methods targeting drug sequestration may help improving the effect of chemotherapy.

It's still in passionate debate whether autophagy should be inhibited or stimulated in tumor therapy. On the one hand, extensively activated autophagy can result in autophagic cell death [229]. On the other hand, massive evidence have highlighted autophagy as a process protecting cancer cells against chemotherapy
[230, 231]. In pre-clinical researches, inhibition of autophagy flux enhanced anti-tumor effects of drugs against glioblastoma [232], breast cancer [233], gastric cancer, [234], and pancreatic cancer [235]. On the contrary, a positive correlation between autophagy and cell death has been found in squamous carcinoma [236] and lymphoblastic leukemia [237]. In clinical trials, both autophagy stimulator, rapamycin, and inhibitor, hydroxychloroquine are largely tested. Further results with quantification or semi-quantification, rather than stimulation/inhibition, of autophagy in cancer cells might be helpful in determining how interventions targeting autophagy should be administrated.

The lysosome-related mechanisms have been summarized in Fig. 2. Interventions targeting these mechanisms seem to be promising. Interestingly, different mechanisms are found in tumor associated macrophages and other components of tumors.

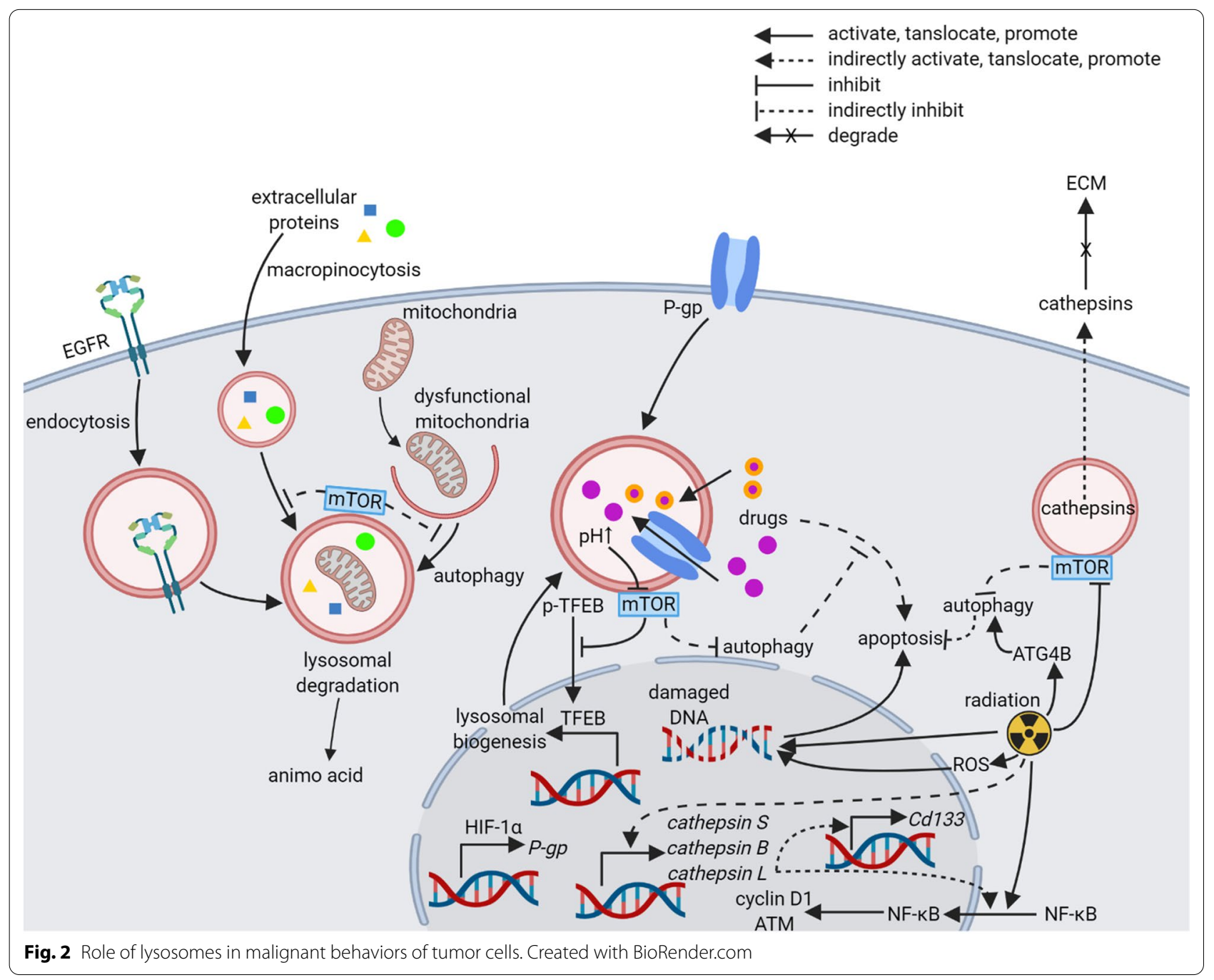


Table 4 Interventions targeting lysosomes

\begin{tabular}{|c|c|c|c|c|}
\hline Disease & Intervention & Stage of development & Comment & NCT number \\
\hline \multirow[t]{4}{*}{ Atherosclerosis } & Temsirolimus \pm Dexamethasone & Phase II & mTOR inhibitor & NCT03942601 \\
\hline & Temsirolimus & Phase III & mTOR inhibitor & NCT04433572 \\
\hline & Chloroquine & Not applicable & Autophagy/lysosome inhibitor & NCT00455403 \\
\hline & Hydroxychloroquine & Phase IV & Autophagy/lysosome inhibitor & NCT04161339 \\
\hline \multirow[t]{4}{*}{ Alzheimer's disease } & Trehalose & Phase I & Autophagy inducer & NCT04663854 \\
\hline & Hydralazine & Phase III & Autophagy inducer & NCT04842552 \\
\hline & Rapamune & Phase I & Autophagy inducer & NCT04200911 \\
\hline & Rapamycin & Phase II & Autophagy inducer & NCT04629495 \\
\hline Parkinson's disease & Exablate BBBD with Cerezyme & Not applicable & Enzyme replacement therapy & NCT04370665 \\
\hline \multirow[t]{4}{*}{ Systemic lupus erythematosus } & Hydroxychloroquine or chloroquine & Phase II & Autophagy/lysosome inhibitor & NCT01946880 \\
\hline & Sirolimus & Phase II & Autophagy inducer & NCT04582136 \\
\hline & Sirolimus & Phase II & Autophagy inducer & NCT04736953 \\
\hline & Rapamycin & Phase ॥ & Autophagy inducer & NCT00779194 \\
\hline \multirow[t]{2}{*}{ Crohn's disease } & Rapamycin & Not applicable & Autophagy inducer & NCT02675153 \\
\hline & $\begin{array}{l}\text { Ciprofloxacin + Doxycy- } \\
\text { cline + Hydroxychloro- } \\
\text { quine + Budesonide }\end{array}$ & Phase II & $\begin{array}{l}\text { Combination of hydroxychloroquine } \\
\text { with others }\end{array}$ & NCT01783106 \\
\hline \multirow[t]{3}{*}{ Rheumatoid arthritis } & Temsirolimus & Phase II & mTOR inhibitor & NCT00076206 \\
\hline & Sirolimus & Phase I/II & Autophagy inducer & NCT00392951 \\
\hline & $\begin{array}{l}\text { Infliximab + DMARDs (methotrexate; } \\
\text { chloroquine; leflunomidum; cyclo- } \\
\text { sporin A; sulfasalazine; OM 89) }\end{array}$ & Phase III & $\begin{array}{l}\text { Combination of chloroquine with } \\
\text { others }\end{array}$ & NCT00521924 \\
\hline \multirow[t]{2}{*}{ Multiple sclerosis } & Temsirolimus & Phase II & mTOR inhibitor & NCT00228397 \\
\hline & Sirolimus & Phase $|/| \mid$ & Autophagy inducer & NCT00095329 \\
\hline \multirow[t]{2}{*}{ Fabry disease } & Agalsidase alfa & Phase III & Enzyme replacement therapy & NCT01298141 \\
\hline & Agalsidase beta & Phase IV & Enzyme replacement therapy & NCT00081497 \\
\hline Tay-Sachs disease & AXO-AAV-GM2 & Phase I & Gene therapy & NCT04669535 \\
\hline \multirow[t]{8}{*}{ Mucopolysaccharidosis diseases } & Aldurazyme (for type I) & Phase III & Enzyme replacement therapy & NCT00258011 \\
\hline & Idursulfase (for type II) & Phase II/III & Enzyme replacement therapy & NCT00630747 \\
\hline & SAF-301 (for type III) & Phase I/II & Gene therapy & NCT02053064 \\
\hline & ABO-102 (for type III) & Phase $|/| \mid$ & Gene therapy & NCT04088734 \\
\hline & Naglazyme (for type IV) & Phase IV & Enzyme replacement therapy & NCT00299000 \\
\hline & elosulfase alfa (for type IV) & Not applicable & Enzyme replacement therapy & NCT03204370 \\
\hline & AAV2/8.TBG.hARSB (for type IV) & Phase $1 / \|$ & Gene therapy & NCT03173521 \\
\hline & UX003 (for type VII) & Phase I/II & Enzyme replacement therapy & NCT01856218 \\
\hline Pompe disease & Alglucosidase alfa & Phase IV & Enzyme replacement therapy & NCT04676373 \\
\hline \multirow[t]{3}{*}{ Gaucher disease } & Imiglucerase & Phase IV & Enzyme replacement therapy & NCT04656600 \\
\hline & Velaglucerase alfa & Phase IV & Enzyme replacement therapy & NCT04718779 \\
\hline & taliglucerase alfa & Phase IV & Enzyme replacement therapy & NCT04002830 \\
\hline \multirow[t]{5}{*}{ Non-small cell lung cancer } & Binimetinib + Hydroxychloroquine & Phase II & Combination Therapy & NCT04735068 \\
\hline & $\begin{array}{l}\text { Paclitaxel + Carboplatin } \pm \text { Bevaci- } \\
\text { zumab } \pm \text { Hydroxychloroquine }\end{array}$ & Phase II & Combination Therapy & NCT01649947 \\
\hline & $\begin{array}{l}\text { Bevacizumab + Carboplatin + Pacli- } \\
\text { taxel + Hydroxychloroquine }\end{array}$ & Phase I/II & Combination Therapy & NCT00728845 \\
\hline & Sunitinib + Rapamycin & Phase I & Combination Therapy & NCT00555256 \\
\hline & Neratinib \pm Temsirolimus & Phase II & Combination Therapy & NCT01827267 \\
\hline \multirow[t]{2}{*}{ Small cell lung cancer } & Chloroquine & Phase I & Autophagy/lysosome inhibitor & NCT00969306 \\
\hline & $\begin{array}{l}\text { Etoposide + Carboplatin + Atezoli- } \\
\text { zumab + BNT411 (TLR7/8 agonist) }\end{array}$ & Phase I/II & Combination Therapy & NCT04101357 \\
\hline
\end{tabular}


Table 4 (continued)

\begin{tabular}{|c|c|c|c|c|}
\hline Disease & Intervention & Stage of development & Comment & NCT number \\
\hline \multirow[t]{7}{*}{ Colon cancer } & $\begin{array}{l}\text { Bupivacaine liposome suspension } \\
\text { (for pain control) }\end{array}$ & Phase IV & $\begin{array}{l}\text { Bupivacaine slowly released from } \\
\text { lysosomes }\end{array}$ & NCT02052557 \\
\hline & $\begin{array}{l}\text { FOLFOX/bevacizumab } \pm \text { Hydroxy- } \\
\text { chloroquine }\end{array}$ & Phase I/II & Combination Therapy & NCT01206530 \\
\hline & Vorinostat + Hydroxychloroquine & Phase II & Combination Therapy & NCT02316340 \\
\hline & $\begin{array}{l}\text { nab-rapamycin + mFOLFOX6 and } \\
\text { Bevacizumab }\end{array}$ & Phase I & Combination Therapy & NCT03439462 \\
\hline & Temsirolimus + Cetuximab & Phase I & Combination Therapy & NCT00593060 \\
\hline & $\begin{array}{l}\text { Pembrolizumab + Poly-ICLC (TLR3 } \\
\text { agonist) }\end{array}$ & Phase $|/| \mid$ & Combination Therapy & NCT02834052 \\
\hline & $\begin{array}{l}\text { FOLFIRI + Cetuximab + IMO-2055 } \\
\text { (TLR9 agonist) }\end{array}$ & Phase I & Combination Therapy & NCT00719199 \\
\hline \multirow[t]{9}{*}{ Breast cancer } & Hydrochloroquine & Phase II & Autophagy/lysosome inhibitor & NCT01292408 \\
\hline & Ixabepilone + Hydroxychloroquine & Phase I/II & Combination Therapy & NCT00765765 \\
\hline & $\begin{array}{l}\text { Letrozole + Palbociclib + Hydroxy- } \\
\text { chloroquine }\end{array}$ & Phase I/II & Combination Therapy & NCT03774472 \\
\hline & Chloroquine & Phase II & Autophagy/lysosome inhibitor & NCT02333890 \\
\hline & $\begin{array}{l}\text { Zoledronic acid + Odanacatib (cath- } \\
\text { epsin K inhibitor) }\end{array}$ & Phase $1 / \|$ & Combination Therapy & NCT00399802 \\
\hline & Trastuzumab + Rapamycin & Phase ॥ & Combination Therapy & NCT00411788 \\
\hline & $\begin{array}{l}\text { Inetetamab + Rapamycin + Chemo- } \\
\text { therapy }\end{array}$ & Phase III & Combination Therapy & NCT04736589 \\
\hline & Rapamycin & Phase II & mTOR inhibitor & NCT02642094 \\
\hline & $\begin{array}{l}\text { Radiation + Cyclophospha- } \\
\text { mide + Imiquimod (TLR7 agonist) }\end{array}$ & Phase I/II & Combination Therapy & NCT01421017 \\
\hline \multirow[t]{3}{*}{ Hepatocellular cancer } & Sorafenib \pm Hydroxychloroquine & Phase II & Combination Therapy & NCT03037437 \\
\hline & temsirolimus & Phase II & mTOR inhibitor & NCT01079767 \\
\hline & RO7119929 & Phase I & TLR7 agonist & NCT04338685 \\
\hline Cholangiocarcinoma & ABC294640 \pm Hydroxychloroquine & Phase II & Combination Therapy & NCT03377179 \\
\hline Gastrointestinal cancer & $\begin{array}{l}\text { Cobimetinib + Atezoli- } \\
\text { zumab + Hydroxychloroquine }\end{array}$ & Phase $1 / \|$ & Combination Therapy & NCT04214418 \\
\hline \multirow[t]{6}{*}{ Prostate cancer } & Hydroxychloroquine & Early Phase 1 & Autophagy/lysosome inhibitor & NCT02421575 \\
\hline & Docetaxel \pm Hydroxychloroquine & Phase II & Combination Therapy & NCT00786682 \\
\hline & Odanacatib & Phase II & Cathepsin K inhibitor & NCT00691899 \\
\hline & Temsirolimus & Phase II & mTOR inhibitor & NCT00919035 \\
\hline & Bevacizumab + Temsirolimus & Phase $1 / \|$ & Combination Therapy & NCT01083368 \\
\hline & Temsirolimus + Diphenhydramine & Phase II & Combination Therapy & NCT00887640 \\
\hline Biliary cancer & Trametinib + Hydroxychloroquine & Phase II & Combination Therapy & NCT04566133 \\
\hline \multirow[t]{3}{*}{ Ovarian cancer } & Temsirolimus & Phase II & mTOR inhibitor & NCT00926107 \\
\hline & $\begin{array}{l}\text { Cisplatin + Pembrolizumab + Rinta- } \\
\text { tolimod (TLR3 agonist) }\end{array}$ & Phase $1 / \|$ & Combination Therapy & NCT03734692 \\
\hline & OC-L+ Ampligen (TLR3 agonist) & Phase I/II & Combination Therapy & NCT01312389 \\
\hline
\end{tabular}


Table 4 (continued)

\begin{tabular}{|c|c|c|c|c|}
\hline Disease & Intervention & Stage of development & Comment & NCT number \\
\hline \multirow[t]{7}{*}{ Pancreatic cancer } & $\begin{array}{l}\text { LY3214996 } \pm \text { Hydroxychloro- } \\
\text { quine sulfate }\end{array}$ & Phase II & Combination Therapy & NCT04386057 \\
\hline & $\begin{array}{l}\text { Gemcitabine + Abraxane + Hydroxy- } \\
\text { chloroquine }\end{array}$ & Phase I/II & Combination Therapy & NCT01506973 \\
\hline & Binimetinib + Hydroxychloroquine & Phase I & Combination Therapy & NCT04132505 \\
\hline & Sirolimus & Phase II & mTOR inhibitor & NCT00499486 \\
\hline & Bevacizumab + Temsirolimus & Phase II & Combination Therapy & NCT01010126 \\
\hline & $\begin{array}{l}\text { Radiation Ther- } \\
\text { apy + Nivolumab + SD-101 (TLR9 } \\
\text { agonist) }\end{array}$ & Phase I & Combination Therapy & NCT04050085 \\
\hline & $\begin{array}{l}\text { INCAGN01949+CMP-001 (TLR9 } \\
\text { agonist) }\end{array}$ & Phase I & Combination Therapy & NCT04387071 \\
\hline \multirow[t]{4}{*}{ Melanoma } & $\begin{array}{l}\text { Dabrafenib }+ \text { Trametinib } \pm \text { Hydroxy- } \\
\text { chloroquine }\end{array}$ & Phase II & Combination Therapy & NCT04527549 \\
\hline & Sorafenib + Temsirolimus & Phase I & Combination Therapy & NCT00349206 \\
\hline & $\begin{array}{l}\text { MART-1 Antigen } \pm \text { GLA-SE (TLR4 } \\
\text { agonist) }\end{array}$ & Early Phase I & Combination Therapy & NCT02320305 \\
\hline & $\begin{array}{l}\text { NY-ESO-1 protein + Monta- } \\
\text { nide + Poly ICLC (TLR3 agonist) }\end{array}$ & Phase $1 / \|$ & Vaccine & NCT01079741 \\
\hline Multiple myeloma & Bortezomib + hydroxychloroquine & Phase I & Combination Therapy & NCT00568880 \\
\hline Brain neoplasms & Temsirolimus & Phase I & mTOR inhibitor & NCT00949026 \\
\hline \multirow[t]{2}{*}{ Head and neck cancer } & $\begin{array}{l}\text { Temsirolimus + Weekly Pacli- } \\
\text { taxel + Carboplatin }\end{array}$ & Phase $1 / \|$ & Combination Therapy & NCT01016769 \\
\hline & $\begin{array}{l}\text { Cetuximab + EMD } 1201081 \text { (TLR9 } \\
\text { agonist) }\end{array}$ & Phase II & Combination Therapy & NCT01040832 \\
\hline Renal cell cancer & Sunitinib + Temsirolimus & Phase I & Combination Therapy & NCT01122615 \\
\hline \multirow[t]{2}{*}{ Bladder cancer } & Temsirolimus & Phase II & mTOR inhibitor & NCT01827943 \\
\hline & Sirolimus & Early Phase I & mTOR inhibitor & NCT02753309 \\
\hline Glioma & $\begin{array}{l}\text { Tumor-lysate pulsed DC vaccina- } \\
\text { tion + adjuvant poly ICLC (TLR3 } \\
\text { agonist) }\end{array}$ & Phase II & Vaccine & NCT01204684 \\
\hline Esophageal cancer & $\begin{array}{l}\text { URLC10-177+ TTK-567 + CpG-7909 } \\
\text { (TLR9 agonist) }\end{array}$ & Phase $|/| \mid$ & Vaccine & NCT00669292 \\
\hline Follicular Lymphoma & $\begin{array}{l}\text { Radiation Therapy + lbruti- } \\
\text { nib + SD-101 (TLR9 agonist) }\end{array}$ & Phase I/II & Combination Therapy & NCT02927964 \\
\hline Non-Hodgkin Lymphoma & $\begin{array}{l}\text { local irradiation + CPG } 7909 \text { (TLR9 } \\
\text { agonist) }\end{array}$ & Phase l/II & Combination Therapy & NCT00185965 \\
\hline $\begin{array}{l}\text { Advanced or metastatic tumor } \\
\text { combined with COVID-19 }\end{array}$ & $\begin{array}{l}\text { Avdoralimab + Monali- } \\
\text { zumab + GNS651 (autophagy } \\
\text { inhibitor) }\end{array}$ & Phase II & Combination Therapy & NCT04333914 \\
\hline \multirow[t]{7}{*}{ Nonspecific cancer } & GSK1795091 & Phase I & TLR4 agonist & NCT02798978 \\
\hline & $\begin{array}{l}\text { Anti-Cancer Agent + SHR2150 (TLR7 } \\
\text { agonist) }\end{array}$ & Phase l/II & Combination Therapy & NCT04588324 \\
\hline & $\begin{array}{l}\text { Echopulse + PD- } 1+\text { Imiquimod } \\
\text { (TLR7 agonist) }\end{array}$ & Phase I & Combination Therapy & NCT04116320 \\
\hline & $\begin{array}{l}\text { Durvalumab + MEDI9197 (TLR7/8 } \\
\text { agonist) }\end{array}$ & Phase I & Combination Therapy & NCT02556463 \\
\hline & $\begin{array}{l}\text { Ipilimumab + Nivolumab + Tilsotoli- } \\
\text { mod (TLR9 agonist) }\end{array}$ & Phase I & Combination Therapy & NCT04270864 \\
\hline & $\begin{array}{l}\text { NY-ESO-1 protein + Monta- } \\
\text { nide } \pm \text { Resiquimod (TLR7/8 } \\
\text { agonist) }\end{array}$ & Phase I & Vaccine & NCT00821652 \\
\hline & BMS $986178+$ SD-101 (TLR9 agonist) & Phase I & Combination Therapy & NCT03831295 \\
\hline
\end{tabular}


Lysosomes in tumor-associated macrophages (TAMs)

Massive infiltrated TAMs in tissues always indicate chemotherapy resistance, tumor angiogenesis, immune suppression, metastasis, and poor prognosis [238-240]. Therefore, TAMs have been a hotspot for a few decades. Polarization of TAMs has been proposed to give an outline of diverse phenotype changes of TAMs, which are able to assume distinct and metastable phenotypes in response to different environmental stimuli [241, 242]. Although more complicated spectrum of macrophage polarization have been proposed [243, 244], the paradigm of M1/M2 is now wildly used. M1 macrophages, namely activated macrophages, show pro-inflammatory phenotype, which is stimulated by ligands of TLRs, interferon gamma (IFN- $\gamma$ ), tumor necrosis factor alpha (TNF- $\alpha$ ), and pathogenic microorganisms [241, 245247]. On the contrary, transforming growth factor beta (TGF- $\beta$ ), interleukin-4 (IL-4), interleukin-10 (IL-10), and IL-13 induce M2 macrophages, also known as alternatively activated, macrophages that serve as anti-inflammatory factors [241, 242, 248-251]. TAMs are broadly M2-like macrophages even though they may temporarily express M1-like phenotypes at the early stage of tumor growth [252]. Lysosomes in TAMs have been shown to participate in polarization regulation, as well as additional behaviors distinct from macrophage polarization, such as immune mediation, stromal degradation, and angiogenesis.

\section{Regulation of TAM polarization by autophagy}

Direct regulators of macrophage polarization are transcription factors such as NF- $\mathrm{kB}$, signal transducer and activator of transcription 3 (STAT3), signal transducer and activator of transcription 6 (STAT6), and hypoxiainducible factor- $2 \alpha$ (HIF-2 $\alpha$ ) [253-256]. Through activation or degradation of these transcription factors or their up-stream mediators, many factors take part in regulation of macrophage polarization. Lysosomal membrane proteins and luminal proteins participate in macrophage polarization by mediating autophagy, as well as other degradation activities. Alternatively, these lysosomal proteins, together with luminal ions, are able to regulate polarization through aforementioned transcription factors independently from degradation activities.

The relationship between autophagy and macrophage polarization is controversial. Many researches manifested that autophagy promoted M2-like polarization of macrophages, but several others showed opposite discoveries. In a model of colorectal carcinoma, autophagosome degradation and downstream M2-like polarization of TAMs were demonstrated to be positively related, which was mediated by cathepsin S [257]. In vitro treatment of chloroquine or knockout of cathepsin $\mathrm{S}$ retarded autophagic flux, increased expression of M1-type gene, inducible nitric oxide synthase (iNOS), and abrogated upregulation of M2-type genes, arginase-1 (Arg-1), found in inflammatory zone 1 (FIZZ1), and IL-10 [257]. Accordingly, in vivo experiment found that cathepsin $S$ knockout significantly decreased tumor burden and liver metastasis [257]. A possible link between autophagy and M1-like polarization has been proposed to be degradation of NF- $\mathrm{KB}[256,258]$. Selective autophagy was involved in M2-like polarization of bone marrow-derived macrophages (BMDMs) treated with hepatoma tumor cell conditional medium $[256,258]$. The conditional medium from hepatoma cell line ML- $1_{4 \mathrm{a}}$ elevated M2-like expression pattern in BMDMs by stimulating sequestosome 1 (p62/SQSTM1) depended ubiquitination of NF- $\mathrm{KB}$ p65 followed by autophagy-mediated degradation of NF- $k B$ p65 [256]. Afterwards, autophagosomes loaded with NF-kB p65 formed autolysosomes with lysosomes under the guidance of extracellular signal-regulated kinase 1/2 (ERK1/2), downstream of TLR2 signal [256]. However, M. Shan et al. reported that M2-like markers were heightened in RAW 264.7 incubated with conditional medium from mouse breast cancer cell line 4T1, and at the same time autophagy indicated by puncta of GFPLC3 and western blot of IC3-II was inhibited [253]. The M2-like polarization could be attributed to elevated ROS from mitochondrial, which was able to be diminished by rapamycin, an autophagy inducer [253]. In vivo, stimulation of autophagy by rapamycin dampened tumor growth and metastasis in tumor-bearing mice injected with isoprenaline, an inducer of intracellular ROS [253]. The more detailed mechanism was that rapamycin-induced autophagy decreased levels of p-mTOR, ROS/p-ERK1/2 causing inhibition of downstream signal molecules pTyr705-STAT3 and HIF- $1 \alpha$, which attenuated isoprenaline-mediated M2-like polarization [253]. The conflicting role of autophagy in macrophage polarization could be explained by diverse substrates of autophagy in different conditions. Therefore, it should be carefully evaluated to decide whether stimulating or suppressing autophagy is beneficial in different situations.

Except for canonical autophagy, other degradation activities can also mediate TAM polarization. LC3-associated phagocytosis (LAP), a non-canonical autophagy, was positively associated with M2-like markers in TAMs [259]. In mice deficient in LC3-associated phagocytosis, stimulator of interferon genes (STING)-dependent type I IFN response in TAMs might be the key for reducing expression of CD206 in TAMs and enhancing anti-tumor effects of T cells [259]. LAMP2A-mediated selective lysosomal degradation in TAMs was another newly discovered process that regulated phenotypes of TAMs [260]. Although LAMP2A has been reported to 
contribute to chaperone-mediated autophagy, the author did not clarify the classification of LAMP2A-mediated degradation here. M2-like macrophage activation, immunosuppressive tumor microenvironment, and tumor growth were reversed by inhibiting LAMP2A, whose targets were found to be peroxiredoxin 1 (PRDX1) and CREB-regulated transcription coactivator 1 (CRTC1) [260]. In the context of LAMP2A knockdown, heightened PRDX1 was correlated with a higher level of $\mathrm{H}_{2} \mathrm{O}_{2}$ and downstream inflammatory activation. At the same time, elevated CRTC1 increased phosphorylated cAMP responsive element binding protein ( $p$-CREB) without perturbing downstream CCAAT/enhancer-binding protein $\beta(\mathrm{CEBP} / \beta)$ resulting in inflammatory activation of macrophages [260]. However, a contrary finding showed that blocking selective lysosomal degradation by ATPase $\mathrm{H}^{+}$transporting V0 subunit d2 (ATP6V0d2) knockout elevated M2-like markers in TAMs resulting in promoted tumor growth in tumor-bearing mice [255]. The different results can be explained by distinct degradation target, which was found to be HIF-2 $\alpha$ here [255]. Of note, downregulation of ATP6V0d2 can also be achieved in TAMs by lactate in TME through mTORC1/TFEB pathway [255]. These results indicate that lysosomal degradation targets can vary in different contexts, thus leading to different phenotypes of TAMs. More details of the degradation processes are in need for understanding the mediation of TAM polarization.

\section{Activation of TAMs by TLRs}

TLRs belong to a family of pattern recognition receptors that senses invading pathogens during innate immune response. Although some specific stimulators for TLRs have been found, TLRs recognize diverse microbial and host-derived ligands physiologically. Two main localizations of TLRs in cells have been found. Roughly, TLR1, $2,4-6$, and 10 localize to plasma membrane, while TLR3, 4, 7-9, and 11-13 localize to endolysosomal membranes [6]. Downstream signals of these TLRs are transduced through either myeloid differentiation factor 88 (MyD88) or TIR-domain containing adaptor molecule (TRIF) [6]. Interestingly, TLR4 primarily activates to induce MyD88 signal at the plasma membrane, and then it is endocytosed to elicit TRIF signal [261]. These two pathways compose a network causing changes in transcription level via several transcription factors including NF- $\mathrm{kB}$. Here we focus on the anti-tumor effects of ligands eliciting lysosomal TLRs. A plethora of TLR ligands have been developed to imitate the situation of innate immune response, which have shown fascinating effects in reversing M2-like phenotypes of TAMs. Both poly(I:C), a TLR3 stimulator, and LPS, classical TLR4 stimulator, activated M1 macrophages to produce antitumor nitric oxide (NO) leading to inhibited tumor growth [262]. This antitumor effect could be augmented when TLR ligands synergized with type I and II IFNs [262]. Besides NO production, LPS-treated M1-like TAMs increased lysis of ovarian carcinoma cells mediated by nature killer cells (NK cells) [263]. In addition, polyethyleneimine [264], cationic dextran [264], and multiwalled carbon nanotubes [265] also activated TLR4 signal in TAMs leading to reversed M2-like phenotypes and reduced tumor burden possibly through NF- $\mathrm{kB}$. Several TLR7 ligands including CL264 [262], 1V270 [266], Gardiquimod [267], let-7b [268], and R848 [269] yielded similar impacts on M2-like TAMs. Improved anti-tumor effects of TLR7 ligands were achieved when the ligands were combined with IFNs [262], anti-programmed cell death protein 1 (PD1) antibody [266], and TGF- $\beta$ receptor inhibitor [267]. Differently, TLR9 agonist, CpG ODN, potentiated tumor antigen presentation activity of TAMs, instead of M1-like polarization, causing slowed tumor growth in vivo when combined with engineered $\mathrm{T}$ cell transfer [270]. It is worth noting that, ligands of TLRs should be selected carefully or delivered specifically, because they may also activate TLRs in tumor cells leading to facilitated proliferation, survival, drug resistance, immunotolerance, and angiogenesis [271, 272]. At present, some TLR agonists have entered clinical trials listed in Table 4, indicating their potential capability in improving combination therapy and immunotherapy for cancer.

\section{Activation of TAMs by inorganic ions and $\mathrm{pH}$ changes}

Luminal inorganic ions are another factors influencing TAM polarization. Lysosomes are characterized by low luminal $\mathrm{pH}$ around 4-6, which is dynamically maintained by diverse transmembrane proteins on lysosomal membrane. Thanks to the profound development of endolysosomal patch clamp technique, plenty of ion channels and transporters have been identified [273]. Basing on these findings, regulation of luminal $\mathrm{pH}$ and related mechanisms involving these transmembrane proteins are able to be explored. Chloroquine, a weak base agent, is able to be trapped in lysosomes, causing elevated lysosomal $\mathrm{pH}$ [274]. Interestingly, chloroquine switched TAMs from M2 to M1 phenotype resulting in decreased myeloid-derived suppressor cells (MDSCs) and Tregs, which enhanced anti-tumor T-cell immunity. In chloroquine treated TAMs, the elevated lysosomal $\mathrm{pH}$ caused $\mathrm{Ca}^{2+}$ release through lysosomal $\mathrm{Ca}^{2+}$ channel TRPML1. Released lysosomal $\mathrm{Ca}^{2+}$ activated $\mathrm{p} 38$ and NF- $k B$, which implemented M1 polarization of TAMs [275]. In parallel, metabolism reprogramming in TAMs from oxidative phosphorylation to glycolysis by TFEB was $\mathrm{Ca}^{2+}$-dependent facilitating anti-tumor effect further [275]. Likewise, hydroxychloroquine, a derivative 
of chloroquine, heightened M1-like molecules (iNOS, IFN- $\gamma$, IL-12b, IL-1b, and MHC II) in TAMs and induced $\mathrm{CD} 8^{+} \mathrm{T}$ cell infiltration and activation [276]. In accordance with these findings, an intriguing comparison of acidity between M1 and M2 polarized macrophages found phagosomes in M1 macrophages to preserve more neutral $\mathrm{pH}$, greater oscillatory alkalinization, and slower acidification than phagosomes in M2 macrophages [277]. Mechanistically, the property of phagosomes in M1 macrophages was attributed to proton consumption upon superoxide generation by the nicotinamide adenine dinucleotide phosphate (NADPH) oxidase, intermittent opening of voltage-gated proton channel $\left(\mathrm{H}_{\mathrm{V}} 1\right)$ channels, and reduced proton-pumping activity [277]. It seems that luminal $\mathrm{pH}$ could dynamically interact with phenotype of macrophages. Not only are interventions of luminal $\mathrm{pH}$ able to change phenotypes of macrophages, but also polarized macrophages demonstrate different luminal $\mathrm{pH}$. Limited information about the relationship between ion channels and phenotype of TAMs are available at present. Since totally 22 ion channels have been discovered on lysosome-related vesicles, compelling findings may exist in this field. Novel inhibitors or activators of the lysosomal ion channels may provide extra access to regulating phenotype of TAMs.

\section{Role of cathepsins in function of TAMs}

Although polarization of TAMs is the greatest focus, other behaviors of TAMs are also of importance. As mentioned above, expression alteration of cathepsins is detected wildly in TME. The origins of cathepsins in tumor tissues have been revealed to be both tumor cells $[191,192]$ and TAMs [191, 278-280]. For TAMs, the versatile proteins regulate extracellular matrix degradation, angiogenesis, chemoresistance, and macrophage recruitment in TME. As a family of peptidases, cathepsins degrade not only peptide in lysosomes but also extracellular stroma. Although the extracellular environment does not provide optimal $\mathrm{pH}$ condition for cathepsins, cathepsins could still retain proteolytic activities. For example, cathepsin B can function as an exopeptidase at acid $\mathrm{pH}$, while it has endopeptidase activity at neutral $\mathrm{pH}$ due to the conformational change of the occluding loop in cathepsin B [281]. Including cathepsins, other proteases such as urokinase-type plasminogen activator (uPA), tissue plasminogen activator (tPA), elastases, and matrix metalloproteinases (MMPs) form a cascade of proteolytic activation to facilitate degradation of extracellular matrix [282]. In models of breast cancer, TAM-derived cathepsin B [283], X [283], and L [284] were requisite for tumor cell invasion and metastasis. Likewise, cathepsin B [280], S [280], and X [191] from TAMs contributed to tumor cell invasion in pancreatic cancer. IL-4 has been repeatedly accused of stimulating cathepsin secretion in TAMs [254, $280,284]$. Besides secreted cathepsins, cathepsins in lysosomes of TAMs could be responsible for the digestion of internalized collagen fragment from tumor microenvironment [285]. Owning, at least in part, to extracellular matrix degradation, cathepsins augment angiogenesis. It has been reported that TAM-derived cathepsin S contributed to angiogenesis in colorectal tumor [286]. More in-depth results highlighted IL-4 to be responsible for inducing TAM-supplied cathepsins B and $\mathrm{S}$ to promote angiogenesis in pancreatic tumor [280]. Thus, cathepsins from not only tumor cells but also TAMs are able to promote invasion and angiogenesis.

Importantly, catalytic activity may be or may not be pivotal for the functions of cathepsins, which would elicit diverse mechanisms by different motifs [191]. In the apoptosis pathway induced by chemotherapy agents, cathepsins released from disturbed lysosomes into cytoplasm are crucial for eliciting tumor cell death [64], which is a process independent of catalytic activity [287]. However, paclitaxel increased macrophage-derived cathepsins $\mathrm{B}$ and $\mathrm{S}$ that protected tumor cells from apoptosis [279]. The effect that TAMs curtailed mammary tumor cell death induced by paclitaxel, etoposide, or doxorubicin was reversed by cathepsin inhibition [279]. I. Larionova et al. proposed a possible mechanism in their review to explain how cathepsin B from TAMs protected tumor cells. These cathepsin B elicited NF- $\mathrm{kB}$ in tumor cells and enhanced chemoresistance by inducing IL-1 $\beta$ and TNF $\alpha$ secretion [288]. It's fairly reasonable, since a similar mechanism has been deciphered in MDSCs [289]. The paradoxical results on apoptosis regulation imply a variable function of cathepsins depending on their origin and location. Thus, knockdown or inhibiting TAM-derived cathepsins may be able to mitigate chemoresistance.

For macrophage recruitment, macrophage-supplied cathepsin $\mathrm{K}$ upregulated cyclooxygenase-2 (COX2) and chemokine ligand 2 (CCL2), two cytokines recruiting macrophages, and knockout of cathepsin $\mathrm{K}$ decreased macrophage infiltration [290]. Later research unraveled role of cathepsin S in the regulation of CCL2 [291]. This regulation relied on CD74, a substrate of cathepsin S, and NF-kB [291]. There seems to be a positive feedback that cathepsins from TAMs or tumor cells regulated cytokines that participated in the recruitment of more macrophages.

In summary, malignant behaviors of tumors are attributed, on a large scale, to M2-like polarization and several other activities of TAMs. Lysosomes are able to regulate phenotypes of TAMs with or without degradationrelated mechanisms. These mechanisms are achieved based on components of lysosomes, including membrane proteins, luminal proteins and ions, which have been 
exhibited in Fig. 3. Potential therapy targets can be found based on the detailed understanding of these compelling mechanisms.

\section{Lysosomes in dendritic cells (DCs)}

Besides macrophages, DCs are the other subset of antigen-presentation cells that prime $\mathrm{CD}^{+} \mathrm{T}$ cells by MHC-I or CD4 ${ }^{+} \mathrm{T}$ cells by MHC-II. Functions of DCs are negatively regulated by a number of factors in TME, such as IL-6, IL-10, and TGF- $\beta$ [292]. Mechanistically,
IL-6 reduced human leukocyte antigen (HLA)-DR surface expression levels by lysosomal protease, cyclooxygenase 2, arginase, and STAT3 activation, thus attenuating $T$ cell stimulation [293]. Despite the mechanisms that inhibit activities of DCs, a group of $\mathrm{LAMP}^{+}$DCs in hepatocellular carcinoma have been found to possess the ability to regulate multiple $\mathrm{T}$ cell subsets and migrate from tumors to hepatic lymph nodes [294]. An evaluation of esophageal squamous cell carcinoma samples from 80 patients also found that infiltrating LAMP3 $^{+}$

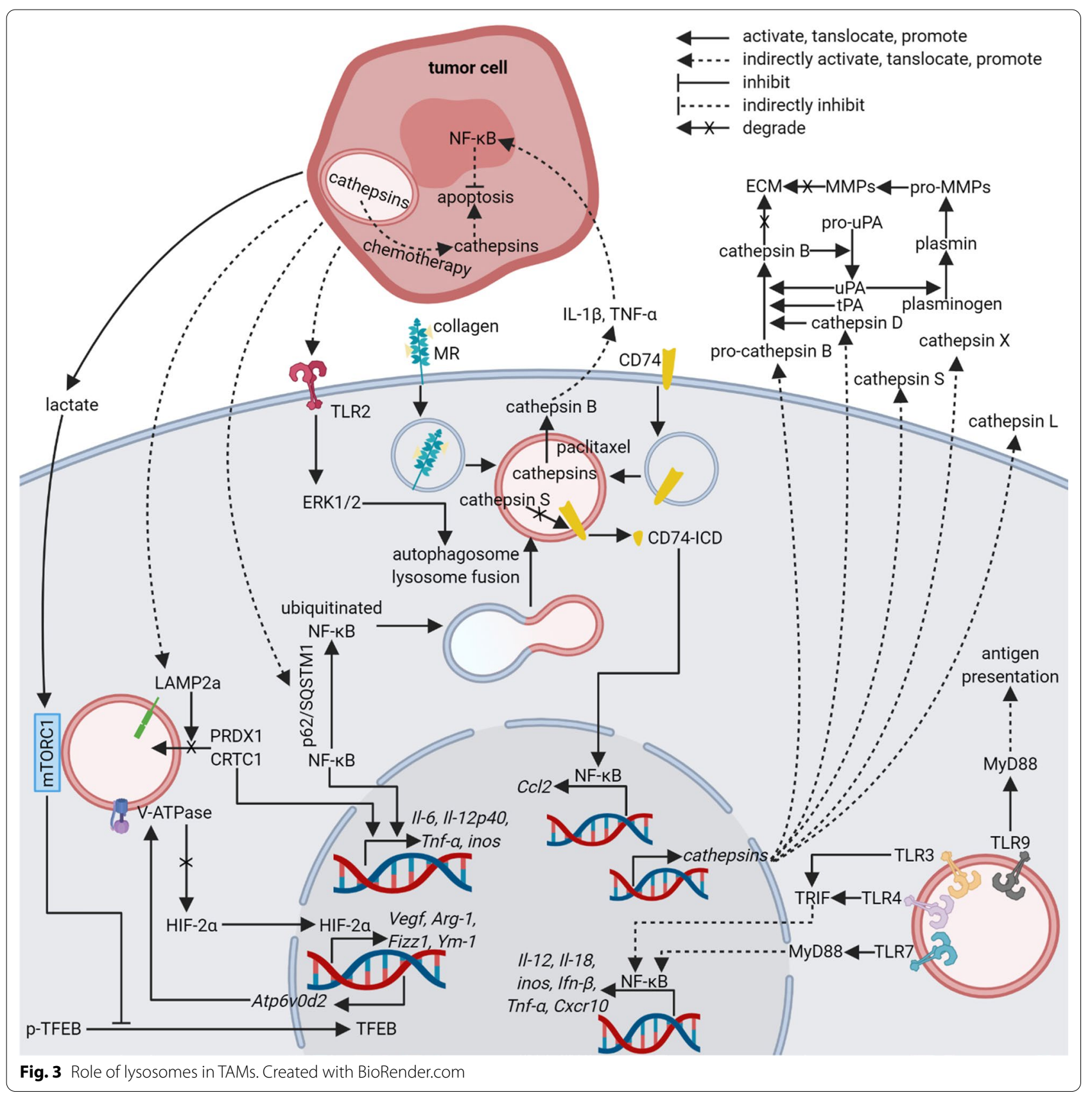


DCs were positively correlated with intratumoral CD8 ${ }^{+}$ $\mathrm{T}$ cells and favorable prognosis indicating a potential important role of LAMP3 in antigen presentation by DCs [295]. Although lysosomal proteases are involved in inhibition of HLA-DR and antigen presentation [293], conditional knockout of vacuolar protein sorting 34 (Vps34), an autophagy-related protein, in DCs caused defect in corpse-associated antigen cross-presentation to MHCI-restricted $\mathrm{T}$ cells and higher incidence of lung metastases by melanoma [296]. However, classical MHC-I and MHC-II antigen presentation pathways were enhanced in Vps34 knockout DCs [296], indicating multi-facetted mediation of antigen presentation by autophagy. In summary, the role of lysosomes in DCs during infection has been extensively studied, but it remains largely fuzzy how lysosome-related mechanisms in DCs are involved in anti-tumor immunity and immune evasion in TME.

\section{Lysosomes in cancer-associated fibroblasts (CAFs)}

In tumor, another prevalent subset of stromal cells is CAFs that interact with tumor cells through oxidative stress and NF- $\mathrm{KB}$ activation to secrete plenty of cytokines (e.g., IL-6, IL-8, IL-10, and IFN $\gamma$ ), growth factors (e.g., basic fibroblast growth factor (FGF $\beta$ ) and TGF $\beta 2$ ), and other factors (e.g., MMP-2, MMP-9, and fibronectin) [297, 298]. Several cytokines, such as IFN $\gamma$, IL-6, IL-8, IL-10, TGF $\beta$, and TNF $\alpha$, induce autophagy in CAFs [298]. Autophagy in CAFs degrades caveolin-1, which in turn enhances autophagy in CAFs through a feedforward mechanism [299]. Autophagy in CAFs promotes tumor progression by providing recycled nutrients, protecting from apoptosis, and inducing genomic instability in cancer cells [299, 300]. Additionally, down-regulation of breast-cancer susceptibility gene 1 (BRCA1) [301] and activation of peroxisome proliferator-activated receptor $\gamma$ (PPAR $\gamma$ ) [302] in CAFs also increases autophagy and promotes tumor growth in vivo.

Downstream mechanisms that are mediated by CAF autophagy during tumor progression include promoting chemotherapy resistance, EMT, and cancer stem cells. Contradictory associations have been reported in CAF autophagy and chemotherapy resistance of pancreatic cancer, where inhibition of CAF autophagy augmented [303] or diminished [304] anti-proliferation effect of gemcitabine. Triple-negative breast cancer cells showed potentiated migration, invasion, proliferation, and EMT after treatment with conditional medium from CAFs with a high level of autophagy, while conditional medium from CAFs pretreated with 3-Methyladenine, an autophagy inhibitor, did not have this effect [305]. Stemness of luminal breast cancer cells was enhanced depending on TLR4 stimulated by high-mobility group box 1 (HMGB1) from autophagic CAFs indicating high LC3II/TLR4 to be poor prognosis markers for breast cancer [306].

In summary, cross-talk between CAFs and tumor cells through oxidative stress, cytokines, and nutrients depend largely on autophagy resulting in more malignant behaviors of tumor cells. Disturbing autophagy in CAFs seems to be promising to control tumor progression.

\section{Lysosomes in T cells}

In TME, $T$ cells are the group of cells responsible for killing tumor cells. Upon recognition of tumor antigen by $\mathrm{T}$-cell receptor, cytotoxic $\mathrm{T}$ lymphocytes release perforin and granzyme B from secretory lysosomes to kill target cells [307]. Autophagy has been revealed to influence $\mathrm{T}$ cell homeostasis, differentiation, function, and aging [308]. Yet, there are only a few researches focusing on the detailed role of lysosomal activities, such as autophagy, in $\mathrm{T}$ cell behaviors in TME.

Elevated extracellular potassium owing to necrotic cells reduced nutrient uptake in $\mathrm{CD}^{+} \mathrm{T}$ cells thereby inducing autophagy [309]. Elevated autophagy triggered metabolic and epigenetic reprogramming resulting in suppressed $\mathrm{CD}^{+} \mathrm{T}$ cell effector yet preserved stemlike behaviors including self-renewal, expansion, and multipotency, which suppressed B16 tumor growth and improved survival of mice in general [309]. Differently, another research shows that knockout of autophagyrelated genes in $\mathrm{T}$ cells enhanced their immunity against breast cancer characterized as promotion of effector memory phenotype and IFN- $\gamma$ and TNF- $\alpha$ production [310]. Atg $5^{-/-} \mathrm{CD}^{+} \mathrm{T}$ cells presented promoted glucose metabolism, altered histone methylation, and upregulated transcription of metabolic and effector genes [310]. The contradictory results may be explained by different baselines of control groups, in other words, high extracellular potassium in melanoma may not exist in the model of breast cancer.

As for $\mathrm{CD}^{+} \mathrm{T}$ cells, autophagy selectively degrades PU.1, the main $\mathrm{T}_{\mathrm{H}} 9$ cell transcription factor, and inhibited anti-tumor immunity [311]. On the contrary, genetic or pharmacological inhibition of autophagy restored anti-tumor effects by enhancing IL-9 production from $\mathrm{T}_{\mathrm{H}} 9$ cells [312]. Other $\mathrm{CD} 4^{+}$subsets were not modulated by autophagy in TME [312].

Treg cells are an immune-suppressive subset of $\mathrm{T}$ cells in TME. Conditional knockout of $\operatorname{Atg} 5$ or $\operatorname{Atg} 7$ in Treg cells impaired survival and stability of Treg cells, thus suppressing colon adenocarcinoma growth, which was underpinned by upregulated mTORC1, c-Myc, and glycolytic metabolism owing to autophagy deficiency [313]. Similar mTORC1-related hyper-glycolytic metabolism has been found in Treg cells deficient in lysosomal TRAF3-interacting protein 3 (TRAF3IP3) [314]. 
Knockout of TRAF3IP3 in Treg cells also booted antitumor responses [314].

In general, genetic or pharmacological inhibition of autophagy in $\mathrm{T}$ cells is able to promote anti-tumor immunity. The link between autophagy and alteration of metabolic states in different subsets of $\mathrm{T}$ cells from TME needs more intensive illustrations.

\section{Emerging therapy strategies targeting lysosomes}

With the knowledge of various lysosome-related mechanisms in development of diseases, massive researches targeting lysosomes for therapy are reasonable. Several kinds of strategies have been proposed. First, enzyme replacement therapies are exploited for lysosomal storage disorders like GD. Second, huge amount of chemicals are able to specifically target lysosomal proteins or lysosome-related signal proteins in order to modulate behaviors of cells. Third, plenty of selective vehicles have been developed for transfecting exogenous nucleic acid or antigens to mediate expression of lysosomal proteins or elicit adaptive immunity. Finally, some nanomaterials are designed to aggregate in lysosomes for eliminating target cells. Many of these therapies have entered clinical trials, which are summarized in Table 4. Potential therapeutic interventions in pre-clinical results are listed in Table 5.

\section{Enzyme replacement therapies}

Although lysosomal enzymes are usually synthesized in ER and modified in Golgi network, some extracellular enzymes can be taken up and delivered to lysosomes, which makes enzyme replacement therapy possible [315]. Decades ago, patients with GD were treated with glucocerebrosidase extracted from placentae. Afterward, recombinant enzymes produced by $\mathrm{CHO}$ cells were invented [316]. At present, enzyme replacement therapy for type 1 Gaucher disease has been a successful commercial therapy [315]. Additional clinical trials applying enzyme replacement therapies for other LSDs have been summarized in Table 4. More effective enzyme replacement therapies are expectable. However, there is still a big challenge for the application of enzyme replacement therapy, because we lack efficient methods for systematical delivery, especially across blood-brain barrier. Thus, both recombinant enzymes and delivery strategies are of great importance for enzyme replacement therapies.

\section{Regulating autophagy}

Autophagy is the key process in the development of atherosclerosis, neurodegeneration diseases, autoimmune disorders, and tumor, especially in orchestrating macrophage phenotypes. As mentioned above, activating autophagy by Latrepirdine and CCI-779 are potential therapy methods for PD [114] and HTT [124], respectively. This complex cellular process has many feasible targets for intervention. Among the set of proteins constituting the pathway that regulates autophagy, mTOR is the central one for targeting. Table 4 shows plenty of clinical trials where mTOR inhibitors, such as temsirolimus, sirolimus, and rapamycin, are applied alone or in combination with other therapies for atherosclerosis, autoimmune disorders, and malignant tumors. Although it is well known that inhibition of mTOR would elicit autophagy, limited results are available to prove that antiatherogenic effects of mTOR inhibitors are achieved via autophagy induction [74]. Everolimus cleared macrophages in plaques through autophagy-dependent cell death, a downstream event of mTOR inhibition [317]. In fact, more researches demonstrate anti-inflammatory effect to be responsible for antiatherogenic outcome of mTOR inhibitors, such as rapamycin [318], everolimus [319], and sirolimus [320]. The anti-inflammatory effect may also be caused by balancing M1 and M2-like macrophages through mTOR intervention [70]. Moreover, two mTOR inhibitors, LY294002 and PP242, evoked transport of TFEB to nucleus [9], which would initiate lysosomal biogenesis leading to ameliorating lysosomal dysfunction [58]. Besides targeting mTOR, other agents can also modulate cell phenotypes via regulating autophagy. For example, trehalose and hydralazine might have therapeutic effects for AD through inducing autophagy (NCT04663854 and NCT04842552). By inhibiting autophagy, bafilomycin A1 [256], chloroquine [321], and 3-methyladenine [322, 323] promoted proinflammatory markers or suppressed anti-inflammatory markers in macrophages, which may, at least partially, underpin the huge amount of clinical trials for malignant tumors applying chloroquine or hydroxychloroquine alone or in combination with other therapies in Table 4. In contrast, anti-inflammation function of sorafenib [324], urolithin A [325], and spermine [326] are autophagy-dependent. It's an interesting question why both autophagy stimulator, such as rapamycin, and inhibitor, such as hydroxychloroquine, are largely applied in trials for tumors. A possible explanation is the multifaceted role of mTOR pathway that not only inhibits autophagy but also regulates anabolism and proliferation [327]. An additional reason might be diverse autophagyrelated mechanisms in different cell subsets at different stages. For instance, autophagy suppresses M2-like polarization of TAMs [253] but promotes survival and stability of Treg cells [313]. The positive and negative relationships between autophagy and cell death have been found in different cancer cells [232-237]. Thus, administration of autophagy inhibitors or activators should be carefully determined and specifically delivered. 
Table 5 Potential pre-clinical lysosome-targeted interventions for tumors

\begin{tabular}{|c|c|c|c|}
\hline Classification & Intervention & Outcome & Reference \\
\hline \multirow[t]{2}{*}{ Autophagy activator } & Rapamycin & Rapamycin suppresses M2 macrophage polarization & [253] \\
\hline & Sorafenib & Sorafenib suppresses classical macrophage activation & [324] \\
\hline \multirow[t]{4}{*}{ Autophagy inhibitor } & Hydroxychloroquine & Chloroquine and hydroxychloroquine switches TAMs from M2 to M1 phenotype & {$[275,276]$} \\
\hline & Chloroquine & & \\
\hline & Bafilomycin A1 & Bafilomycin A1-induced M1-like polarization by preventing NF-KB degradation & [256] \\
\hline & 3-Methyladenine & $\begin{array}{l}\text { 3-Methyladenine prevents cross-talk between cancer cells and CAF through } \\
\text { autophagy }\end{array}$ & [305] \\
\hline \multirow{2}{*}{ Cathepsin B inhibitor } & CA074Me & CA074Me inhibits cell invasion and inflammasome activation & {$[192,289]$} \\
\hline & CA-074 & CA-074 inhibits EMT & [195] \\
\hline Cathepsin S inhibitor & Fsn0503 & Fsn0503 inhibits cell invasion & [286] \\
\hline \multirow{3}{*}{ Cathepsin L inhibitor } & $\mathrm{Z}-\mathrm{FY}-\mathrm{CHO}$ & Z-FY-CHO inhibits radio-resistance & [214] \\
\hline & KGP94 & KGP94 and KGP207 inhibits cancer cell invasion and M2-like TAMs & [284] \\
\hline & KGP207 & & \\
\hline \multirow{2}{*}{$\begin{array}{l}\text { General cysteine } \\
\text { cathepsin inhibitor }\end{array}$} & E64 & E64 inhibits cell invasion & [283] \\
\hline & JPM-OEt & $\begin{array}{l}\text { JPM-OEt inhibits drug resistance, tumorigenesis, angiogenesis, proliferation, and } \\
\text { invasion }\end{array}$ & {$[197,254,279]$} \\
\hline \multirow[t]{5}{*}{ Transfection vehicle } & Ghost & Ghost is applied for transfection of LAMP2A siRNA in TAMs & {$[260]$} \\
\hline & $P E G=M T / P C N P S$ & $P E G=M T / P C$ NPs is applied for transfection of VEGF and PIGF siRNA & [330] \\
\hline & Porous silicon micro-particles & Porous silicon micro-particles is applied for delivering HER2 antigen into DCs & [334] \\
\hline & $\begin{array}{l}\text { Lipid-coated calcium phos- } \\
\text { phate nanoparticles }\end{array}$ & $\begin{array}{l}\text { Lipid-coated calcium phosphate nanoparticles is applied for delivering antigen } \\
\text { TRP2 mRNA and PD-1 siRNA }\end{array}$ & [335] \\
\hline & Metal-organic framework & $\begin{array}{l}\text { Metal-organic framework is applied for delivering tumor-associated antigens } \\
\text { into macrophages }\end{array}$ & [336] \\
\hline \multirow[t]{3}{*}{ TAM remover } & M-chlorin & M-chlorin can enter lysosomes and delete M2 macrophages & [430] \\
\hline & DOX-SPCL & DOX-SPCL concentrates in lysosomes and delete macrophages & [332] \\
\hline & MEN 4901/T-0128 & MEN 4901/T-0128 releases cytotoxic T-2513 in lysosomes & [333] \\
\hline TLR3 agonist & Poly $(l: C)$ & Poly(l:C) activates M1 macrophages & [262] \\
\hline \multirow[t]{4}{*}{ TLR4 agonist } & LPS & LPS activates M1 macrophages & [262] \\
\hline & Polyethyleneimine & Polyethyleneimine reverses M2-like polarization & [264] \\
\hline & Cationic dextran & Cationic dextran reverses M2-like polarization & [264] \\
\hline & Multiwalled carbon nanotubes & Multiwalled carbon nanotubes reverses M2-like polarization & [265] \\
\hline \multirow[t]{6}{*}{ TLR7 agonist } & CL264 & CL264 reverses M2-like polarization & [262] \\
\hline & $1 \mathrm{~V} 270$ & 1V270 reverses M2-like polarization & [266] \\
\hline & Gardiquimod & Gardiquimod increases M1-like polarization & [267] \\
\hline & Let-7b & Let-7b reverses M2-like polarization and suppresses IL-10 production & [268] \\
\hline & R848 & R848 increases M1-like polarization & [269] \\
\hline & R837 & R837 enhances anti-tumor immunity & [338] \\
\hline TLR9 agonist & CpG ODN & CpG ODN potentiates antigen presentation in macrophages & [270] \\
\hline Other & Spermine modified pullulan & $\begin{array}{l}\text { Spermine modified pullulan can enter lysosomes and reprogram M2 mac- } \\
\text { rophages to M1 }\end{array}$ & [337] \\
\hline
\end{tabular}

\section{Inhibiting cathepsins}

As mentioned above, cathepsins from both tumor cells and TAMs promoted malignant phenotype of tumors, including invasion, EMT, radiotherapy resistance, angiogenesis, and anti-inflammatory TME. In the laboratory, cathepsin B inhibitor, CA074Me, inhibited invasion [192] and 5FU-induced inflammasome activation that intensified growth of tumor cells [289]. Similarly, CA-074 dampened E-cadherin down-regulation induced by cathepsin
$\mathrm{B}$, implying its role in impeding cathepsin B-induced EMT [195]. Cathepsin S inhibitory antibody, Fsn0503, also inhibited invasion of colon adenocarcinoma cell line MC38 [286]. An unnamed cathepsin S selective inhibitor, compound 6, reduced pro-inflammatory CCL2 expression in a dose-dependent manner [291]. Z-FY-CHO, specific cathepsin $\mathrm{L}$ inhibitor, increased radiosensitivity in glioma cell line U251 [214, 216]. Cathepsin L/K inhibitors, KGP94 and KGP207, were able to reduce invasion of 
breast cancer cell line 4T1 and M2-like markers of TAMs [284]. A general cysteine cathepsin inhibitor, E64, significantly mitigated invasion of tumor cells [283]. JPM-OEt, a cell-permeable derivative of E64, diminished drug resistance [279], tumorigenesis, angiogenesis, proliferation, and invasion [197, 254]. Although a host of cathepsin inhibitors have been developed in pre-clinical researches, only a few, such as Odanacatib, have entered clinical trials. Unfortunately, the effectiveness of cathepsin inhibitors is not always satisfying. Side effects may be caused by the inhibited important physiological function of cathepsins and nonspecific inhibition [328]. Odanacatib, the only selective inhibitor that entered phase III clinical trials, discontinued due to stroke-related side effects [190]. Further cathepsin inhibitors may need specific delivery or local administration and combination with other therapies. For example, since cathepsins regulate radioresistance [214], a combination of radiotherapy with cathepsin inhibitors may potentiate therapeutic effect.

\section{Nucleic acid transfection}

Overexpression of tumor suppressor genes or downregulation of tumor promoter genes is reasonable strategies for therapies. A large number of transfection agents have been developed nowadays, but in vivo transfection of primary cells, especially macrophages, seems to be more difficult than others. More than a decade ago, a nonviral DNA delivery system, bacterial ghost, was invented [329]. Gram-negative bacterial cells were perforated after induction by gene $\mathrm{E}$ from bacteriophage to create empty envelopes for DNA loading. The envelopes filled with DNA were termed bacterial ghost that was able to be engulfed by macrophages. In some ways, could DNA escape from these bacterial ghost entrapped in phagoendolysosomes. Although the details remain elusive, the genes in the plasmid DNA could be expressed in macrophages [329]. Recently, this system was applied for LAMP2A knockdown in TAMs from breast cancer, which curtailed TAM anti-inflammatory activation and tumor growth [260]. Besides bacterial ghost, a novel nanomaterial named PEG $=\mathrm{MT} / \mathrm{PC}$ NPs was invented [330]. This nanomaterial with dual $\mathrm{pH}$-responsiveness was able to deliver specific siRNA to knockdown vascular endothelial growth factor (VEGF) and placental growth factor (PIGF) in both TAMs and breast cancer cells. $\mathrm{PEG}=\mathrm{MT} / \mathrm{PC}$ NPs internalized in TAMs via mannose-mediated access escaped from endosome/lysosome and released siVEGF and siPIGF resulting in suppression of tumor growth and lung metastasis [330]. At present, there is a lack of clinical trials applying such delivery systems for gene transfection. The application of nucleic acid delivery systems targeting lysosomes needs to be more intensively explored.

\section{Removing TAMs}

Since TAMs promote tumor development by too many mechanisms, some researches attempted to kill TAMs instead of reprogramming them. In order to selectively delete tumor cells and TAMs, a photosensitizer, mannose-conjugated chlorin (M-chlorin) was used in photodynamic therapy [331]. M-chlorin localized mainly in lysosomes and endoplasmic reticula revealing strong cytotoxicity for both cancer cells and M2 macrophages [331]. Modified classical chemotherapy agent, sialic acidpolyethylenimine-cholesterol modified liposomal doxorubicin (DOX-SPCL), was also able to selectively bind to TAMs, concentrate in lysosomes, and exhaust TAMs [332]. Tumor-baring mice administrated with DOXSPCL manifested exhausted TAMs and inhibited tumor growth without significant side effect [332]. Alternatively, MEN 4901/T-0128 was designed as a cytotoxic prodrug that could release cytotoxic T-2513 after digestion by lysosomal cathepsin $\mathrm{B}$ at $\mathrm{pH}$ values ranging from 3 to 5 [333]. THP-1 derived macrophages or primary macrophages from peritoneum and spleen internalized MEN 4901/T-0128 into lysosomes and released T-2513 in the culture media, which generated sufficient concentration of T-2513 to kill human carcinoma A2780 cells [266, 333]. Further improvement of these strategies might be realized if they are combined with methods that inhibit macrophage recruitment.

\section{Nano/micro-particle antigen carriers}

Several kinds of nano/micro-particles have been developed to carry tumor antigens into antigen presentation cells, such as DCs and macrophages. These novel particles excel at selective transport and enhanced immune stimulation. Porous silicon micro-particles developed by Xia et al. achieved prolonged early endosome localization, potentiated cross-presentation, and activated type I interferon responses when engulfed by DCs [334]. Cancer vaccines based on this micro-particles loaded with human epidermal growth factor receptor 2 (HER2) stimulated robust $\mathrm{CD} 8^{+} \mathrm{T}$ cell immunity against HER2 ${ }^{+}$ mammary gland tumors in mice [334]. Besides protein, mRNA vaccine can also be loaded into nanoparticles. Wang et al. created lipid-coated calcium phosphate nanoparticles to co-deliver tyrosinase-related protein 2 (TRP2) mRNA and programmed cell death-ligand 1 (PDL1) siRNA into DCs [335]. The cargoes can be released when calcium phosphate core is dissolved in endo-lysosomal compartment, which elicited strong specific $\mathrm{T}$ cell response and humoral immune response and downregulated PD-L1 in DCs in mouse model of B16F10 melanoma [335]. Another interesting nanoparticle, metal-organic framework, was fabricated in an attempt to achieve powerful delivery of tumor-associated antigens [336]. Loaded 
tumor-associated antigens could be released when the metal-organic framework is degraded in acidic lysosomes in macrophages. This novel nanoparticle exerted enhanced prominent antitumor outcome in B16-OVA melanoma model without obvious toxicity in mice [336]. In summary, these novel nano/micro-particles have achieved targeted delivery of antigens and strengthened immune stimulation, both of the two advantages are crucial for the development of tumor vaccines in the future.

\section{TLR agonists and other selective agents}

In order to reverse M2-like polarization of TAMs, several compounds have been invented, and their effects are lysosome-dependent. In a mouse breast cancer model of 4T1, cationic polysaccharide spermine modified pullulan (PS) was internalized into lysosomes of macrophages and reprogramed M2 macrophages to M1, which increased $\mathrm{CD}^{+}$and $\mathrm{CD}^{+} \mathrm{T}$ cells and inhibited tumor progression [337]. Other prevalent compounds that influence phenotypes of TAMs are the family of TLRs agonists. As mentioned above, TLR3/4/7/9 are located in lysosomal membranes, whose agonists are able to elicit pro-inflammatory phenotype of TAMs. Targeting TLR7 by imiquimod (R837) which was delivered to TAMs via polymer micelles stimulated antitumor immune response [338]. In clinical trials listed in Table 4, these agonists are usually combined with chemotherapy, radiotherapy, and bio-therapy. Combination of TLR agonists with tumor antigens and anti-PD1 antibodies seems to be promising for immunotherapy.

In summary, a great deal of methods targeting lysosomes have been designed. In laboratory, these strategies have yielded promising therapeutic effects. Although a great many compounds have been developed, lysosome-targeting interventions in clinical trials are limited. Rapamycin, hydroxychloroquine, and chloroquine are the most commonly used interventions. Compelling results might be found in clinical trials applying novel lysosometargeting interventions. Notably, the side effects and offtarget effects of these compounds are the major concerns in their further application. Temporary and controllable, instead of permanent, inhibition or activation may facilitate limiting side effects, because they can minimize perturbation of important physiological function. Furthermore, specific groups, such as mannose, would help improving the specificity of these lysosome-targeting nanoparticles.

\section{Conclusions}

In this review, we summarized physiological function of lysosomes, roles of lysosomes in the process of several diseases, and potential therapeutic methods targeting lysosomes. Although a great deal of lysosomal proteins and their functions have been illustrated, many mechanisms are still elusive. For example, it's common sense that lysosomes are acid organelles, but knowledge about the dynamic balance of the ions between the acid luminal environment and cytoplasm is limited. Besides v-ATPase, knockout of the $\mathrm{K}+$ channel, transmembrane protein 175 (TMEM175), elevated luminal $\mathrm{pH}$ in nutrient starvation [339], indicating a relationship between luminal $\mathrm{K}+$ and $\mathrm{H}+$. In fact, totally twenty-two ion channels in lysosomerelated vesicles have been identified [273]. Deciphering the homeostasis of ions in lysosomes seems to be an intriguing work.

For atherosclerosis that is quite dependent on metabolic disorder of LDL-C and oxLDL, a fascinating question is whether a lipid sensing mechanism exist. The amino acid sensing by mTOR and the pivotal role of mTOR in atherosclerosis development are now well illustrated. It's reasonable to hypothesis that a certain mean of lipid sensing with or without activation of mTOR exist. Further researches will provide us a better understanding of lipid in atherosclerosis development. For neurodegeneration diseases, although defect autophagy and potential therapeutic effects have been revealed, reliable delivery of interventions across blood-brain barrier is a big challenge.

In tumor therapy, methods targeting lysosomes have shown promising effects. Improved therapeutic outcomes may be realized when these methods are combined with other conventional therapies. It would be better if the combination is well designed. For example, combination of TLR ligands and immunotherapy improved therapy effects [266, 270]. Noteworthy, role of autophagy in tumor progression varies in different stage and different cells. Thus, interventions for inhibiting or stimulating autophagy should be selected carefully and delivered specifically.

In summary, present evidences have highlighted lysosomes to be crucial organelles in disease. More in-depth understanding of lysosome-related mechanisms would facilitate development of therapies targeting lysosomes.

\section{Abbreviations}

v-ATPase: Vacuolar H+-ATPase; ATP: Adenosine triphosphate; LAMPs: Lysosome-associated membrane proteins; CMA: Chaperone-mediated autophagy; SNAREs: Soluble $\mathrm{N}$-ethylmaleimide-sensitive factor activating protein receptors; TLRs: Toll-like receptors; PAMPs: Pathogen-associated molecular patterns; mTOR: Mammalian target of rapamycin; MiT/TFE: Microphthalmia/transcription factor E; TFEB: Transcription factor EB; TFEC: Transcription factor EC; TFE3: Transcription factor binding to IGHM enhancer 3; MITF: Melanocyte inducing transcription factor; mTORC 1: Mechanistic target of rapamycin complex 1 ; GSK3 $\beta$ : Glycogen synthase kinase 3 $\beta$; ERK: Extracellular signal-regulated kinase; MAP4K3: Mitogen-activated protein kinase kinase kinase kinase 3; PKB: Protein kinase B; PP2A: Protein phosphatase 2; TRPML1: Transient receptor potential mucolipin 1; CLEAR: Coordinated lysosomal expression and regulation; M6PRs: Mannose-6-phosphate receptors; LIMP-2: Lysosomal integral membrane protein 2; GD: Gaucher disease; GGAs: Golgi-localizing, Gamma-adaptin 
ear domain homology, ARF-binding proteins; ULK: Unc-51-like kinase; PI3K: Phosphatidylinositol 3-kinase; LC3B: Microtubule-associated protein 1A/B light chain 3B; VPS4: Vacuolar protein sorting 4; ALIX: ALG-2 interacting protein X; HSPS: Heat shock proteins; MHC-II: Major histocompatibility complex class II; MHC-I: Major histocompatibility complex class I; SLC38A9: Solute carrier family 38 member 9; CASTOR: Cellular arginine sensor for mTORC1; LDL: Low-density lipoprotein; LDL-C: Low-density lipoprotein cholesterol; oxLDL: Oxidized LDL; HDL-C: High-density lipoprotein cholesterol; SR-A: Scavenger receptor A; LOX1: Lipoprotein receptor-1; Atg5: Autophagy-related 5; NLRP3: NOD-like receptor family, pyrin domain containing 3; IL-1 $\beta$ : Interleukin-1 beta; ROS: Reactive oxygen species; ALP: Autophagy-lysosome pathway; AD: Alzheimer's disease; PD: Parkinson's disease; HD: Huntington disease; A $\beta$ : Amyloid-beta; APP: Amyloid precursor protein; PS1: Presenilin 1; a-syn: Alphasynuclein; ATP13A2: ATPase cation transporting 13A2; CAG: Cysteine, adenine, and guanine; $\mathrm{mHTT}$ : HTT mutants; polyQ: Polyglutamine; ALFY: Autophagy-linked FYVE protein; TNF-a: Tumor necrosis factor-a; Tregs: Regulatory T cells; LSDs: Lysosomal storage disorders; GCs: Gaucher cells; NF-KB: Nuclear factor-kappaB; IL-13: Interleukin-13; MCP-1: Monocyte chemotactic protein-1; TME: Tumor microenvironment; RTK: Receptor tyrosine kinases; EGFR: Epidermal growth factor receptor; Grb2: Growth factor receptor bound protein 2; EGF: Epidermal growth factor; RALT: Receptor-associated late transducer; EMT: Epithelial-mesenchymal transition; JNK: C-Jun amino terminal kinase; RNS: Reactive nitrogen; ATG4B: Autophagy-related 4B cysteine peptidase; LKB1: Liver kinase B1; ATM: Ataxiatelangiectasia-mutated kinase; DNA-PKcs: DNA-dependent protein kinase; P-gp: P-glycoprotein; HIF-1 a: Hypoxia-inducible factor-1a; TAMs: Tumor-associated macrophages; IFN- : Interferon gamma; TGF- $\beta$ : Transforming growth factor beta; IL-4: Interleukin-4; IL-10: Interleukin-10; STAT3: Signal transducer and activator of transcription 3; STAT6: Signal transducer and activator of transcription 6; HIF-2a: Hypoxia-inducible factor-2a; iNOS: Inducible nitric oxide synthase; Arg-1: Arginase-1; FIZZ1: Found in inflammatory zone 1; BMDMs: Bone marrow-derived macrophages; p62/SQSTM1: Sequestosome 1; LAP: LC3-associated phagocytosis; STING: Stimulator of interferon genes; LAMP2a: Lysosome-associated membrane protein type 2a; PRDX1: Peroxiredoxin 1; CRTC1: CREB-regulated transcription coactivator 1; $\mathrm{p}$-CREB: Phosphorylated CAMP responsive element binding protein; CEBP/ $\beta$ : CCAAT/enhancer-binding protein $\beta$; ATP6V0d2: ATPase $\mathrm{H}+$ transporting V0 subunit d2; MyD88: Myeloid differentiation factor 88; TRIF: TIR-domain containing adaptor molecule; NO: Nitric oxide; NK cells: Nature killer cells; PD1: Programmed cell death protein 1; MDSCs: Myeloid-derived suppressor cells; NADPH: Nicotinamide adenine dinucleotide phosphate; HV1:Voltage-gated proton channel; uPA: Urokinasetype plasminogen activator; tPA: Tissue plasminogen activator; MMPs: Matrix metalloproteinases; COX2: Cyclooxygenase-2; CCL2: Chemokine ligand 2; HLA Human leukocyte antigen; DCs: Dendritic cells; CAFs: Cancer-associated fibroblasts; FGFB: Basic fibroblast growth factor; BRCA1: Breast-cancer susceptibility gene 1; PPARY: Peroxisome proliferator-activated receptor $\gamma$; HMGB1: Highmobility group box 1; TRAF3IP3: TRAF3-interacting protein 3; HER2: Human epidermal growth factor receptor 2; TRP2: Tyrosinase-related protein 2; PS: Spermine-modified pullulan; VEGF: Vascular endothelial growth factor; PIGF: Placental growth factor; M-chlorin: Mannose-conjugated chlorin; DOX-SPCL: Sialic acid-polyethylenimine-cholesterol modified liposomal doxorubicin; TMEM175: Transmembrane protein 175; NPC: Niemann-Pick type C.

\section{Acknowledgements}

Not applicable.

\section{Authors' contributions}

Xiawei Wei put forward the topic of the review. Ziqi Zhang, Pengfei Yue, and Tianqi Lu wrote the manuscript and table. Yang Wang prepared the figures. Yuquan Wei helped with the final revision of the article. All authors reviewed the manuscript and approved the final manuscript.

\section{Funding}

This work is supported by the National Natural Science Foundation Regional Innovation and Development (U19A2003), the Excellent Youth Foundation of Sichuan Scientific Committee Grant in China (No. 2019JDJQ008), and the Development Program of China (No. 2016YFA0201402).

\section{Availability of data and materials}

The materials supporting our conclusion of this review is included within the article.

\section{Declarations}

Ethics approval and consent to participate

Not applicable.

\section{Consent for publication}

Not applicable.

\section{Competing interests}

The authors declare that they have no competing interests.

Received: 17 February 2021 Accepted: 3 May 2021

Published online: 14 May 2021

\section{References}

1. Kornfeld S. Trafficking of lysosomal enzymes. FASEB J. 1987;1 (6):462-8.

2. Forgac M. Vacuolar ATPases: rotary proton pumps in physiology and pathophysiology. Nat Rev Mol Cell Biol. 2007;8(11):917-29.

3. Chen CC, Cang C, Fenske S, et al. Patch-clamp technique to characterize ion channels in enlarged individual endolysosomes. Nat Protoc. 2017;12(8):1639-58.

4. Alessandrini F, Pezzè L, Ciribilli Y. LAMPs: shedding light on cancer biology. Semin Oncol. 2017:44(4):239-53.

5. Zhao YG, Zhang H. Autophagosome maturation: an epic journey from the ER to lysosomes. J Cell Biol. 2019;218(3):757-70.

6. Balka KR, De Nardo D. Understanding early TLR signaling through the Myddosome. J Leukoc Biol. 2019;105(2):339-51.

7. Carroll B, Dunlop EA. The lysosome: a crucial hub for AMPK and mTORC1 signalling. Biochem J. 2017:474(9):1453-66.

8. Settembre C, Fraldi A, Medina DL, et al. Signals from the lysosome: a control centre for cellular clearance and energy metabolism. Nat Rev Mol Cell Biol. 2013;14(5):283-96.

9. Martina JA, Chen Y, Gucek M, et al. MTORC1 functions as a transcriptional regulator of autophagy by preventing nuclear transport of TFEB. Autophagy. 2012;8(6):903-14.

10. Settembre C, Zoncu R, Medina DL, et al. A lysosome-to-nucleus signalling mechanism senses and regulates the lysosome via mTOR and TFEB. EMBO J. 2012;31(5):1095-108.

11. Vega-Rubin-de-Celis S, Pena-Llopis S, Konda M, et al. Multistep regulation of TFEB by MTORC1. Autophagy. 2017;13(3):464-72.

12. Li Y, $X u M$, Ding $X$, et al. Protein kinase $C$ controls lysosome biogenesis independently of mTORC1. Nat Cell Biol. 2016;18(10):1065-77.

13. Settembre C, Di Malta C, Polito VA, et al. TFEB links autophagy to lysosomal biogenesis. Science. 2011;332(6036):1429-33.

14. Hsu CL, Lee EX, Gordon KL, et al. MAP4K3 mediates amino aciddependent regulation of autophagy via phosphorylation of TFEB. Nat Commun. 2018;9(1):942.

15. Palmieri M, Pal R, Nelvagal HR, et al. mTORC1-independent TFEB activation via Akt inhibition promotes cellular clearance in neurodegenerative storage diseases. Nat Commun. 2017;8:14338.

16. Medina DL, Di Paola S, Peluso I, et al. Lysosomal calcium signalling regulates autophagy through calcineurin and TFEB. Nat Cell Biol. 2015;17(3):288-99.

17. Chen L, Wang K, Long A, et al. Fasting-induced hormonal regulation of lysosomal function. Cell Res. 2017;27(6):748-63.

18. Palmieri M, Impey S, Kang H, et al. Characterization of the CLEAR network reveals an integrated control of cellular clearance pathways. Hum Mol Genet. 2011;20(19):3852-66.

19. Bajaj L, Lotfi P, Pal R, et al. Lysosome biogenesis in health and disease. J Neurochem. 2019;148(5):573-89.

20. Kornfeld R, Kornfeld S. Assembly of asparagine-linked oligosaccharides. Annu Rev Biochem. 1985;54:631-64.

21. Do H, Lee WS, Ghosh P, et al. Human mannose 6-phosphate-uncovering enzyme is synthesized as a proenzyme that is activated by the endoprotease furin. J Biol Chem. 2002;277(33):29737-44.

22. Zeng J, Racicott J, Morales CR. The inactivation of the sortilin gene leads to a partial disruption of prosaposin trafficking to the lysosomes. Exp Cell Res. 2009:315(18):3112-24. 
23. Ni X, Morales CR. The lysosomal trafficking of acid sphingomyelinase is mediated by sortilin and mannose 6-phosphate receptor. Traffic 2006;7(7):889-902.

24. Canuel M, Korkidakis A, Konnyu K, et al. Sortilin mediates the lysosomal targeting of cathepsins D and H. Biochem Biophys Res Commun. 2008;373(2):292-7.

25. Reczek D, Schwake M, Schroder J, et al. LIMP-2 is a receptor for lysosomal mannose-6-phosphate-independent targeting of beta-glucocerebrosidase. Cell. 2007;131(4):770-83.

26. Nakatsu F, Ohno H. Adaptor protein complexes as the key regulators of protein sorting in the post-Golgi network. Cell Struct Funct. 2003;28(5):419-29.

27. Nielsen MS, Madsen P, Christensen El, et al. The sortilin cytoplasmic tail conveys Golgi-endosome transport and binds the VHS domain of the GGA2 sorting protein. EMBO J. 2001;20(9):2180-90.

28. Trivedi PC, Bartlett JJ, Pulinilkunnil T. Lysosomal biology and function: modern view of cellular debris bin. Cells. 2020;9(5):66.

29. Perera RM, Zoncu R. The lysosome as a regulatory hub. Annu Rev Cell Dev Biol. 2016;32:223-53.

30. Bonam SR, Wang F, Muller S. Lysosomes as a therapeutic target. Nat Rev Drug Discov. 2019;18(12):923-48.

31. Tanida I. Autophagosome formation and molecular mechanism of autophagy. Antioxid Redox Signal. 2011;14(11):2201-14.

32. Xie $Y$, Kang $R$, Sun $X$, et al. Posttranslational modification of autophagyrelated proteins in macroautophagy. Autophagy. 2015;11(1):28-45.

33. Tekirdag K, Cuervo AM. Chaperone-mediated autophagy and endosomal microautophagy: jointed by a chaperone. J Biol Chem. 2018;293(15):5414-24

34. Kaushik S, Cuervo AM. The coming of age of chaperone-mediated autophagy. Nat Rev Mol Cell Biol. 2018;19(6):365-81.

35. Nakagawa I, Amano A, Mizushima N, et al. Autophagy defends cells against invading group A Streptococcus. Science. 2004;306(5698):1037-40.

36. Gutierrez MG, Master SS, Singh SB, et al. Autophagy is a defense mechanism inhibiting BCG and Mycobacterium tuberculosis survival in infected macrophages. Cell. 2004;119(6):753-66.

37. Saric A, Hipolito VE, Kay JG, et al. mTOR controls lysosome tubulation and antigen presentation in macrophages and dendritic cells. Mol Bio Cell. 2016;27(2):321-33.

38. Mantegazza AR, Zajac AL, Twelvetrees A, et al. TLR-dependent phagosome tubulation in dendritic cells promotes phagosome cross-talk to optimize MHC-II antigen presentation. Proc Natl Acad Sci USA. 2014;111(43):15508-13.

39. Schmid D, Pypaert M, Münz C. Antigen-loading compartments for major histocompatibility complex class II molecules continuously receive input from autophagosomes. Immunity. 2007;26(1):79-92.

40. Paludan C, Schmid D, Landthaler M, et al. Endogenous MHC class $\|$ processing of a viral nuclear antigen after autophagy. Science. 2005;307(5709):593-6.

41. Loi M, Müller A, Steinbach K, et al. Macroautophagy proteins control MHC class I levels on dendritic cells and shape anti-viral CD8(+) T cell responses. Cell Rep. 2016;15(5):1076-87.

42. Chantranupong L, Wolfson RL, Sabatini DM. Nutrient-sensing mechanisms across evolution. Cell. 2015;161(1):67-83.

43. Wang S, Tsun ZY, Wolfson RL, et al. Metabolism Lysosomal amino acid transporter SLC38A9 signals arginine sufficiency to mTORC1. Science. 2015;347(6218):188-94

44. Rebsamen M, Pochini L, Stasyk T, et al. SLC38A9 is a component of the lysosomal amino acid sensing machinery that controls mTORC1. Nature. 2015;519(7544):477-81.

45. Wolfson RL, Chantranupong L, Saxton RA, et al. Sestrin2 is a leucine sensor for the mTORC1 pathway. Science. 2016:351(6268):43-8.

46. Chantranupong L, Scaria SM, Saxton RA, et al. The CASTOR proteins are arginine sensors for the mTORC1 pathway. Cell. 2016:165(1):153-64.

47. Ahmadi A, Argulian E, Leipsic J, et al. From subclinical atherosclerosis to plaque progression and acute coronary events: JACC state-of-the-art review. J Am Coll Cardiol. 2019;74(12):1608-17.

48. Herrington W, Lacey B, Sherliker P, et al. Epidemiology of atherosclerosis and the potential to reduce the global burden of atherothrombotic disease. Circ Res. 2016;118(4):535-46.
49. Hamburg NM, Creager MA. Pathophysiology of intermittent claudication in peripheral artery disease. Circ J. 2017;81(3):281-9.

50. Peshkova IO, Schaefer G, Koltsova EK. Atherosclerosis and aortic aneurysm-Is inflammation a common denominator? FEBS J. 2016;283(9):1636-52.

51. Linton MF, Yancey PG, Davies SS, et al: The role of lipids and lipoproteins in atherosclerosis. In Endotext. Feingold KR, Anawalt B, Boyce A, Chrousos G, de Herder WW, Dungan K, Grossman A, Hershman JM, Hofland J, Kaltsas G, et al. 2000-2021, MDText.com, Inc.: 2000.

52. Hendrikx T, Walenbergh SM, Hofker MH, et al. Lysosomal cholesterol accumulation: driver on the road to inflammation during atherosclerosis and non-alcoholic steatohepatitis. Obes Rev. 2014;15(5):424-33.

53. Libby P, Buring JE, Badimon L, et al. Atherosclerosis Nat Rev Dis Primers. 2019;5(1):56

54. Sheedy F, Grebe A, Rayner K, et al. CD36 coordinates NLRP3 inflammasome activation by facilitating the intracellular nucleation from soluble to particulate ligands in sterile inflammation. Nat Immunol. 2013;14:66.

55. Kunjathoor W, Febbraio M, Podrez EA, et al. Scavenger receptors class A-1/II and CD36 are the principal receptors responsible for the uptake of modified low density lipoprotein leading to lipid loading in macrophages. J Biol Chem. 2002;277(51):49982-8.

56. Schaeffer DF, Riazy M, Parhar KS, et al. LOX-1 augments oxLDL uptake by lysoPC-stimulated murine macrophages but is not required for oxLDL clearance from plasma. J Lipid Res. 2009;50(8):1676-84.

57. Reynolds T. Cholesteryl ester storage disease: a rare and possibly treatable cause of premature vascular disease and cirrhosis. J Clin Pathol. 2013;66:56.

58. Emanuel R, Sergin I, Bhattacharya S, et al. Induction of Iysosomal biogenesis in atherosclerotic macrophages can rescue lipid-induced lysosomal dysfunction and downstream sequelae. Arterioscler Thromb Vasc Biol. 2014;34:66.

59. Ouimet M, Franklin V, Mak E, et al. Autophagy regulates cholesterol efflux from macrophage foam cells via lysosomal acid lipase. Cell Metab. 2011;13:655-67.

60. Liao X, Sluimer J, Wang Y, et al. Macrophage autophagy plays a protective role in advanced atherosclerosis. Cell Metab. 2012;15:545-53.

61. Sergin I, Evans T, Zhang X, et al. Exploiting macrophage autophagylysosomal biogenesis as a therapy for atherosclerosis. Nat Commun. 2017:8:66.

62. Razani B, Feng C, Coleman T, et al. Autophagy links inflammasomes to atherosclerotic progression. Cell Metab. 2012;15:534-44.

63. Grootaert M, Roth L, Schrijvers D, et al. Defective autophagy in atherosclerosis: to die or to senesce? Oxid Med Cell Longev. 2018;2018:1-12.

64. Conus S, Simon H-U. Cathepsins: key modulators of cell death and inflammatory responses. Biochem Pharmacol. 2008;76:1374-82.

65. Jakos T, Pislar A, Jewett A, et al. Cysteine cathepsins in tumor-associated immune cells. Front Immunol. 2019;10:2037.

66. Castellano BM, Thelen AM, Moldavski O, et al. Lysosomal cholesterol activates mTORC1 via an SLC38A9-Niemann-Pick C1 signaling complex. Science. 2017;355(6331):1306-11.

67. Eid W, Dauner K, Courtney KC, et al. mTORC1 activates SREBP-2 by suppressing cholesterol trafficking to lysosomes in mammalian cells. Proc Natl Acad Sci USA. 2017;114(30):7999-8004.

68. Ai D, Jiang $H$, Westerterp $M$, et al. Disruption of mammalian target of rapamycin complex 1 in macrophages decreases chemokine gene expression and atherosclerosis. Circ Res. 2014;114(10):1576-84.

69. Sanches-Silva A, Testai L, Nabavi SF, et al. Therapeutic potential of polyphenols in cardiovascular diseases: Regulation of mTOR signaling pathway. Pharmacol Res. 2020;152:104626.

70. Tian F, Yu B, Hu J. MTOR mediates the cross-talk of macrophage polarization and autophagy in atherosclerosis. Int J Cardiol. 2014;177:144-5.

71. Guo Y-Y, Yao M. Wu S 2015 Response to Feng Tian et al.: MTOR mediates the croß-talk of macrophage polarization and autophagy in atherosclerosis. Int J Cardiol. 2015:184C:262.

72. Barrett TJ. Macrophages in atherosclerosis regression. Arterioscler Thromb Vasc Biol. 2020;40(1):20-33.

73. Xie Y, Zhang J, Tian L, et al. Bushen Kangshuai tablet inhibits progression of atherosclerosis by intervening in macrophage autophagy and polarization. J Tradit Chin Med. 2020;40:28-37.

74. Cao Q, Du H, Fu X, et al. Artemisinin attenuated atherosclerosis in highfat diet-fed ApoE-/ - mice by promoting macrophage autophagy 
through the AMPK/mTOR/ULK1 pathway. J Cardiovasc Pharmacol. 2020;75(4):321-32.

75. Cochain C, Vafadarnejad E, Arampatzi P, et al. Single-cell RNA-Seq reveals the transcriptional landscape and heterogeneity of aortic macrophages in murine atherosclerosis. Circ Res. 2018;122(12):1661-74.

76. Li Q, Liu Y, Sun M. Autophagy and Alzheimer's disease. Cell Mol Neurobiol. 2017:37(3):377-88.

77. Martini-Stoica H, Xu Y, Ballabio A, et al. The autophagy-lysosomal pathway in neurodegeneration: a TFEB perspective. Trends Neuroences. 2016;39(4):221-34.

78. Menzies FM, Fleming A, Rubinsztein DC. Compromised autophagy and neurodegenerative diseases. Nat Rev Neurosci. 2015;16(6):345-57.

79. Darios F, Stevanin G. Impairment of lysosome function and autophagy in rare neurodegenerative diseases. J Mol Biol. 2020;432(8):2714-34.

80. Cai Q, Jeong YY. Mitophagy in Alzheimer's disease and other agerelated neurodegenerative diseases. Cells. 2020;9(1):66.

81. Hampel H, Frank R, Broich K, et al. Biomarkers for Alzheimer's disease: academic, industry and regulatory perspectives. Nat Rev Drug Discov. 2010;9(7):560-74.

82. Whyte LS, Lau AA, Hemsley KM, et al. Endo-lysosomal and autophagic dysfunction: a driving factor in Alzheimer's disease? J Neurochem. 2017;140(5):703-17.

83. Haass C, Schlossmacher MG, Hung AY, et al. Amyloid $\beta$-peptide is produced by cultured cells during normal metabolism. Nature. 1992;359(6393):322-5.

84. Sisodia SS. Evidence that beta-amyloid protein in Alzheimer's disease is not derived by normal processing. Science. 1990;248:492-5.

85. Vassar R. $\beta$-Secretase cleavage of Alzheimer's amyloid precursor protein by the transmembrane aspartic protease. BACE. 1999;286(5440):735-41.

86. Ma LY, LV YL, Huo K, et al. Autophagy-lysosome dysfunction is involved in Abeta deposition in STZ-induced diabetic rats. Behav Brain Res. 2017;320:484-93.

87. Takashima A. Tau aggregation is a therapeutic target for Alzheimer's disease. Curr Alzheimer Res. 2010;7(8):56.

88. Guo JL, Lee MY. Seeding of normal Tau by pathological Tau conformers drives pathogenesis of Alzheimer-like Tangles*. J Biol Chem. 2011;286:66.

89. Wang Y, Mandelkow E. Degradation of tau protein by autophagy and proteasomal pathways. Biochem Soc Trans. 2012;40(4):644-52.

90. Zhenzhen $L$, Tao $L$, Ping $L$, et al. The ambiguous relationship of oxidative stress, Tau hyperphosphorylation, and autophagy dysfunction in Alzheimer's disease. Oxid Med Cell Longevity. 2015:2015:352723.

91. Mueller-Steiner $\mathrm{S}$, Zhou Y, Arai $\mathrm{H}$, et al. Antiamyloidogenic and neuroprotective functions of cathepsin B: implications for Alzheimer's disease. Neuron. 2006;51(6):703-14.

92. Schuur M, et al. Cathepsin D gene and the risk of Alzheimer's disease: a population-based study and meta-analysis-ScienceDirect. Neurobiol Aging. 2011;32(9):1607-14.

93. Bekris LM, Yu CE, Bird TD, et al. Genetics of Alzheimer disease. J Geriatr Psychiatry Neurol. 2010;23(4):213-27.

94. Sherrington $\mathrm{R}$, et al. Cloning of a gene bearing missense mutations in early-onset familial Alzheimer's disease. Nature. 1995;6:66.

95. Lee JH, Yu WH, Kumar A, et al. Lysosomal proteolysis and autophagy require presenilin 1 and are disrupted by Alzheimer-related PS1 mutations. Cell. 2010;141(7):1146-58.

96. Salminen A, Kaarniranta K, Kauppinen A, et al. Impaired autophagy and APP processing in Alzheimer's disease: the potential role of Beclin 1 interactome. Prog Neurobiol. 2013;106-107:33-54.

97. Pickford F, Masliah E, Britschgi M, et al. The autophagy-related protein beclin 1 shows reduced expression in early Alzheimer disease and regulates amyloid beta accumulation in mice. J Clin Invest. 2008:118(6):2190-9.

98. Harris $\mathrm{H}$, Rubinsztein DC. Control of autophagy as a therapy for neurodegenerative disease. Nat Rev Neurol. 2012;8(2):108-17.

99. Xiao Q, Yan P, Ma X, et al. Neuronal-targeted TFEB accelerates lysosomal degradation of APP, reducing Abeta generation and amyloid plaque pathogenesis. J Neurosci. 2015;35(35):12137-51.

100. Olanow CW. The pathogenesis of cell death in Parkinson's disease-2007. Mov Disord. 2007;22(S17):S335-42.

101. Spillantini M. Alpha-synuclein in Lewy bodies. Nature. 1997;66:388.
102. Xilouri M, Brekk OR, Stefanis L. Alpha-synuclein and protein degradation systems: a reciprocal relationship. Mol Neurobiol. 2013;47(2):537-51.

103. Cuervo AM, Stefanis L, Fredenburg R, et al. Impaired degradation of mutant alpha-synuclein by chaperone-mediated autophagy. Science. 2004:305(5688):1292-5.

104. Lee HJ, Khoshaghideh F, Patel S, et al. Clearance of alpha-synuclein oligomeric intermediates via the lysosomal degradation pathway. J Neurosci. 2004;24(8):1888-96.

105. Tereza V, Maria X, Kostas V, et al. Wild type alpha-synuclein is degraded by chaperone-mediated autophagy and macroautophagy in neuronal cells. J Biol Chem. 2008;283(35):23542-56.

106. Xilouri M, Vogiatzi T, Vekrellis $K$, et al. Abberant alpha-synuclein confers toxicity to neurons in part through inhibition of chaperone-mediated autophagy. PLoS ONE. 2009;4(5):e5515.

107. Mihael $\mathrm{H}$, et al. Mutation in the alpha-synuclein gene identified in families with Parkinson's disease. Science. 1997;6:18.

108. Conway KA, Harper JD, Lansbury PT. Accelerated in vitro fibril formation by a mutant |[alpha]|-synucleinlinked to early-onset Parkinson disease. Nat Med. 1998;4(11):1318-20.

109. Schultheis PJ, Fleming SM, Clippinger AK, et al. Atp13a2-deficient mice exhibit neuronal ceroid lipofuscinosis, limited alpha-synuclein accumulation and age-dependent sensorimotor deficits. Hum Mol Genet. 2013;22(10):2067-82.

110. Tsunemi T, Krainc D. Zn(2)(+) dyshomeostasis caused by loss of ATP13A2/PARK9 leads to lysosomal dysfunction and alpha-synuclein accumulation. Hum Mol Genet. 2014;23(11):2791-801.

111. Mazzulli JR, Xu YH, Sun Y, et al. Gaucher disease glucocerebrosidase and alpha-synuclein form a bidirectional pathogenic loop in synucleinopathies. Cell. 2011;146(1):37-52.

112. Mazzulli JR, Zunke F, Isacson O, et al. alpha-Synuclein-induced lysosomal dysfunction occurs through disruptions in protein trafficking in human midbrain synucleinopathy models. Proc Natl Acad Sci USA. 2016;113(7):1931-6

113. Neudorfer O, Giladi N, Elstein D, et al. Occurrence of Parkinson's syndrome in type I Gaucher disease. Qjm Mon J Assoc Phys. 1996;89(9):691.

114. Steele JW, Ju S, Lachenmayer ML, et al. Latrepirdine stimulates autophagy and reduces accumulation of alpha-synuclein in cells and in mouse brain. Mol Psychiatry. 2013;18(8):882-8.

115. Dehay B, Bove J, Rodriguez-Muela N, et al. Pathogenic lysosomal depletion in Parkinson's disease. J Neurosci. 2010;30(37):12535-44.

116. Sturrock A, Leavitt BR. The clinical and genetic features of Huntington disease. J Geriatr Psychiatry Neurol. 2010:23(4):243-59.

117. Gusella JF, Gilliam TC, Tanzi RE, et al. Molecular genetics of Huntington's disease. Arch Neurol. 1993;50(11):1157-63.

118. Ha T, Rob W, Nicolle M, et al. Characterization and localization of the Huntington disease gene product. Hum Mol Genet. 2016;12:2069-73.

119. Buerlein FJB, Saha I, Mishra A, et al. In situ architecture and cellular interactions of PolyQ inclusions. Cell. 2017;66:179-87.

120. Claire-Anne G, Shi-Hua L, Hong Y, et al. Nuclear and neuropil aggregates in Huntington's disease: relationship to neuropathology. J Neuroence Off J Soc Neuroence. 1999;19(7):2522-34.

121. Rui YN, et al. Huntingtin functions as a scaffold for selective macroautophagy. Nat Cell Biol. 2015;17(3):262-75.

122. Kegel KB, Manho K, Ellen S, et al. Huntingtin expression stimulates endosomal-lysosomal activity, endosome tubulation, and autophagy. J Neurosci. 2000;20(19):7268-78.

123. Martinez-Vicente M, Talloczy Z, Wong E, et al. Cargo recognition failure is responsible for inefficient autophagy in Huntington's disease. Nat Neurosci. 2010;13(5):567-76.

124. Ravikumar B, Vacher C, Berger Z, et al. Inhibition of mTOR induces autophagy and reduces toxicity of polyglutamine expansions in fly and mouse models of Huntington disease. Nat Genet. 2004;36(6):585-95.

125. Johnston Jennifer A, et al. Aggresomes: a cellular response to misfolded proteins. J Cell Biol. 1998;6:56

126. Ravikumar B, Imarisio S, Sarkar S, et al. Rab5 modulates aggregation and toxicity of mutant huntingtin through macroautophagy in cell and fly models of Huntington disease. J Cell Sci. 2008;121(10):1649-60.

127. Maria F, et al. The selective macroautophagic degradation of aggregated proteins requires the PI3P-binding protein Alfy. Mol Cell. 2010;6:56. 
128. Bjørkøy G, LamarkT, Brech A, et al. p62/SQSTM1 forms protein aggregates degraded by autophagy and has a protective effect on huntingtin-induced cell death. J Cell Biol. 2005;171(4):603-14.

129. Kaushik S, Massey AC, Mizushima N, et al. Constitutive activation of chaperone-mediated autophagy in cells with impaired macroautophagy. Mol Biol Cell. 2008;19(5):2179.

130. Koga $\mathrm{H}$, Martinez-Vicente M, Arias E, et al. Constitutive upregulation of chaperone-mediated autophagy in Huntington's disease. J Neurosci. 2011:31(50):18492-505.

131. Mayerle J, Sendler M, Hegyi E, et al. Genetics, cell biology, and pathophysiology of pancreatitis. Gastroenterology. 2019;156(7):1951.e1-68.e1.

132. Pandol SJ, Saluja AK, Imrie CW, et al. Acute pancreatitis: bench to the bedside. Gastroenterology. 2007;132(3):1127-51.

133. Krüger $B$, Albrecht $E$, Lerch MM. The role of intracellular calcium signaling in premature protease activation and the onset of pancreatitis. Am J Pathol. 2000;157(1):43-50.

134. Muili KA, Wang D, Orabi Al, et al. Bile acids induce pancreatic acinar cell injury and pancreatitis by activating calcineurin. J Biol Chem. 2013;288(1):570-80

135. Gukovskaya AS, Gukovsky I. Autophagy and pancreatitis. Am J Physiol Gastrointest Liver Physiol. 2012;303(9):G993-1003.

136. Sendler M, Weiss FU, Golchert J, et al. Cathepsin B-mediated activation of trypsinogen in endocytosing macrophages increases severity of pancreatitis in mice. Gastroenterology. 2018;154(3):704e10-18e10.

137. Talukdar R, Sareen A, Zhu H, et al. Release of Cathepsin B in cytosol causes cell death in acute pancreatitis. Gastroenterology. 2016:151(4):747e5-58e5.

138. Louhimo J, Steer ML, Perides G. Necroptosis is an important severity determinant and potential therapeutic target in experimental severe pancreatitis. Cell Mol Gastroenterol Hepatol. 2016;2(4):519-35.

139. Sendler M, Mayerle J, Lerch MM. Necrosis, apoptosis, necroptosis, pyroptosis: it matters how acinar cells die during pancreatitis. Cell Mol Gastroenterol Hepatol. 2016;2(4):407-8.

140. Mareninova OA, Hermann K, French SW, et al. Impaired autophagic flux mediates acinar cell vacuole formation and trypsinogen activation in rodent models of acute pancreatitis. J Clin Invest. 2009;119(11):3340-55.

141. Halangk W, Lerch MM, Brandt-Nedelev B, et al. Role of cathepsin B in intracellular trypsinogen activation and the onset of acute pancreatitis. J Clin Invest. 2000;106(6):773-81.

142. Wartmann T, Mayerle J, Kahne T, et al. Cathepsin L inactivates human trypsinogen, whereas cathepsin L-deletion reduces the severity of pancreatitis in mice. Gastroenterology. 2010;138(2):726-37.

143. Diakopoulos KN, Lesina M, Wörmann S, et al. Impaired autophagy induces chronic atrophic pancreatitis in mice via sex- and nutritiondependent processes. Gastroenterology. 2015;148(3):626e7-38e17.

144. Antonucci L, Fagman JB, Kim JY, et al. Basal autophagy maintains pancreatic acinar cell homeostasis and protein synthesis and prevents ER stress. Proc Natl Acad Sci USA. 2015;112(45):E6166-74.

145. Mareninova OA, Sendler M, Malla SR, et al. Lysosome associated membrane proteins maintain pancreatic acinar cell homeostasis: LAMP-2 deficient mice develop pancreatitis. Cell Mol Gastroenterol Hepatol. 2015;1(6):678-94.

146. Gros F, Arnold J, Page N, et al. Macroautophagy is deregulated in murine and human lupus T lymphocytes. Autophagy. 2012;8(7):1113-23.

147. Clarke AJ, Ellinghaus $U$, Cortini A, et al. Autophagy is activated in systemic lupus erythematosus and required for plasmablast development. Ann Rheum Dis. 2015;74(5):912-20.

148. An N, Chen Y, Wang C, et al. Chloroquine autophagic inhibition rebalances Th17/Treg-mediated immunity and ameliorates systemic lupus erythematosus. Cell Physiol Biochem. 2017;44(1):412-22.

149. Martinez J, Cunha LD, Park S, et al. Noncanonical autophagy inhibits the autoinflammatory, lupus-like response to dying cells. Nature. 2016;533(7601):115-9.

150. Saitoh T, Fujita N, Jang MH, et al. Loss of the autophagy protein Atg16L1 enhances endotoxin-induced IL-1 beta production. Nature. 2008:456(7219):264-8

151. Hampe J, Franke A, Rosenstiel P, et al. A genome-wide association scan of nonsynonymous SNPs identifies a susceptibility variant for Crohn disease in ATG16L1. Nat Genet. 2007;39(2):207-11.
152. Yang Z, Fujii H, Mohan SV, et al. Phosphofructokinase deficiency impairs ATP generation, autophagy, and redox balance in rheumatoid arthritis T cells. J Exp Med. 2013;210(10):2119-34.

153. Alirezaei M, Fox HS, Flynn CT, et al. Elevated ATG5 expression in autoimmune demyelination and multiple sclerosis. Autophagy. 2009;5(2):152-8.

154. He Y, Xu Y, Zhang C, et al. Identification of a lysosomal pathway that modulates glucocorticoid signaling and the inflammatory response. Sci Signal. 2011;4(180):ra44.

155. Fernandez D, Bonilla E, Mirza N, et al. Rapamycin reduces disease activity and normalizes T cell activation-induced calcium fluxing in patients with systemic lupus erythematosus. Arthritis Rheum. 2006;54(9):2983-8.

156. Vergarajauregui S, Puertollano R. Mucolipidosis type IV: the importance of functional lysosomes for efficient autophagy. Autophagy. 2008;4(6):832-4.

157. Plotegher N, Duchen MR. Mitochondrial dysfunction and neurodegeneration in lysosomal storage disorders. Trends Mol Med. 2017;23(2):116-34

158. Takikita S, Myerowitz R, Schreiner C, et al. The values and limits of an in vitro model of Pompe disease: the best laid schemes o' mice an' men. Autophagy. 2009;5(5):729-31.

159. Nishino I, Fu J, Tanji K, et al. Primary LAMP-2 deficiency causes X-linked vacuolar cardiomyopathy and myopathy (Danon disease). Nature. 2000:406(6798):906-10.

160. Wątek M, Piktel E, Wollny T, et al. Defective sphingolipids metabolism and tumor associated macrophages as the possible links between gaucher disease and blood cancer development. Int J Mol Sci. 2019;20(4):843.

161. Mistry PK, Taddei T, Dahl SV, et al. Gaucher disease and malignancy: a model for cancer pathogenesis in an inborn error of metabolism. Crit Rev Oncog. 2013;18(3):235-46.

162. Sidransky E. Gaucher disease: complexity in a "simple" disorder. Mol Genet Metab. 2004:83(1-2):15.

163. Rosenbloom B, Weinreb N, Zimran A, et al. Gaucher disease and cancer incidence: a study from the Gaucher Registry. Blood. 2005;105:4569-72.

164. Fost MD, Dahl SV, Weverling GJ, et al. Increased incidence of cancer in adult Gaucher disease in Western Europe. Blood Cells Mol Dis. 2006;36(1):58

165. Aflaki E, Moaven N, Borger DK, et al. Lysosomal storage and impaired autophagy lead to inflammasome activation in Gaucher macrophages. Aging Cell. 2016;15(1):77-88.

166. Mistry P, Liu J, Yang M, et al. Glucocerebrosidase gene-deficient mouse recapitulates Gaucher disease displaying cellular and molecular dysregulation beyond the macrophage. Proc Natl Acad Sci USA. 2010;107:19473-8.

167. Boven LA, Van Meurs M, Boot RG, et al. Gaucher cells demonstrate a distinct macrophage phenotype and resemble alternatively activated macrophages. Am J Clin Pathol. 2004;122(3):359-69.

168. Ivanova M, Limgala RP, Changsila E, et al. Gaucheromas: when macrophages promote tumor formation and dissemination. Blood Cells Mol Dis. 2018:68:100-5.

169. Elinav E, Nowarski R, Thaiss C, et al. Inflammation-induced cancer: crosstalk between tumours, immune cells and microorganisms. Nat Rev Cancer. 2013;13:759-71.

170. Korniluk $\mathrm{A}$, Koper $\mathrm{O}$, Kemona $\mathrm{H}$, et al. From inflammation to cancer. Irish J Med Sci. 2016;186:66.

171. Murata M. Inflammation and cancer. Environ Health Prev Med. 2018;23(1):50

172. Reuter S, Gupta S, Chaturvedi M, et al. Oxidative stress, inflammation, and cancer: How are they linked? Free Radical Biol Med. 2010;49:1603-16

173. Najafi M, Hashemi Goradel N, Farhood B, et al. Tumor microenvironment: interactions and therapy. J Cell Physiol. 2018;6:17.

174. Davidson S, Heiden M. Critical functions of the lysosome in cancer biology. Annu Rev Pharmacol Toxicol. 2017;57:698.

175. Maria, C., et al. Therapeutic modulation of autophagy: which disease comes first? 2019.

176. Rybstein M, Bravo San Pedro JM, Kroemer G, et al. The autophagic network and cancer. Nat Cell Biol. 2018;6:20. 
177. Karantza V, Patel S, Kravchuk O, et al. Autophagy mitigates metabolic stress and genome damage in mammary tumorigenesis. Genes Dev. 2007;21:1621-35.

178. Mathew R, Karp CM, Beaudoin B, et al. Autophagy suppresses tumorigenesis through elimination of p62. Cell. 2009;137(6):1062-75.

179. Ivanov A, Pawlikowski J, Manoharan I, et al. Lysosome-mediated processing of chromatin in senescence. J Cell Biol. 2013;202:56.

180. Bartsch K, Knittler K, Borowski C, et al. Absence of RNase $\mathrm{H} 2$ triggers generation of immunogenic micronuclei removed by autophagy. Hum Mol Genet. 2017;26:3960-72.

181. Guo H, Chitiprolu M, Gagnon D, et al. Autophagy supports genomic stability by degrading retrotransposon RNA. Nat Commun. 2014;5(1):5276.

182. Yang $S$, Wang $X$, Contino $G$, et al. Pancreatic cancers require autophagy for tumor growth. Genes Dev. 2011;25(7):717-29.

183. Guo JY, Chen H-Y, Mathew R, et al. Activated Ras requires autophagy to maintain oxidative metabolism and tumorigenesis. Genes Dev. 2011;25(5):460-70.

184. Dionne LK, Sorkin A. Endocytosis of receptor tyrosine kinases. Cold Spring Harbor Perspect Biol. 2013;5:66.

185. Yamazaki T, Zaal K, Hailey D, et al. Role of Grb2 in EGF-stimulated EGFR internalization. J Cell Sci. 2002;115:1791-802.

186. Frosi Y, Anastasi S, Ballarò C, et al. A two-tiered mechanism of EGFR inhibition by RALT/MIG6 via kinase suppression and receptor degradation. J Cell Biol. 2010;189:557-71.

187. Commisso C, Davidson SM, Soydaner-Azeloglu RG, et al. Macropinocytosis of protein is an amino acid supply route in Ras-transformed cells. Nature. 2013;497(7451):633-7.

188. Kamphorst J, Nofal M, Commisso C, et al. Human pancreatic cancer tumors are nutrient poor and tumor cells actively scavenge extracellular protein. Can Res. 2015;75:544-53.

189. Palm W, Park $Y$, Wright $K$, et al. The utilization of extracellular proteins as nutrients is suppressed by mTORC1. Cell. 2015;162(2):259-70.

190. Vidak E, Javoršek U, Vizovišek M, et al. Cysteine cathepsins and their extracellular roles: shaping the microenvironment. Cells. 2019;8(3):56.

191. Akkari L, Gocheva V, Kester J, et al. Distinct functions of macrophagederived and cancer cell-derived cathepsin Z combine to promote tumor malignancy via interactions with the extracellular matrix. Genes Dev. 2014:28:2134-50.

192. Bengsch F, Buck A, Günther S, et al. Cell type-dependent pathogenic functions of overexpressed human cathepsin B in murine breast cancer progression. Oncogene. 2013;33:56.

193. Emmert-Buck M, Karustis DG, Day NA, et al. Degradation of extracellular-matrix proteins by human cathepsin B from normal and tumor tissues. Biochem J. 1992;282(Pt 1):273-8.

194. Cox J. Cystatins and cancer. Front Biosci. 2009;14:463-74.

195. Mitrović A, Pecar Fonovic U, Kos J. Cysteine cathepsins B and X promote epithelial-mesenchymal transition of tumor cells. Eur J Cell Biol. 2017;96:56.

196. Alapati K, Kesanakurti D, Rao JS, et al. UPAR and cathepsin B-mediated compartmentalization of JNK regulates the migration of glioma-initiating cells. Stem Cell Res. 2014;12(3):716-29.

197. Joyce JA, Baruch A, Chehade K, et al. Cathepsin cysteine proteases are effectors of invasive growth and angiogenesis during multistage tumorigenesis. Cancer Cell. 2004;5(5):443-53.

198. Jechorek D, Votapek J, Meyer F, et al. Characterization of cathepsin X in colorectal cancer development and progression. Pathol Res Pract. 2014;210(12):822-9.

199. Fisher O, Levert A, Lord S, et al. High expression of cathepsin E in tissues but not blood of patients with Barrett's esophagus and adenocarcinoma. Ann Surg Oncol. 2014;22:563.

200. Kiuchi S, Tomaru U, Ishizu A, et al. Expression of cathepsins V and S in thymic epithelial tumors. Hum Pathol. 2016;60:56.

201. Fristrup N, Ulhøi B, Demtroder K, et al. Cathepsin E, Maspin, Plk1, and Survivin are promising prognostic protein markers for progression in non-muscle invasive bladder cancer. Am J Pathol. 2012;180:1824-34.

202. Kawakubo-Yasukochi T, Yasukochi A, Toyama T, et al. Repression of cathepsin E expression increases the risk of mammary carcinogenesis and links to poor prognosis in breast cancer. Carcinogenesis. 2013;35:53.

203. Gao L, Zheng H, Cai Q, et al. Autophagy and Tumour Radiotherapy. 2020.

204. Liang N, Jia L, Liu Y, et al. ATM pathway is essential for ionizing radiationinduced autophagy. Cell Signal. 2013;25(12):2530-9.
205. Huang T, Kim CK, Alvarez AA, et al. MST4 phosphorylation of ATG4B regulates autophagic activity, tumorigenicity, and radioresistance in glioblastoma. Cancer Cell. 2017;32(6):840-55.e8.

206. Lu C, Xie C. Radiation-induced autophagy promotes esophageal squamous cell carcinoma cell survival via the LKB1 pathway. Oncol Rep. 2016;35(6):3559-65.

207. Chakradeo S, Sharma K, Alhaddad A, et al. Yet another function of p53-the switch that determines whether radiation-induced autophagy will be cytoprotective or nonprotective: implications for autophagy inhibition as a therapeutic strategy. Mol Pharmacol. 2015;87(5):803-14.

208. Rosenfeld MR, Ye X, Supko JG, et al. A phase I/II trial of hydroxychloroquine in conjunction with radiation therapy and concurrent and adjuvant temozolomide in patients with newly diagnosed glioblastoma multiforme. Autophagy. 2014;10(8):1359-68.

209. Bilger A, Bittner MI, Grosu AL, et al. FET-PET-based reirradiation and chloroquine in patients with recurrent glioblastoma: first tolerability and feasibility results. Strahlenther Onkol. 2014;190(10):957-61.

210. Karagounis IV, Kalamida D, Mitrakas A, et al. Repression of the autophagic response sensitises lung cancer cells to radiation and chemotherapy. Br J Cancer. 2016;115(3):312-21.

211. Kim WY, Oh SH, Woo JK, et al. Targeting heat shock protein 90 overrides the resistance of lung cancer cells by blocking radiationinduced stabilization of hypoxia-inducible factor-1alpha. Cancer Res. 2009:69(4):1624-32.

212. Malla RR, Gopinath S, Alapati K, et al. UPAR and cathepsin B inhibition enhanced radiation-induced apoptosis in gliomainitiating cells. Neuro Oncol. 2012;14(6):745-60.

213. Seo HR, Bae S, Lee Y-S. Radiation-induced cathepsin $S$ is involved in radioresistance. Int J Cancer. 2009;124(8):1794-801.

214. Zhang QQ, Wang WJ, Li J, et al. Cathepsin L suppression increases the radiosensitivity of human glioma U251 cells via G2/M cell cycle arrest and DNA damage. Acta Pharmacol Sin. 2015;36(9):1113-25.

215. Wang W, Long L, Wang $L$, et al. Knockdown of Cathepsin $L$ promotes radiosensitivity of glioma stem cells both in vivo and in vitro. Cancer Lett. 2016:371(2):274-84.

216. Yang N, Wang P, Wang WJ, et al. Inhibition of cathepsin $L$ sensitizes human glioma cells to ionizing radiation in vitro through NF-kappaB signaling pathway. Acta Pharmacol Sin. 2015;36(3):400-10.

217. Gopinath S, Malla R, Alapati K, et al. Cathepsin B and uPAR regulate selfrenewal of glioma-initiating cells through GLI-regulated Sox2 and Bmi1 expression. Carcinogenesis. 2013;34(3):550-9.

218. Wang W, Long L, Wang $L$, et al. Knockdown of Cathepsin $L$ promotes radiosensitivity of glioma stem cells both in vivo and in vitro. Cancer Lett. 2015:371:66.

219. Bao S, Wu Q, McLendon RE, et al. Glioma stem cells promote radioresistance by preferential activation of the DNA damage response. Nature. 2006;444(7120):756-60.

220. Geisslinger F, Muller M, Vollmar AM, et al. Targeting lysosomes in cancer as promising strategy to overcome chemoresistance-a mini review. Front Oncol. 2020;10:1156.

221. Halaby R, Resistance CD. Influence of lysosomal sequestration on multidrug resistance in cancer cells. Cancer Drug Resistance. 2019;2:31-42.

222. Zhitomirsky B, Assaraf Y. Lysosomes as mediators of drug resistance in cancer. Drug Resist Updates. 2015;24:56.

223. Al-Akra L, Bae DH, Sahni S, et al. Tumor stressors induce two mechanisms of intracellular P-glycoprotein-mediated resistance that are overcome by lysosomal-targeted thiosemicarbazones. J Biol Chem. 2018;293(10):3562-87.

224. Yamagishi T, Sahni S, Sharp DM, et al. P-glycoprotein mediates drug resistance via a novel mechanism involving lysosomal sequestration. J Biol Chem. 2013;288(44):31761-71.

225. Schindler M, Grabski S, Hoff E, et al. Defective $\mathrm{pH}$ regulation of acidic compartments in human breast cancer cells (MCF-7) is normalized in adriamycin-resistant cells (MCF-7adr). Biochemistry. 1996;35(9):2811-7.

226. You H, Jin J, Shu H, et al. Small interfering RNA targeting the subunit ATP6L of proton pump V-ATPase overcomes chemoresistance of breast cancer cells. Cancer Lett. 2009;280(1):110-9.

227. Zhitomirsky B, Assaraf YG. Lysosomal sequestration of hydrophobic weak base chemotherapeutics triggers lysosomal biogenesis and lysosome-dependent cancer multidrug resistance. Oncotarget. 2015:6(2):1143-56. 
228. Zhitomirsky B, Yunaev A, Kreiserman R, et al. Lysosomotropic drugs activate TFEB via lysosomal membrane fluidization and consequent inhibition of mTORC1 activity. Cell Death Dis. 2018;9(12):1191.

229. Shimizu S, Yoshida T, Tsujioka M, et al. Autophagic cell death and cancer Int J Mol Sci. 2014;15(2):3145-53.

230. Cai $Q$, Wang S, Jin L, et al. Long non-coding RNA GBCDRInc1 induces chemoresistance of gallbladder cancer cells by activating autophagy. Mol Cancer. 2019;18(1):56.

231. Wu J, Li W, Ning J, et al. Long noncoding RNA UCA1 targets miR-582-5p and contributes to the progression and drug resistance of bladder cancer cells through ATG7-mediated autophagy inhibition. Onco Targets Ther. 2019;12:495-508.

232. Zhu Z, Zhang P, Li N, et al. Lovastatin enhances cytotoxicity of temozolomide via impairing autophagic flux in glioblastoma cells. Biomed Res Int. 2019;2019:2710693.

233. Lin Z, Zhang Z, Jiang X, et al. Mevastatin blockade of autolysosome maturation stimulates LBH589-induced cell death in triple-negative breast cancer cells. Oncotarget. 2017:8(11):17833-48.

234. Vallecillo-Hernandez J, Barrachina MD, Ortiz-Masia D, et al. Indomethacin disrupts autophagic flux by inducing lysosomal dysfunction in gastric cancer cells and increases their sensitivity to cytotoxic drugs. Sci Rep. 2018;8(1):3593.

235. Zhang X, Kumstel S, Jiang K, et al. LW6 enhances chemosensitivity to gemcitabine and inhibits autophagic flux in pancreatic cancer. J Adv Res. 2019;20:9-21.

236. Huang AC, Lien JC, Lin MW, et al. Tetrandrine induces cell death in SAS human oral cancer cells through caspase activation-dependent apoptosis and LC3-I and LC3-II activation-dependent autophagy. Int J Oncol. 2013;43(2):485-94.

237. Kuo HH, Kakadiya R, Wu YC, et al. Derivatives of 6-cinnamamido-quinoline-4-carboxamide impair lysosome function and induce apoptosis. Oncotarget. 2016;7(25):38078-90.

238. Ruffell B, Coussens LM. Macrophages and therapeutic resistance in cancer. Cancer Cell. 2015;27(4):462-72.

239. Hambardzumyan D, Gutmann DH, Kettenmann $H$. The role of microglia and macrophages in glioma maintenance and progression. Nat Neurosci. 2016;19(1):20-7.

240. Song W, Mazzieri R, Yang T, et al. Translational significance for tumor metastasis of tumor-associated macrophages and epithelial-mesenchymal transition. Front Immunol. 2017:8:1106

241. Jayasingam SD, Citartan M, Thang TH, et al. Evaluating the polarization of tumor-associated macrophages into M1 and M2 phenotypes in human cancer tissue: technicalities and challenges in routine clinical practice. Front Oncol. 2019;9:1512.

242. Mantovani A, Sozzani S, Locati M, et al. Macrophage polarization: tumor-associated macrophages as a paradigm for polarized M2 mononuclear phagocytes. Trends Immunol. 2002;23(11):549-55.

243. Mosser DM, Edwards JP. Exploring the full spectrum of macrophage activation. Nat Rev Immunol. 2008;8(12):958-69.

244. Hume DA. The many alternative faces of macrophage activation. Front Immunol. 2015;6:370.

245. Sica A, Erreni M, Allavena P, et al. Macrophage polarization in pathology. Cell Mol Life Sci. 2015:72(21):4111-26.

246. Genin M, Clement F, Fattaccioli A, et al. M1 and M2 macrophages derived from THP-1 cells differentially modulate the response of cancer cells to etoposide. BMC Cancer. 2015;15:577.

247. Lawrence T, Natoli G. Transcriptional regulation of macrophage polarization: enabling diversity with identity. Nat Rev Immunol. 2011;11(11):750-61.

248. Ghassabeh $\mathrm{GH}$, De BP, Brys L, et al. Identification of a common gene signature for type II cytokine-associated myeloid cells elicited in vivo in different pathologic conditions. Blood. 2006;108(2):575-83.

249. Stein MB, Keshav S, Harris N, et al. Interleukin 4 potently enhances murine macrophage mannose receptor activity: a marker of alternative immunologic macrophage activation. J Exp Med. 1992;176(1):287-92.

250. Goerdt S, Orfanos CE. Other functions, other genes: alternative activation of antigen-presenting cells. Immunity. 1999;10(2):137-42.

251. Galli SJ, Borregaard N, Wynn TA. Phenotypic and functional plasticity of cells of innate immunity: macrophages, mast cells and neutrophils. Cells. 2011;12(11):1035-44.
252. Yin M, Zhou HJ, Zhang J, et al. ASK1-dependent endothelial cell activation is critical in ovarian cancer growth and metastasis. JCI Insight. 2017:2(18):56

253. Shan M, Qin J, Jin F, et al. Autophagy suppresses isoprenaline-induced M2 macrophage polarization via the ROS/ERK and mTOR signaling pathway. Free Radic Biol Med. 2017;16:25.

254. Dongyao, Yan, Hao-Wei, et al. STAT3 and STAT6 signaling pathways synergize to promote cathepsin secretion from macrophages via IRE1a activation. 2016.

255. Liu N, Luo J, Kuang D, et al. Lactate inhibits ATP6V0d2 expression in tumor-associated macrophages to promote HIF-2a-mediated tumor progression. J Clin Investig. 2019;129(2):631-46.

256. Chang CP, Su YC, Hu CW, et al. TLR2-dependent selective autophagy regulates NF-kappaB lysosomal degradation in hepatoma-derived M2 macrophage differentiation. Cell Death Differ. 2013;20(3):515-23.

257. Yang M, Liu J, Shao J, et al. Cathepsin S-mediated autophagic flux in tumor-associated macrophages accelerate tumor development by promoting M2 polarization. Mol Cancer. 2014;13(1):43-43.

258. Chang CP, Su Y-C, Lee P-H, et al. Targeting NFKB by autophagy to polarize hepatoma-associated macrophage differentiation. Autophagy. 2013;9(4):619-21.

259. Cunha LD, Yang $M$, Carter R, et al. LC3-associated phagocytosis in myeloid cells promotes tumor immune tolerance. Cell. 2018;175(2):429-41.

260. Ruibo W, et al. Tumor cells induce LAMP2a expression in tumor-associated macrophage for cancer progression. 2019.

261. Kagan J, Su T, Horng T, et al. TRAM couples endocytosis of Tolllike receptor 4 to the induction of interferon-beta. Nat Immunol. 2008;9:361-8

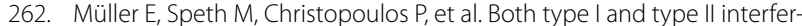
ons can activate antitumor M1 macrophages when combined with TLR stimulation. Front Immunol. 2018:9:56.

263. Bellora F, Castriconi R, Dondero A, et al. TLR activation of tumorassociated macrophages from ovarian cancer patients triggers cytolytic activity of NK cells. Eur J Immunol. 2014;44:56.

264. Huang $Z$, Yang $Y$, Jiang $Y$, et al. Anti-tumor immune responses of tumorassociated macrophages via toll-like receptor 4 triggered by cationic polymers. Biomaterials. 2013;34(3):746-55.

265. Wu L, Tang H, Zheng H, et al. Multiwalled carbon nanotubes prevent tumor metastasis through switching M2-polarized macrophages to M1 via TLR4 activation. J Biomed Nanotechnol. 2019;15(1):138-50.

266. Sato-Kaneko F, Yao S, Ahmadi A, et al. Combination immunotherapy with TLR agonists and checkpoint inhibitors suppresses head and neck cancer. JCI Insight. 2017;2:56.

267. Peng J, Tsang J, Li D, et al. Inhibition of TGF- $\beta$ signaling in combination with TLR7 ligation re-programs a tumoricidal phenotype in tumorassociated macrophages. Cancer Lett. 2013;331:56.

268. Huang Z, Gan J, Long Z, et al. Targeted delivery of let-7b to reprogramme tumor-associated macrophages and tumor infiltrating dendritic cells for tumor rejection. Biomaterials. 2016;90:56

269. Liu Z, Xie $Y$, Xiong $Y$, et al. TLR $7 / 8$ agonist reverses oxaliplatin resistance in colorectal cancer via directing the myeloid-derived suppressor cells to tumoricidal M1-macrophages. Cancer Lett. 2019;469:56.

270. Muraoka D, Seo N, Hayashi T, et al. Antigen delivery targeted to tumorassociated macrophages overcomes tumor immune resistance. J Clin Investig. 2019;129:56.

271. Sato Y, Goto Y, Narita N, et al. Cancer cells expressing toll-like receptors and the tumor microenvironment. Cancer Microenviron. 2009:2:S205-14.

272. Korneev K, Atretkhany K-S, Drutskaya M, et al. TLR-signaling and proinflammatory cytokines as drivers of tumorigenesis. Cytokine. 2016;89:514.

273. Chen C-C, Cang C, Fenske S, et al. Patch-clamp technique to characterize ion channels in enlarged individual endolysosomes. Nat Protoc. 2017:12:1639-58.

274. Seglen P, Grinde B, Solheim A. Inhibition of the lysosomal pathway of protein degradation in isolated rat hepatocytes by ammonia, methylamine, chloroquine and leupeptin. Eur J Biochem/FEBS. 1979;95:215-25.

275. Chen D, Xie J, Fiskesund R, et al. Chloroquine modulates antitumor immune response by resetting tumor-associated macrophages toward M1 phenotype. Nat Commun. 2018;9(1):873. 
276. Li Y, Cao F, Li M, et al. Hydroxychloroquine induced lung cancer suppression by enhancing chemo-sensitization and promoting the transition of M2-TAMs to M1-like macrophages. J Exp Clin Cancer Res. 2018;37:56.

277. Canton J, Khezri R, Glogauer M, et al. Contrasting phagosome pH regulation and maturation in human $\mathrm{M} 1$ and $\mathrm{M} 2$ macrophages. Mol Biol Cell. 2014;25(21):3330-41.

278. Wang R, Zhang J, Chen S, et al. Tumor-associated macrophages provide a suitable microenvironment for non-small lung cancer invasion and progression. Lung Cancer. 2011;74:188-96.

279. Shree T, Olson O, Elie B, et al. Macrophages and cathepsin proteases blunt chemotherapeutic response in breast cancer. Genes Dev. 2011:25:2465-79.

280. Gocheva V, Wang H-W, Gadea B, et al. Abstract LB-379: IL-4 induces cathepsin protease activity in tumor-associated macrophages to promote cancer growth and invasion. Genes Dev. 2010;24:241-55.

281. Naegler D, Storer A, Portaro F, et al. Major increase in endopeptidase activity of human cathepsin B upon removal of occluding loop contactst. Biochemistry. 1997;36:12608-15.

282. Koblinski J, Ahram M, Sloane B. Unraveling the role of proteases in cancer. Clin Chim Acta Int J Clin Chem. 2000;291:113-35.

283. Vasiljeva O, Papazoglou A, Krüger A, et al. Tumor cell-derived and macrophage-derived cathepsin B promotes progression and lung metastasis of mammary cancer. Can Res. 2006:66:5242-50.

284. Dykes SS, Batis N, Franke AC, et al. Cathepsin L secretion by host and neoplastic cells potentiates invasion. Oncotarget. 2019;10(53):5560-8.

285. Madsen DH, Jurgensen HJ, Siersbaek M, et al. Tumor-associated macrophages derived from circulating inflammatory monocytes degrade collagen through cellular uptake. Cell Rep. 2017;21(13):3662-71.

286. Small D, Burden R, Jaworski J, et al. Cathepsin S from both tumor and tumor-associated cells promote cancer growth and neovascularization. Int J Cancer J Cancer. 2013;133:568.

287. Beaujouin M, Baghdiguian S, Glondu-Lassis M, et al. Overexpression of both catalytically active and -inactive cathepsin D by cancer cells enhances apoptosis-dependent chemo-sensitivity. Oncogene. 2006;25(13):1967-73.

288. Larionova I, Cherdyntseva N, Liu T, et al. Interaction of tumor-associated macrophages and cancer chemotherapy. Oncoimmunology. 2019;8(7):1596004-104.

289. Bruchard M, Mignot G, Derangère $V$, et al. Chemotherapy-triggered cathepsin $B$ release in myeloid-derived suppressor cells activates the Nlrp3 inflammasome and promotes tumor growth. Natre Med. 2012;19:568.

290. Herroon M, Rajagurubandara E, Rudy D, et al. Macrophage cathepsin K promotes prostate tumor progression in bone. Oncogene. 2012;2:568.

291. Wilkinson R, Magorrian S, Williams R, et al. CCL2 is transcriptionally controlled by the lysosomal protease cathepsin S in a CD74-dependent manner. Oncotarget. 2015;6:56.

292. Fu C, Jiang A. Dendritic cells and CD8 T cell immunity in tumor microenvironment. Front Immunol. 2018;9:3059.

293. Kitamura H, Ohno Y, Toyoshima Y, et al. Interleukin-6/STAT3 signaling as a promising target to improve the efficacy of cancer immunotherapy. Cancer Sci. 2017;108(10):1947-52.

294. Zhang Q, He Y, Luo N, et al. Landscape and dynamics of single immune cells in hepatocellular carcinoma. Cell. 2019;179(4):829e20-45e20.

295. Nishimura J, Tanaka H, Yamakoshi Y, et al. Impact of tumor-infiltrating LAMP-3 dendritic cells on the prognosis of esophageal squamous cell carcinoma. Esophagus. 2019;16(4):333-44.

296. Parekh W, Pabbisetty SK, Wu L, et al. Autophagy-related protein Vps34 controls the homeostasis and function of antigen crosspresenting CD8alpha(+) dendritic cells. Proc Natl Acad Sci USA. 2017:114(31):E6371-80

297. Chen X, Song E. Turning foes to friends: targeting cancer-associated fibroblasts. Nat Rev Drug Discov. 2019;18(2):99-115.

298. Martinez-Outschoorn UE, Whitaker-Menezes D, Lin Z, et al. Cytokine production and inflammation drive autophagy in the tumor microenvironment: role of stromal caveolin-1 as a key regulator. Cell Cycle. 2011;10(11):1784-93.

299. Martinez-Outschoorn UE, Trimmer C, Lin Z, et al. Autophagy in cancer associated fibroblasts promotes tumor cell survival: role of hypoxia,
HIF1 induction and NFkappaB activation in the tumor stromal microenvironment. Cell Cycle. 2010;9(17):3515-33.

300. Martinez-Outschoorn UE, Balliet RM, Rivadeneira DB, et al. Oxidative stress in cancer associated fibroblasts drives tumor-stroma co-evolution: a new paradigm for understanding tumor metabolism, the field effect and genomic instability in cancer cells. Cell Cycle. 2010;9(16):3256-76.

301. Salem AF, Howell A, Sartini M, et al. Downregulation of stromal BRCA1 drives breast cancer tumor growth via upregulation of HIF-1alpha, autophagy and ketone body production. Cell Cycle. 2012;11(22):4167-73.

302. Avena P, Anselmo W, Whitaker-Menezes D, et al. Compartmentspecific activation of PPARgamma governs breast cancer tumor growth, via metabolic reprogramming and symbiosis. Cell Cycle. 2013;12(9):1360-70.

303. Zhang $X$, Schonrogge $M$, Eichberg J, et al. Blocking autophagy in cancer-associated fibroblasts supports chemotherapy of pancreatic cancer cells. Front Oncol. 2018:8:590.

304. Molejon MI, Swayden M, Fanale D, et al. Chloroquine plays a celldependent role in the response to treatment of pancreatic adenocarcinoma. Oncotarget. 2018;9(56):30837-46.

305. Wang $M$, Zhang J, Huang Y, et al. Cancer-associated fibroblasts autophagy enhances progression of triple-negative breast cancer cells. Med Sci Monit. 2017:23:3904-12.

306. Zhao XL, Lin Y, Jiang J, et al. High-mobility group box 1 released by autophagic cancer-associated fibroblasts maintains the stemness of luminal breast cancer cells. J Pathol. 2017;243(3):376-89.

307. Voskoboinik I, Whisstock JC, Trapani JA. Perforin and granzymes: function, dysfunction and human pathology. Nat Rev Immunol. 2015;15(6):388-400.

308. Macian F. Autophagy in T cell function and aging. Front Cell Dev Biol. 2019;7:213.

309. Vodnala SK, Eil R, Kishton RJ, et al. T cell stemness and dysfunction in tumors are triggered by a common mechanism. Science. 2019:363:6434.

310. DeVorkin L, Pavey N, Carleton G, et al. Autophagy regulation of metabolism is required for CD8(+) T cell anti-tumor immunity. Cell Rep. 2019;27(2):502e5-13e5.

311. Rivera Vargas T, Cai Z, Shen Y, et al. Selective degradation of PU.1 during autophagy represses the differentiation and antitumour activity of TH9 cells. Nat Commun. 2017;8(1):559.

312. Benoit-Lizon I, Jacquin $E$, Apetoh L. Selective autophagy restricts IL-9 secretion from TH9 cells: relevance in cancer growth. Cell Cycle. 2018;17(4):391-2.

313. Wei J, Long L, Yang K, et al. Autophagy enforces functional integrity of regulatory $T$ cells by coupling environmental cues and metabolic homeostasis. Nat Immunol. 2016;17(3):277-85.

314. Yu X, Teng XL, Wang F, et al. Metabolic control of regulatory T cell stability and function by TRAF3IP3 at the lysosome. J Exp Med. 2018;215(9):2463-76

315. Platt FM. Emptying the stores: lysosomal diseases and therapeutic strategies. Nat Rev Drug Discov. 2018;17(2):133-50.

316. Brady RO. Enzyme replacement for lysosomal diseases. Annu Rev Med. 2006;57:283-96.

317. Verheye S, Martinet W, Kockx MM, et al. Selective clearance of macrophages in atherosclerotic plaques by autophagy. J Am Coll Cardiol. 2007;49(6):706-15.

318. Pakala R, Stabile E, Jang GJ, et al. Rapamycin attenuates atherosclerotic plaque progression in apolipoprotein E knockout mice: inhibitory effect on monocyte chemotaxis. J Cardiovasc Pharmacol. 2005;46(4):481-6.

319. Mueller MA, Beutner F, Teupser D, et al. Prevention of atherosclerosis by the mTOR inhibitor everolimus in LDLR-/- mice despite severe hypercholesterolemia. Atherosclerosis. 2008;198(1):39-48.

320. Zhao L, Ding T, Cyrus T, et al. Low-dose oral sirolimus reduces atherogenesis, vascular inflammation and modulates plaque composition in mice lacking the LDL receptor. Br J Pharmacol. 2009;156(5):774-85.

321. Yang M, Liu J, Shao J, et al. Cathepsin S-mediated autophagic flux in tumor-associated macrophages accelerate tumor development by promoting M2 polarization. Mol Cancer. 2020;13(1):43. 
322. Zhao Y, Guo Y, Jiang Y, et al. Mitophagy regulates macrophage phenotype in diabetic nephropathy rats. Biochem Biophys Res Commun. 2017:494(1-2):42-50.

323. Cui SN, Chen ZY, Yang XB, et al. Trichostatin A modulates the macrophage phenotype by enhancing autophagy to reduce inflammation during polymicrobial sepsis. Int Immunopharmacol. 2019;77:105973.

324. Lin JC, Liu C-L, Lee J-J, et al. Sorafenib induces autophagy and suppresses activation of human macrophage. Int Immunopharmacol. 2013;15(2):333-9.

325. Boakye YD, Groyer L, Heiss EH. An increased autophagic flux contributes to the anti-inflammatory potential of urolithin A in macrophages. Biochimica Et Biophysica Acta. 2018;32:76.

326. Zhou S, Jian G, Rui L, et al. Spermine alleviates acute liver injury by inhibiting liver-resident macrophage pro-inflammatory response through ATG5-dependent autophagy. Front Immunol. 2018;9:948.

327. Li J, Kim SG, Blenis J. Rapamycin: one drug, many effects. Cell Metab. 2014;19(3):373-9.

328. Kos J, Mitrović A, Mirković B. The current stage of cathepsin B inhibitors as potential anticancer agents. Fut Med Chem. 2014;6(11):1355-71.

329. Paukner S, Kudela P, Kohl G, et al. DNA-loaded bacterial ghosts efficiently mediate reporter gene transfer and expression in macrophages. Mol Ther. 2005;11:215-23.

330. Yudong, $S$, et al. Combination antitumor immunotherapy with VEGF and PIGF siRNA via systemic delivery of multi-functionalized nanoparticles to tumor-associated macrophages and breast cancer cells. 2018.

331. Hayashi N, Kataoka H, Yano S, et al. A novel photodynamic therapy targeting cancer cells and tumor-associated macrophages. Mol Cancer Ther. 2015;14(2):452-60

332. Zheng $\mathrm{H}, \mathrm{Li}$ J, Wang $\mathrm{M}$, et al. Exhausting tumor associated macrophages with sialic acid-polyethyleneimine-cholesterol modified liposomal doxorubicin for enhancing sarcoma chemotherapy. Int J Pharms. 2019;63:558.

333. Binaschi $M$, Parlani $M$, Bellarosa $D$, et al. Human and murine macrophages mediate activation of MEN 4901/T-0128: a new promising camptothecin analogue-polysaccharide conjugate. Anticancer Drugs. 2006;17(10):1119-26.

334. Xia X, Mai J, Xu R, et al. Porous silicon microparticle potentiates antitumor immunity by enhancing cross-presentation and inducing type interferon response. Cell Rep. 2015;11(6):957-66.

335. Wang $Y$, Zhang $L$, $X u Z$, et al. mRNA vaccine with antigen-specific checkpoint blockade induces an enhanced immune response against established melanoma. Mol Ther. 2018;26(2):420-34.

336. Duan F, Feng $X$, Yang $X$, et al. A simple and powerful co-delivery system based on $\mathrm{pH}$-responsive metal-organic frameworks for enhanced cancer immunotherapy. Biomaterials. 2017;122:23-33.

337. Xie L, Yang Y, Meng J, et al. Cationic polysaccharide spermine-pullulan drives tumor associated macrophage towards M1 phenotype to inhibit tumor progression. Int J Biol Macromol. 2019;123:1012-9.

338. Wei $X$, Liu L, Li X, et al. Selectively targeting tumor-associated macrophages and tumor cells with polymeric micelles for enhanced cancer chemo-immunotherapy. J Control Rel. 2019;313:42-53.

339. Cang C, Aranda K, Seo YJ, et al. TMEM175 is an organelle K(+) channel regulating lysosomal function. Cell. 2015;162(5):1101-12.

340. Shen J, Kelleher RJ. The presenilin hypothesis of Alzheimer's disease: evidence for a loss-of-function pathogenic mechanism. Proc Natl Acad Sci. 2007;104(2):403-9.

341. Zhang X, Garbett K, Veeraraghavalu K, et al. A role for presenilins in autophagy revisited: normal acidification of lysosomes in cells lacking PSEN1 and PSEN2. J Neurosci Off J Soc Neurosci. 2012;32(25):8633.

342. Gukovskaya AS, Gukovsky I, Algul H, et al. Autophagy, inflammation, and immune dysfunction in the pathogenesis of pancreatitis. Gastroenterology. 2017;153(5):1212-26.

343. Monteith AJ, Kang S, Scott E, et al. Defects in lysosomal maturation facilitate the activation of innate sensors in systemic lupus erythematosus. Proc Natl Acad Sci USA. 2016;113(15):E2142-51.

344. Lassen KG, McKenzie Cl, Mari M, et al. Genetic coding variant in GPR65 alters lysosomal ph and links lysosomal dysfunction with colitis risk. Immunity. 2016;44(6):1392-405.

345. Vanier MT. Niemann-Pick disease type C. Orphanet J Rare Dis. 2010;5:16.

346. El-Abassi R, Singhal D, England JD. Fabry's disease. J Neurol Sci. 2014:344(1-2):5-19.
347. Fernandes Filho JA, Shapiro BE. Tay-Sachs disease. Arch Neurol. 2004;61(9):1466-8.

348. Muenzer J. Overview of the mucopolysaccharidoses. Rheumatology (Oxford). 2011;50(Suppl 5):v4-12.

349. Kohler L, Puertollano R, Raben N. Pompe disease: from basic science to therapy. Neurotherapeutics. 2018;15(4):928-42.

350. Li C, Chen L, Wang J, et al. Expression and clinical significance of cathepsin B and stefin A in laryngeal cancer. Oncol Rep. 2011;26:869-75.

351. Ebert MP, Kruger S, Fogeron ML, et al. Overexpression of cathepsin $B$ in gastric cancer identified by proteome analysis. Proteomics. 2005;5:1693-704.

352. Lah TT, Cercek M, Blejec A, et al. Cathepsin B, a prognostic indicator in lymph node-negative breast carcinoma patients: comparison with cathepsin D, cathepsin L, and other clinical indicators. Clin Cancer Res. 2000;6:578-84.

353. Ledakis $\mathrm{P}$, Tester $\mathrm{W}$, Rosenberg $\mathrm{N}$, et al. Cathepsins $\mathrm{D}, \mathrm{B}$, and $\mathrm{L}$ in malignant human lung tissue. Clin Cancer Res. 1996;2:561-8.

354. Kos J, Stabuc B, Schweiger A, et al. Cathepsins B, H, and L and their inhibitors stefin $A$ and cystatin $C$ in sera of melanoma patients. Clin Cancer Res. 1997;3:1815-22.

355. McKerrow JH, Bhargava V, Hansell E, et al. A functional proteomics screen of proteases in colorectal carcinoma. Mol Med. 2000;6(5):450-60.

356. Lakka S, Gondi C, Yanamandra N, et al. Inhibition of cathepsin B and MMP-9 gene expression in glioblastoma cell line via RNA interference reduces tumor cell invasion, tumor growth and angiogenesis. Oncogene. 2004;23:4681-9.

357. Nalla A, Gorantla B, Gondi C, et al. Targeting MMP-9, UPAR and Cathep$\sin B$ inhibits invasion and migration and activates apoptosis in prostate cancer cells. Cancer Gene Ther. 2010;17:599-613.

358. Gocheva V, Zeng W, Ke D, et al. Distinct roles for cystein cathepsin genes in multistage tumorigensis. Genes Dev. 2006;20:543-56.

359. Rahman R, Schaijik B, Brasch H, et al. Expression of cathepsins B, D, and G in WHO grade I Meningioma. Front Surg. 2019;6:6.

360. Khaket T, Singh MP, Khan I, et al. Targeting of cathepsin C induces autophagic dysregulation that directs ER stress mediated cellular cytotoxicity in colorectal cancer cells. Cell Signal. 2018;46:65.

361. Chiang KC, Lai CY, Chiou HL, et al. Timosaponin Alll inhibits metastasis of renal carcinoma cells through suppressing cathepsin C expression by AKT/miR-129-5p axis. J Cell Physiol. 2019;234:56.

362. Cordes C, Bartling B, Simm A, et al. Simultaneous expression of Cathepsins $B$ and $K$ in pulmonary adenocarcinomas and squamous cell carcinomas predicts poor recurrence-free and overall survival. Lung Cancer. 2008;64:79-85.

363. Zhang G-P, Yue X, Li S-Q. Cathepsin C interacts with TNF-a/p38 MAPK signaling pathway to promote proliferation and metastasis in hepatocellular carcinoma. Cancer Res Treat. 2019;52:65.

364. Ruffell $B$, Affara N, Cottone $L$, et al. Cathepsin $C$ is a tissue-specific regulator of squamous carcinogenesis. Genes Dev. 2013;27:56.

365. Wang Z, Han B, Zhang Z, et al. Expression of angiopoietin-like 4 and tenascin C but not cathepsin C mRNA predicts prognosis of oral tongue squamous cell carcinoma. Biomarkers. 2009:00:090923083620087-8.

366. Husmann K, Muff R, Bolander M, et al. Cathepsins and osteosarcoma: expression analysis identifies Cathepsin $\mathrm{K}$ as an indicator of metastasis. Mol Carcinog. 2008;47:66-73.

367. Ji C, Zhao Y, Kou Y-W, et al. Cathepsin F knockdown induces proliferation and inhibits apoptosis in gastric cancer cells. Oncol Res. 2017;26:56.

368. Vazquez-Ortiz G, Pina-Sanchez P, Vazquez-Santillan K, et al. Overexpression of cathepsin F, matrix metalloproteinases 11 and 12 in cervical cancer. BMC Cancer. 2005;5:68.

369. Raghav N, Jangra S, Kumar A, et al. Quinazoline derivatives as cathepsins $B, H$ and $L$ inhibitors and cell proliferating agents. Int J Biol Macromol. 2016;94:56.

370. Gocheva V, Chen X, Peters C, et al. Deletion of cathepsin H perturbs angiogenic switching, vascularization and growth of tumors in a mouse model of pancreatic islet cell cancer. Biol Chem. 2010;391:937-45.

371. Schweiger A, Staib A, Werle B, et al. Cysteine proteinase cathepsin H in tumours and sera of lung cancer patients: Relation to prognosis and cigarette smoking. Br J Cancer. 2000;82:782-8.

372. Sivaparvathi M, Sawaya R, Gokaslan ZL, et al. Expression and the role of cathepsin $\mathrm{H}$ in human glioma progression and invasion. Cancer Lett. 1996;104(1):121-6. 
373. Jevnikar Z, Rojnik M, Jamnik P, et al. Cathepsin H mediates the processing of talin and regulates migration of prostate cancer cells. J Biol Chem. 2012;288:56

374. Froehlich E, Moehrle M, Klessen C. Cathepsins in basal cell carcinomas: activity, immunoreactivity and mRNA staining of cathepsins $B, D, H$ and L. Arch Dermatol Res. 2004;295:411-21.

375. Breznik B, Limbäck C, Porcnik A, et al. Localization patterns of cathepsins $\mathrm{K}$ and $\mathrm{X}$ and their predictive value in glioblastoma. Radiol Oncol. 2018:52:56.

376. Gu X, Peng Y, Zhao Y, et al. A novel derivative of artemisinin inhibits cell proliferation and metastasis via down-regulation of cathepsin $\mathrm{K}$ in breast cancer. Eur J Pharmacol. 2019;858:56.

377. Leusink F, Koudounarakis E, Frank M, et al. Cathepsin K associates with lymph node metastasis and poor prognosis in oral squamous cell carcinoma. BMC Cancer. 2018;18:385.

378. Li R, Zhou R, Wang H, et al. Gut microbiota-stimulated cathepsin K secretion mediates TLR4-dependent M2 macrophage polarization and promotes tumor metastasis in colorectal cancer. Cell Death Differ. 2019;26:56.

379. Liang W, Wang F, Chen Q, et al. Targeting cathepsin K diminishes prostate cancer establishment and growth in murine bone. J Cancer Res Clin Oncol. 2019;67:1-14.

380. Tian K, Ma J, Wang L, et al. Expression of cathepsin K in skull base chordoma. World Neurosurg. 2017;101:67.

381. Fan X, Wang C, Song X, et al. Elevated Cathepsin K potentiates metastasis of epithelial ovarian cancer. Histol Histopathol. 2018;33:11960.

382. Petricevic S, Pavlovic A, Capkun V, et al. Cathepsin K expression in melanoma is associated with metastases. Histol Histopathol. 2016;32:11833.

383. Ikeguchi M, Fukuda K, Oka S, et al. Micro-lymph node metastasis and its correlation with cathepsin D expression in early gastric cancer. J Surg Oncol. 2001;77(3):188-94.

384. Burton $L$, Henderson V, Liburd L, et al. Snail transcription factor NLS and importin $\beta 1$ regulate the subcellular localization of Cathepsin $L$ and Cux1. Biochem Biophys Res Commun. 2017;491:66.

385. Fei $Y$, Xiong $Y$, Zhao Y, et al. Cathepsin L knockdown enhances curcumin-mediated inhibition of growth, migration, and invasion of glioma cells. Brain Res. 2016;1646:65

386. Mao Z, Sang M-M, Chen C, et al. CSN6 promotes the migration and invasion of cervical cancer cells by inhibiting autophagic degradation of Cathepsin L. Int J Biol Sci. 2019;15:1310-24.

387. Sui H, Shi C, Yan Z, et al. Overexpression of Cathepsin L is associated with chemoresistance and invasion of epithelial ovarian cancer. Oncotarget. 2016;7:56.

388. Plebani $M$, Herszènyi $L$, Cardin $R$, et al. Cysteine and serine proteases in gastric cancer. Cancer. 1995;76:367-75.

389. Sullivan S, Tosetto M, Kevans D, et al. Localization of nuclear cathepsin $L$ and its association with disease progression and poor outcome in colorectal cancer. Int J Cancer J Int Cancer. 2009;125:54-61.

390. Wang L, Zhao Y, Xiong Y, et al. K-ras mutation promotes ionizing radiation-induced invasion and migration of lung cancer in part via the Cathepsin L/CUX1 pathway. Exp Cell Res. 2017;362:56.

391. Singh N, Das P, Gupta S, et al. Plasma cathepsin L: a prognostic marker for pancreatic cancer. World J Gastroenterol. 2014;20:17532-40.

392. Klose A, Zigrino P, Dennhöfer R, et al. Identification and discrimination of extracellularly active cathepsins $B$ and $L$ in high-invasive melanoma cells. Anal Biochem. 2006;353:57-62.

393. Hato $\mathrm{Y}$, Endo $\mathrm{Y}$, Yoshimoto N, et al. Abstract P5-05-02: prognostic impact of single-nucleotide polymorphisms (SNPS) in or near the ZNF423 and CTSO genes in estrogen receptor (ER)-positive breast cancer patients receiving adjuvant endocrine therapy. Can Res. 2015;75:P5-05.

394. Lindahl C, Simonsson M, Bergh A, et al. Increased levels of macrophagesecreted cathepsin $\mathrm{S}$ during prostate cancer progression in TRAMP mice and patients. Cancer Genom Proteom. 2009;6:149-60.

395. Liu W-L, Liu D, Cheng K, et al. Evaluating the diagnostic and prognostic value of circulating cathepsin S in gastric cancer. Oncotarget. 2014:7:66

396. Wang X, Xiong L, Yu G, et al. Cathepsin S silencing induces apoptosis of human hepatocellular carcinoma cells. Am J Transl Res. 2015;7:100-10.

397. Gautam J, Banskota S, Lee H, et al. Down-regulation of cathepsin S and matrix metalloproteinase-9 via Src, a non-receptor tyrosine kinase, suppresses triple-negative breast cancer growth and metastasis. Exp Mol Med. 2018;50:66.

398. Tan J, Qian X, Song B, et al. Integrated bioinformatics analysis reveals that the expression of cathepsin $\mathrm{S}$ is associated with lymph node metastasis and poor prognosis in papillary thyroid cancer. Oncol Rep. 2018;40:56

399. Willumsen N, Bager C, Leeming D, et al. Nidogen-1 degraded by Cathepsin $\mathrm{S}$ can be quantified in serum and is associated with non-small cell lung cancer. Neoplasia. 2017;19:271-8.

400. Santamaria I, Velasco G, Cazorla M, et al. Cathepsin L2, a novel human cysteine proteinase produced by breast and colorectal carcinomas. Can Res. 1998:58:1624-30.

401. Toss M, Miligy I, Gorringe K, et al. Prognostic significance of cathepsin V (CTSV/CTSL2) in breast ductal carcinoma in situ. J Clin Pathol. 2019;73(2):205939.

402. Skrzypczak M, Springwald A, Lattrich C, et al. Expression of cysteine protease cathepsin $L$ is increased in endometrial cancer and correlates with expression of growth regulatory genes. Cancer Invest. 2012;30(5):398-403.

403. Teller A, Kuester D, Hartig R, et al. Dysregulation of apoptotic signaling pathways by interaction of RPLP0 and cathepsin X/Z in gastric cancer. Pathol Res Pract. 2014;211:56.

404. Nagler DK, Kruger S, Kellner A, et al. Up-regulation of cathepsin X in prostate cancer and prostatic intraepithelial neoplasia. Prostate. 2004;60(2):109-19.

405. Park S, Kwon W, Park J-K, et al. Suppression of cathepsin a inhibits growth, migration, and invasion by inhibiting the p38 MAPK signaling pathway in prostate cancer. Arch Biochem Biophys. 2020;688:108407.

406. Kozłowski L, Stoklosa T, Omura S, et al. Lactacystin inhibits Cathepsin A activity in melanoma cell lines. Tumour Biol. 2001;22:211-5.

407. Kozłowski L, Wojtukiewicz M, Ostrowska H. Cathepsin A activity in primary and metastatic human melanocytic tumors. Arch Dermatol Res. 2000;292:68-71.

408. Hu B, Zhu X, Lu J. Cathepsin A knockdown decreases the proliferation and invasion of A549 lung adenocarcinoma cells. Mol Med Reps. 2020;21:56

409. Ni S, Weiwei W, Xu M-D, et al. miR-106b-5p inhibits the invasion and metastasis of colorectal cancer by targeting CTSA. Onco Targets Ther. 2018;11:3835-45.

410. Toss M, Miligy I, Haj-Ahmad R, et al. The prognostic significance of lysosomal protective protein (Cathepsin A) in breast ductal carcinoma in situ. Histopathology. 2019;74:56.

411. Alatrash $\mathrm{G}$, Garber $H$, Zhang $M$, et al. Cathepsin $\mathrm{G}$ is broadly expressed in acute myeloid leukemia and is an effective immunotherapeutic target. Leukemia. 2016;31:56.

412. Featherston T, Marsh R, Schaijik B, et al. Expression and localization of Cathepsins B, D, and G in two cancer stem cell subpopulations in moderately differentiated oral tongue squamous cell carcinoma. Front Med. 2017:4:56.

413. Khan M, Carmona S, Sukhumalchandra P, et al. Cathepsin $G$ is expressed by acute lymphoblastic leukemia and is a potential immunotherapeutic target. Front Immunol. 2018;8:56.

414. Koh S, Wickremesekera A, Brasch H, et al. Expression of Cathepsins B, D, and $\mathrm{G}$ in isocitrate dehydrogenase-wildtype glioblastoma. Front Surg. 2017:4:56.

415. Ozer E, Mungan MU, Tuna B, et al. Prognostic significance of angiogenesis and immunoreactivity of cathepsin D and type IV collagen in high-grade stage T1 primary bladder cancer. Urology. 1999;54(1):50-5.

416. Gemoll T, Epping F, Heinrich L, et al. Increased cathepsin D protein expression is a biomarker for osteosarcomas, pulmonary metastases and other bone malignancies. Oncotarget. 2015;6(18):16517-26.

417. Ashraf $Y$, Mansouri H, Laurent-Matha $V$, et al. Immunotherapy of triple-negative breast cancer with cathepsin D-targeting antibodies. J Immunother Cancer. 2019;7(1):29-29.

418. Bosscher J, Gercel-Taylor C, Watkins C, et al. Epitope recognition by anticathepsin D autoantibodies in endometrial cancer patients. Gynecol Oncol. 2001;81:138-43.

419. Brouillet J-P, Hanslick B, Maudelonde T, et al. Increased plasma cathepsin $\mathrm{D}$ concentration in hepatic carcinoma and cirrhosis but not in breast cancer. Clin Biochem. 1992;24:491-6. 
420. Chen L, Li H, Liu W, et al. Olfactomedin 4 suppresses prostate cancer cell growth and metastasis via negative interaction with cathepsin D and SDF-1. Carcinogenesis. 2011;32:986-94.

421. Cheng A-L, Huang W-G, Chen Z-C, et al. Identification of novel nasopharyngeal carcinoma biomarkers by laser capture microdissection and proteomic analysis. Clin Cancer Res. 2008;14:435-45.

422. Dumartin L, Whiteman $H$, Weeks $M$, et al. AGR2 is a novel surface antigen that promotes the dissemination of pancreatic cancer cells through regulation of cathepsins B and D. Can Res. 2011;71:7091-102.

423. Fan C, Lin X, Wang E. Clinicopathological significance of cathepsin D expression in non-small cell lung cancer is conditional on apoptosisassociated protein phenotype: an immunohistochemistry study. Tumour Biol. 2012;33:1045-52.

424. Satelur KP, Kumar GS. Immunohistochemical expression of cathepsin $\mathrm{D}$ in primary and recurrent squamous cell carcinoma. J Contemp Dent Pract. 2017;18(9):795-801.

425. Podhajcer OL, Bover L, Bravo Al, et al. Expression of cathepsin D in primary and metastatic human melanoma and dysplastic nevi. J Invest Dermatol. 1995;104(3):340-4.

426. Skrzydlewska E, Sulkowska M, Wincewicz A, et al. Evaluation of serum cathepsin B and D in relation to clinicopathological staging of colorectal cancer. World J Gastroenterol. 2005;11(27):4225-9.
427. Chai Y, Wu W, Zhou C, et al. The potential prognostic value of cathepsin D protein in serous ovarian cancer. Arch Gynecol Obstet. 2012;286(2):465-71.

428. Cruz-Monserrate Z, Abd-Elgaliel W, Grote T, et al. Detection of pancreatic cancer tumours and precursor lesions by cathepsin E activity in mouse models. Gut. 2011;61:1315-22.

429. Konno-Shimizu M, Yamamichi N, Inada K-I, et al. Cathepsin E is a marker of gastric differentiation and signet-ring cell carcinoma of stomach: a novel suggestion on gastric tumorigenesis. PloS ONE. 2013;8:56766.

430. Hayashi N, Kataoka H, Yano S, et al. A novel photodynamic therapy targeting cancer cells and tumor-associated macrophages. Mol Cancer Ther. 2015;14(2):452-60.

\section{Publisher's Note}

Springer Nature remains neutral with regard to jurisdictional claims in published maps and institutional affiliations.
Ready to submit your research? Choose BMC and benefit from:

- fast, convenient online submission

- thorough peer review by experienced researchers in your field

- rapid publication on acceptance

- support for research data, including large and complex data types

- gold Open Access which fosters wider collaboration and increased citations

- maximum visibility for your research: over $100 \mathrm{M}$ website views per year

At BMC, research is always in progress.

Learn more biomedcentral.com/submissions 